\title{
SIMULATION OF \\ SHEAR INDUCED DIFFUSION BASED \\ SEPARATION PROCESSES
}

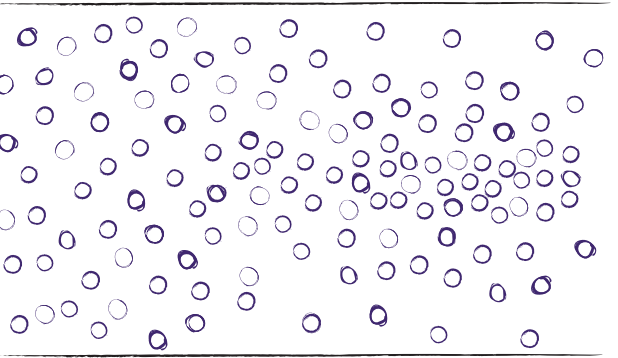

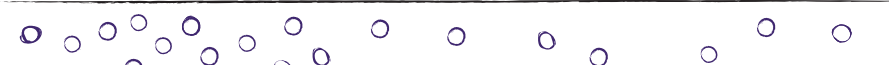

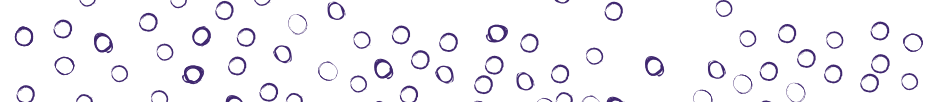

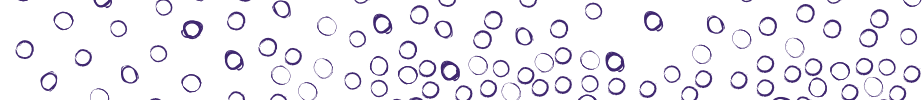

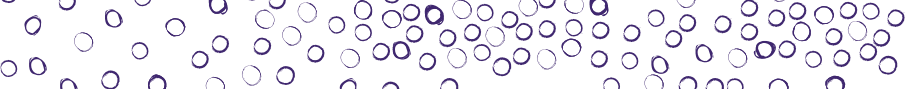

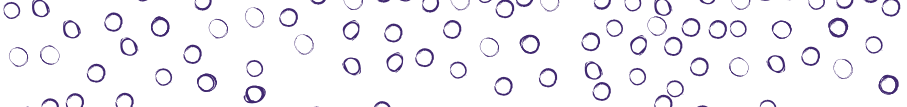

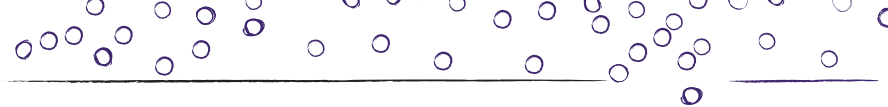

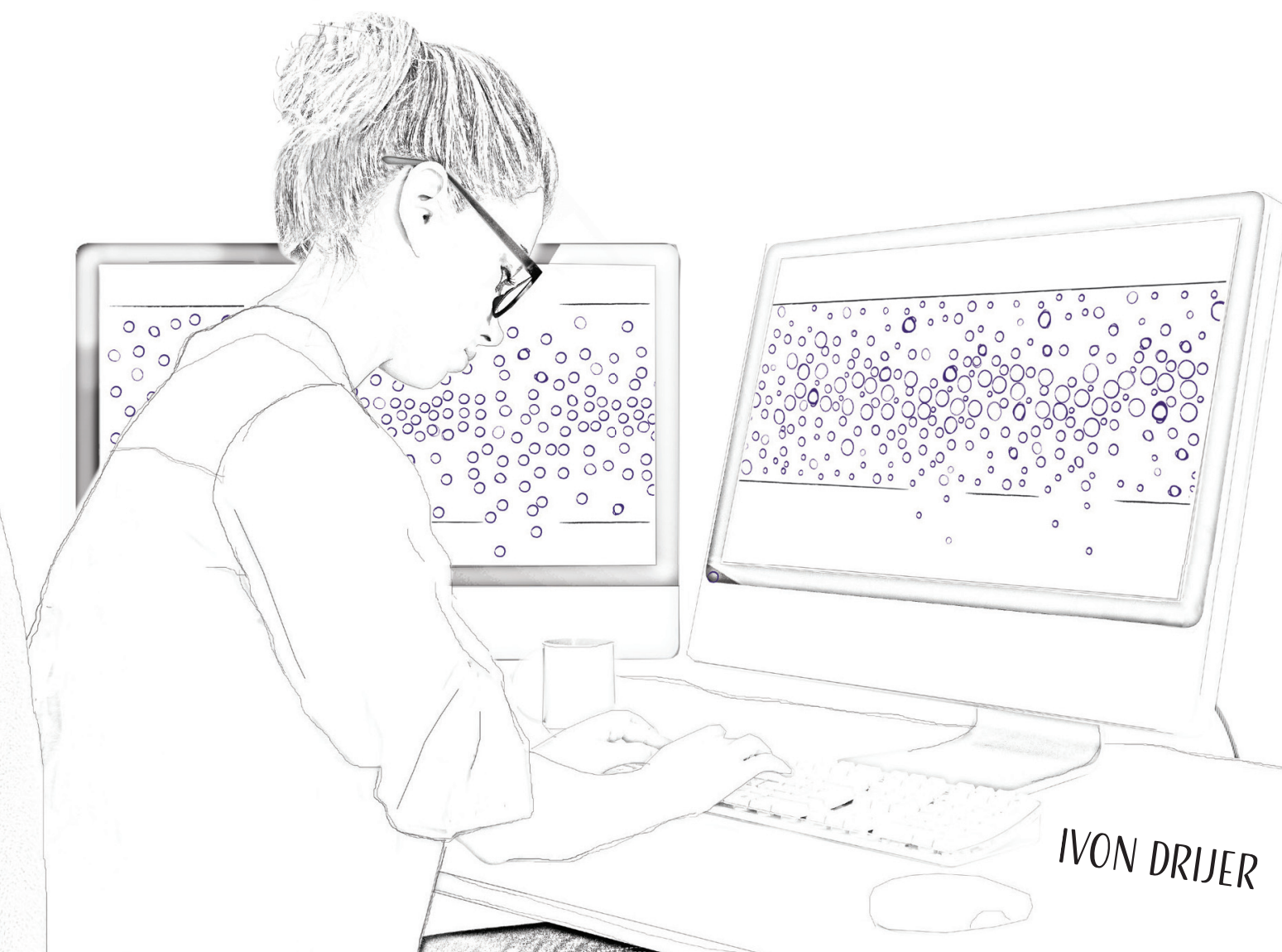



Simulation of shear induced diffusion based separation processes

Ivon Drijer 


\section{Thesis committee}

\section{Promotor}

Prof. Dr C.G.P.H. Schroën

Personal chair at the Laboratory of Food Process Engineering

Wageningen University \& Research

\section{Other members}

Prof. Dr R.G.H. Lammertink, University of Twente, Enschede

Prof. Dr M. van Sint Annaland, Eindhoven University of Technology

Dr K. Hettinga, Wageningen University \& Research

Prof. Dr M.A.J.S. van Boekel, Wageningen University \& Research

This research was conducted under the auspices of the Graduate School VLAG (Advanced studies in Food Technology, Agrobiotechnology, Nutrition and Health Sciences). 


\title{
Simulation of shear induced diffusion based
} separation processes

\author{
Ivon Drijer
}

\section{Thesis}

submitted in fulfilment of the requirements for the degree of doctor

at Wageningen University

by the authority of the Rector Magnificus,

Prof. Dr A.P.J. Mol,

in the presence of the

Thesis Committee appointed by the Academic Board

to be defended in public

on Wednesday 10 October 2018

at 1.30 p.m. in the Aula. 
Ivon Drijer

Simulation of shear induced diffusion based separation processes,

127 pages.

PhD thesis, Wageningen University, Wageningen, the Netherlands (2018)

With references, with summary in English

ISBN: 978-94-6343-790-5

DOI: https://doi.org/10.18174/452178 


\section{Contents}

Chapter 1. Introduction and thesis outline 1

Chapter 2. From highly specialised to generally available modelling of shear

induced particle migration for flow segregation based separation technology

Chapter 3. Modelling shear induced diffusion based particle segregation: a basis for novel separation technology

Chapter 4. Computational evaluation of membrane pore placement for novel shear-induced diffusion based separation processes

Chapter 5. The flow induced particle segregation principle applied to the separation of a polydisperse cream suspension

Chapter 6. General discussion

Summary

Acknowledgements

About the author 



\section{Chapter 1}

Introduction and thesis outline 


\subsection{Separation processes}

Separation processes are often applied in industry, e.g. for the removal of lactose to produce lactose free products [1], to remove salt from sea water [2], fat from milk [1] or yeast from beer [3]. This can be done based on different methods and mechanisms like centrifugation (density difference), evaporation (partial pressure difference) and membrane filtration (mostly size exclusion of one of the components by the pore size) [4]. Particles are, contrary to many other components that are molecularly dissolved, present as small entities with quite different properties as the fluid in which they are present. This makes the separation processes more challenging since particle behaviour is not that well documented. When designing innovative separation processes as is done in this thesis, this implies that particle behaviour should be put at the centre of the design, and not be disregarded as is often currently done.

In a number of processes, particle behaviour is used as a basis, for example in ratchets and fluid skimming devices [5]. Although these techniques have their merit, in general they have not been scaled up [5], unlike membrane filtration that has been applied on industrial scale since decades, and has proven its reliability. However, membrane filtration is designed around overall particle accumulation behaviour, and not specifically around particle behaviour in flow that we believe to be a better starting point for design.

\subsection{Membrane separation}

In this study we focus on membrane processes applied to suspensions with particles in the range of 0.1 to $10 \mu \mathrm{m}[3,6]$, and, that in the ultimate process that is elaborated on in the discussion section, would need to be separated based on their size. In regular membrane filtration, a pressure gradient is applied, which causes the particles to migrate towards the membrane through convection, and this can be done at relatively low energy usage [2]. In general, the size difference of the particles present in the permeate and retentate is rather large; due to particle accumulation on the membrane, the effective pore size is reduced and thus influences the actual separation process to a large extent. On the other hand, it would be very interesting if particles close in size could be separated effectively; e.g. fat particles with a smaller size can improve the creaminess of a product in which then less fat is needed, which in turn could lead to reduced caloric load in the products [7-9].

It is clear that for fractionation of particles close in size, the process needs to be controlled more closely than would be needed in a 'simple' concentration step. Although often used 
as a starting point for design, the pore size may actually be less relevant when particles accumulate on the membrane. This latter effect is most pronounced in dead-end filtration, and can be mitigated to some extent during cross-flow filtration (see Figure 1.1).

For simplicity reasons we now consider a feed that contains only two sizes of particles, and the pore size is such that the small particles can pass the pore, while the large ones cannot. In dead-end filtration, the large particles are retained by the membrane, eventually forming a cake layer that hinders the transmission of the fluid and the small particles that after a certain time will also not be able to pass the membrane anymore. The change in selectivity and the decrease in flux are undesired side effects that need to be minimized by e.g. regular cleaning. A cross-flow can be applied to generate turbulence, which improves mass transfer away from the membrane and allows for control (to some extent) over the thickness of the deposited layer. Nevertheless, additional measures need to be taken to maintain flux and good selectivity during cross-flow filtration, since also in this case the accumulation layer does influence particle retention to a large extent.
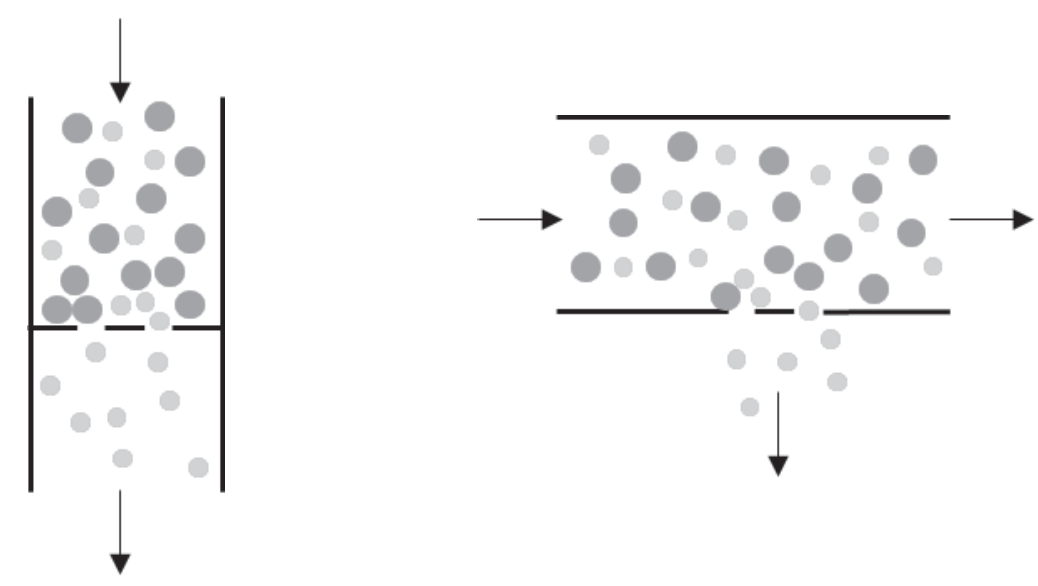

Figure 1.1. Schematic overview of dead-end (left) and cross flow (right) filtration of a bidisperse suspension in case of selective transmission of small particles, which effectively corresponds to the situation before cake formation takes place.

\subsection{Migration mechanisms}

As mentioned, membrane separation of particles is a complex process; and although some successes have been reported $[10,11]$ full fractionation has to the best of our knowledge not been reported. Given the descriptions above it is clear that it is very hard to fractionate 
particles close together in size in a situation in which continuously layers are brought to the membrane, and temporarily removed by e.g. back pulsing.

To achieve fractionation, alternative approaches are needed, and natural particle segregation mechanisms are good candidates to serve as starting points for innovative process design. If it were possible to make use thereof, this could decrease energy usage and thus production costs considerably. In this study we focus on shear induced diffusion which is based on the interaction between particles in flow [12]. Besides shear induced diffusion, there are two other important migration mechanisms, i.e. Brownian diffusion and inertial lift [12]; all will be explained in the next sections, including their characteristic dimensionless numbers.

\subsubsection{Brownian diffusion and inertial lift}

Depending on amongst others the size of a particle, and the process conditions, one of the previously mentioned mechanisms will be dominating. Particles smaller than 0.1 micron are mostly influenced by Brownian diffusion, which makes these particles move around arbitrarily in a certain space. Brownian diffusion is typically characterized by the Péclet number [13]:

$$
P e=\frac{\dot{\gamma} \cdot a^{2}}{D_{B}}
$$

Where $\dot{\gamma}$ is the shear rate $(1 / \mathrm{s})$, $a$ the particle radius $(\mathrm{m})$ and $D_{B}$ the Brownian diffusion coefficient $\left(\mathrm{m}^{2} / \mathrm{s}\right)$ which can be written as:

$$
D_{B}=\frac{k \cdot T}{6 \pi \cdot \bar{\eta} \cdot a}
$$

Here $k$ is the Boltzmann constant $(\mathrm{J} / \mathrm{K}), T$ the temperature $(\mathrm{K})$ and $\bar{\eta}$ the suspension viscosity (Pa s). At Péclet numbers below one, Brownian diffusion dominates.

In general, particles larger than 10 micron are mostly influenced by inertial lift that is the result of forces exerted by the surrounding fluid. The particle Reynolds number is used to characterize inertial lift [13]:

$$
R e_{p}=\frac{\dot{\gamma} \cdot a^{2} \cdot \rho_{f}}{\eta_{f}}
$$


With $\rho_{f}$ and $\eta_{f}$ the fluid density $\left(\mathrm{kg} / \mathrm{m}^{3}\right)$ and the fluid viscosity (Pa s), respectively. At a particle Reynolds number above one, inertial lift will dominate migration behaviour.

\subsubsection{Shear induced diffusion}

In the previous section, the limits for Brownian diffusion and inertial lift are clearly stated. In between, shear induced diffusion is the dominant migration mechanism (see also Figure 1.2).

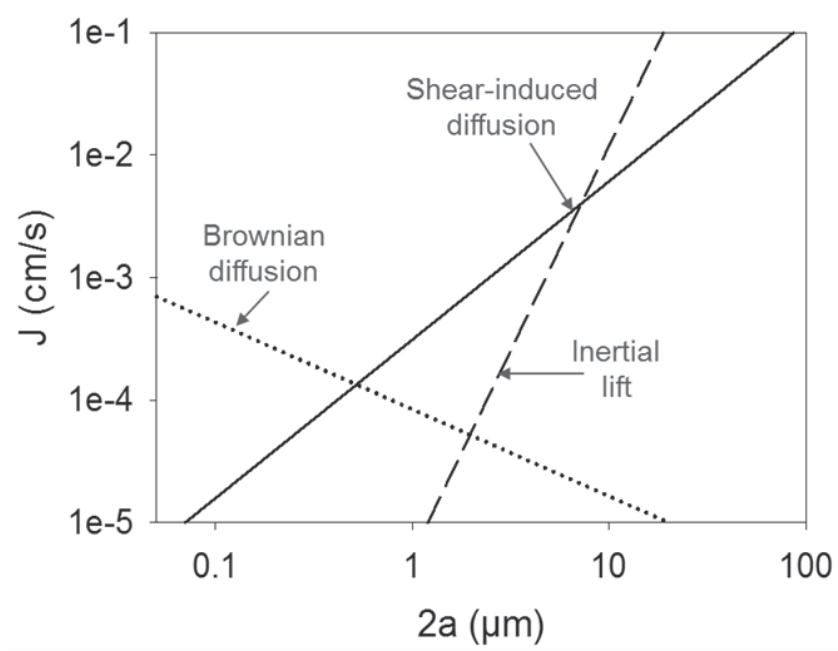

Figure 1.2. Influence of particle size on the flux for the main migration mechanisms mentioned in section 1.3. (Graph is reprinted from Separation and Purification Technology, 174, Karin Schroën; Anna van Dinther and Regine Stockmann, Particle migration in laminar shear fields: A new basis for large scale separation technology?, 372-388, 2017, with permission from Elsevier, original is from Davis [19]).

Shear induced diffusion is based on the interaction between particles and the rate of diffusion will thus be dependent on the volume fraction [14-16]. In the study of amongst others van Dinther and coworkers the shear induced diffusion coefficient $\left(D_{\text {shear }}\right)$ is given by $[15,16]$ :

$$
D_{\text {shear }}=D(\phi) \cdot \gamma \cdot a^{2}
$$

In this equation $D(\phi)$ is a diffusion coefficient that increases with particle volume fraction. From the equation it is further clear that large particles, and high shear lead to higher overall 
diffusivity. In general, the particles will move away from the region with the highest shear which is the region near the wall. If differently sized particles are present in for example equal volume fractions, larger particles will move away from the channel wall faster $[17,18]$, and we use this effect to design innovative separation processes. We establish presegregation in a closed channel, and subsequently apply filtration to separate the particles that are in close proximity of the pores, as schematically shown in Figure 1.3.

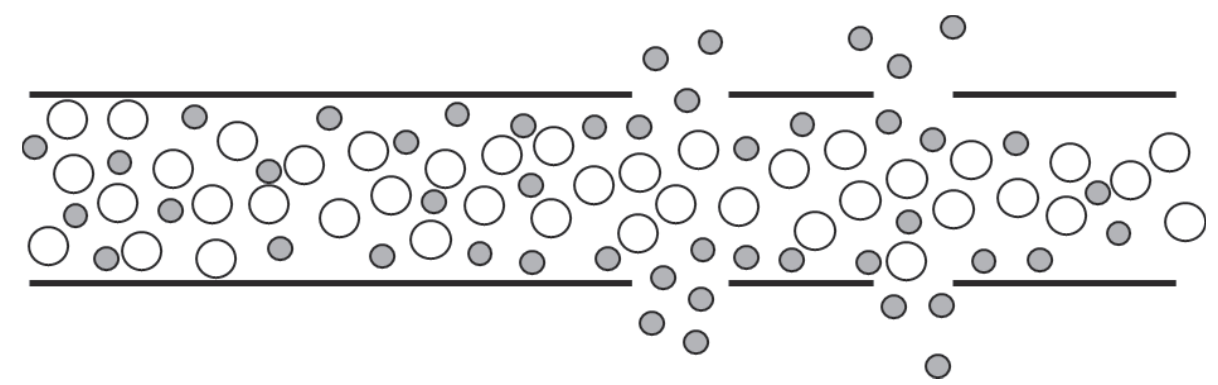

Figure 1.3. Schematic view on particle segregation of a bidisperse suspension due to shear induced diffusion.

Experimentally it has been shown that the pores used in the filtration part can be much larger than the particles present in the suspension because the segregation is established earlier while flowing through the closed channel, and only the layer near the membrane needs to be removed $[15,17]$. To really understand the complexity of shear induced diffusion and use it as a basis for process design, also numerical studies are needed in combination with experimental validation, and quite some information is available. Vollebregt et al. [14,20] and Miller et al. [21] e.g. focused on modelling of concentration profiles of monodisperse and/or bidisperse suspensions in a closed channel, while Lyon and Leal $[22,23]$ and Semwogerere and coworkers [18] focused on experimental verification of this phenomena. Van Dinther and coworkers [15-17] have taken this one step further and applied the principle of shear induced diffusion in a filtration set-up similar to the one described in Figure $\mathbf{1 . 3}$ for bidisperse suspensions. All these studies have contributed to improved understanding of shear induced diffusion, but especially for the filtration system still a lot of parameters that are essential for process design are unknown. For example pore dimensions and placement, and the effect of polydispersity, still need to be investigated, and are all in the core of the work presented here. 


\subsection{Research aim and thesis outline}

The general aim of this thesis is to use numerical tools to better understand shear induced diffusion and ultimately design novel particle segregation technology. The study focusses on both process conditions as well as membrane design, and for this we systematically investigate a number of parameters as detailed in the thesis outline that can be found in the next section. In the thesis we use a commercially available model to describe not only the shear induced diffusion profile in a closed channel but to also look the porous region. Based on our findings we identify the parameters (flow conditions, and membrane characteristics) that are of most influence on the separation process.

A schematic overview of the thesis is shown in Figure 1.4. In the second chapter, a computational fluid dynamics (CFD) model is presented that describes the shear induced diffusion profile in a closed channel for a monodisperse suspension. This model is validated experimentally, and compared to model and experimental results presented in literature. In the third chapter the model is used for a rigorous parameter study, in order to get a better insight in the effects of process conditions and how these influence transmission and recovery of the concentration profile after the pore. In the fourth chapter we zoom in on the porous region. By studying pore size, the distance between pores and the number of pores we get a better insight in separation efficiency. In the fifth chapter, a polydisperse feed consisting of cream particles is used for fractionation purposes in a process that is designed based on the findings in previous chapters. The results are compared with those obtained with the monodisperse CFD model and guidelines are derived. In the general discussion the different chapters are linked, leading to promising directions for future research.

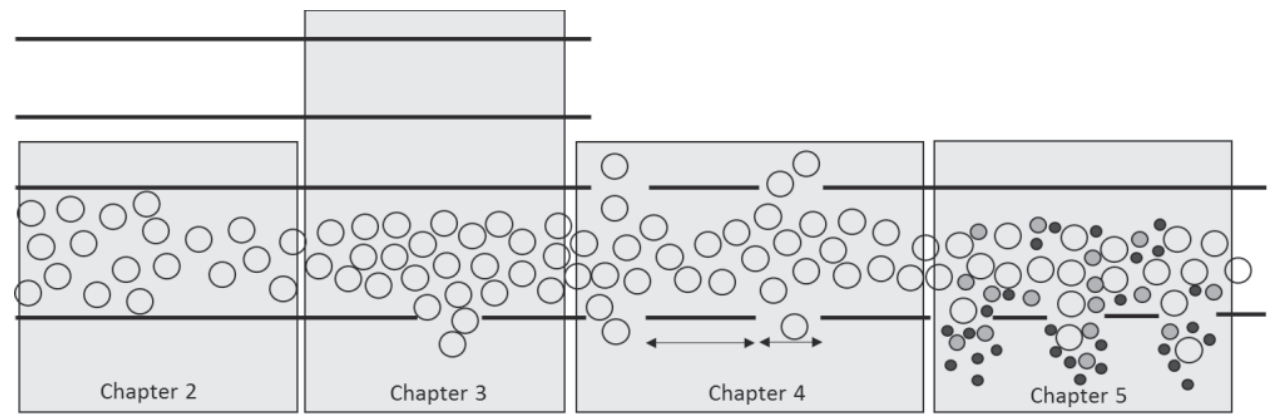

Figure 1.4. Schematic overview of this thesis. 


\subsection{References}

[1] A.S. Grandison, M.J. Lewis, Separation processes in the food and biotechnology industries: principles and applications, Woodhead, Cambridge, 1996.

[2] H. Strathmann, Membrane Separation Processes: Current Relevance and Future Opportunities, AIChE J. 47 (2001) 1077-1087.

[3] R.G.M. van der Sman, H.M. Vollebregt, A. Mepschen, T.R. Noordman, Review of hypotheses for fouling during beer clarification using membranes, J. Memb. Sci. 396 (2012) 22-31.

[4] C. Judson King, Separation processes: second edition, Dover Publications, Inc., Mineola, New York, 2013.

[5] J.P. Dijkshoorn, M.A.I. Schutyser, R.M. Wagterveld, C.G.P.H. Schroën, R.M. Boom, A comparison of microfiltration and inertia-based microfluidics for large scale suspension separation, Sep. Purif. Technol. 173 (2017) 86-92.

[6] G. Brans, C.G.P.H. Schroën, R.G.M. van der Sman, R.M. Boom, Membrane fractionation of milk: State of the art and challenges, J. Memb. Sci. 243 (2004) 263-272.

[7] G. Gésan-Guiziou, Liquid Milk Proccessing, in Membrane Processing: Dairy and Beverage Applications, Blackwell Publishing Ltd, Oxford, UK, 2013.

[8] K. Meister, M.E. Doyle, Obesity and Food Technology, American Council on Science and Health, New York, 2009.

[9] H. Goudédranche, J. Fauquant, J.-L. Maubois, Fractionation of globular milk fat by membrane microfiltration, Lait. 80 (2000) 93-98.

[10] G. Brans, a. van Dinther, B. Odum, C.G.P.H. Schroën, R.M. Boom, Transmission and fractionation of micro-sized particle suspensions, J. Memb. Sci. 290 (2007) 230-240.

[11] K. Schroën, A.M.C. van Dinther, S. Bogale, M. Vollebregt, G. Brans, R.M. Boom, Membrane Processes for Dairy Fractionation, in: Membr. Technol. Vol. 3 Membr. Food Appl., 2010.

[12] G. Belfort, R.H. Davis, A.L. Zydney, The behavior of suspensions and macromolecular solutions in crossflow microfiltration, J. Memb. Sci. 96 (1994) 1-58.

[13] R.G.M. van der Sman, Simulations of confined suspension flow at multiple length scales, Soft Matter. 5 (2009) 4376-1387.

[14] H.M. Vollebregt, R.G.M. van der Sman, R.M. Boom, Suspension flow modelling in particle migration and microfiltration, Soft Matter. 6 (2010) 6052-6064.

[15] A.M.C. van Dinther, C.G.P.H. Schroën, R.M. Boom, Separation process for very concentrated emulsions and suspensions in the food industry, Innov. Food Sci. Emerg. Technol. 18 (2013) $177-182$.

[16] A.M.C. van Dinther, C.G.P.H. Schroën, A. Imhof, H.M. Vollebregt, R.M. Boom, Flow-induced particle migration in microchannels for improved microfiltration processes, Microfluid. Nanofluidics. 15 (2013) 451-465.

[17] A.M.C. van Dinther, C.G.P.H. Schroën, R.M. Boom, Particle migration leads to deposition-free fractionation, J. Memb. Sci. 440 (2013) 58-66.

[18] D. Semwogerere, E.R. Weeks, Shear-induced particle migration in binary colloidal suspensions, Phys. Fluids. 20 (2008). 
[19] R.H. Davis, Modeling of fouling of crossflow microfiltration membranes, Sep. Purif. Methods. 21 (1992) 75-126.

[20] H.M. Vollebregt, R.G.M. van der Sman, R.M. Boom, Model for particle migration in bidisperse suspensions by use of effective temperature, Faraday Discuss. 158 (2012) 89-103.

[21] R.M. Miller, J.F. Morris, Normal stress-driven migration and axial development in pressuredriven flow of concentrated suspensions, J. Nonnewton. Fluid Mech. 135 (2006) 149-165.

[22] M.K. Lyon, L.G. Leal, An experimental study of the motion of concentrated suspensions in two-dimensional channel flow. Part 1. Monodisperse systems, J. Fluid Mech. 363 (1998) 2556.

[23] M.K. Lyon, L.G. Leal, An experimental study of the motion of concentrated suspensions in two-dimensional channel flow. Part 2. Bidisperse systems, J. Fluid Mech. 363 (1998) 57-77. 



\section{Chapter 2}

From highly specialised to generally available modelling

of shear induced particle migration

for flow segregation based separation technology

This chapter has been published as I. Drijer, T. van de Laar, H.M. Vollebregt, C.G.P.H. Schroen, From highly specialised to generally available modelling of shear induced particle migration for flow segregation based separation technology, Sep. Purif. Technol. 192 (2018) 99-109 


\begin{abstract}
Shear induced diffusion can be used to induce particle migration in flow, and this may be a lead to novel separation technology. Under specific conditions, depending on, amongst others, the ratio between channel height and particle diameter, larger particles preferentially move to the centre of a channel. It has been demonstrated earlier that separation and fractionation can be facilitated by this, leading to lower energy and water demand, and prevention of particle accumulation on sieves that have pores that are much larger than the particles. This situation is very different from regular (cross-flow) membrane filtration, in which particles are retained by the pores, and accumulate in various layers.

Unfortunately, the underlying mechanisms of particle migration are not that well understood, and contradicting results are reported in literature. There is clearly a need for a unifying approach that can be used by many; therefore, we developed a CFD computer model that can readily be used, unlike the rather inaccessible computer models that are mostly reported in literature. We focus on particle-particle interactions of monodisperse suspensions in flow, for which we added momentum terms to the general momentum equation. We found amongst others that due to shear induced diffusion the particle volume fraction will be 1.7 times higher at the centre of the channel compared to the channel wall for a bulk particle volume fraction of $50 \%$. Our results describe the experimental results, obtained under similar ideal conditions, to a high level of detail. Our findings are also in reasonable agreement with other modelling and experimental studies from literature, and the discrepancies are most probably due to non-ideal behaviour in the experiments and different approaches used in the models. The big advantage of using this software is that the model can be adapted readily by researchers not specifically trained in modelling or programming, but even more importantly, particle migration can now be used as a starting point in separation design since parameter and geometry studies will take less effort using this software.
\end{abstract}




\subsection{Introduction}

Concentration and segregation of suspensions is needed in different fields, such as biotechnology, water treatment, etc. [1]. Also in the food sector it plays an important role, e.g. in the dairy industry bacteria need to be separated from the product stream [2] in order to obtain a safe product, and in the beer industry yeast is separated to clarify the product [3]. Also during fermentation it would be useful to fractionate mature from not fully mature species, so they can be sent back to the fermentation vessel to obtain higher productivity.

Often the concentration and segregation of suspensions, in the range of 1-10 $\mu \mathrm{m}$, is done by microfiltration [1-3], during which convective flow carries the particles toward the membrane that retains them, forming a layer that in turn is influenced by various back transport mechanisms, amongst which shear induced diffusion [4-6]. We would like to stress that there is a clear difference between shear induced diffusion as used for modelling of microfiltration, and for segregation in flow; therefore both processes are first discussed.

\subsubsection{Microfiltration}

During classic membrane microfiltration particles are separated from the suspension fluid by a membrane. Due to the applied trans-membrane pressure both the fluid and the particles are pushed towards the membrane; the liquid permeates through the membrane, while the particles remain at the retentate side when the membrane pore size is smaller than the size of the particles. Since these particles cannot cross the membrane, they accumulate, pores become blocked and a (cake) layer forms [7], which results in flux reduction and a change in retention due to the presence of the (cake) layer in combination with a possible decrease in effective pore size.

Accumulation of particles can be mitigated in several ways. One solution would be to decrease the concentration of the suspension so that less particles are available to block the membrane pores, although this is not always practical to do [8,9]. A back flush can also be applied to remove the particles from the membrane [10], or a cross flow can be applied that induces back transport of particles (to some extent). Whatever option is chosen, more energy, more water or both will be needed [9], and the membrane will have to be cleaned regularly. Although this is standard procedure in industry, it would be better if particles could be kept from accumulating, leading to an environmentally and economically more sustainable situation by extension of the run period and less need for cleaning. 


\subsubsection{Flow segregation}

Instead of using the membrane's size exclusion mechanism that is responsible for accumulation, the intrinsic migration mechanisms of the particles can be considered as means to facilitate fractionation or concentration of a suspension. These mechanisms include Brownian motion, inertial lift and shear-induced diffusion [7]. In short, Brownian motion describes how particles arbitrarily move around in a certain space, which does not have a specific direction. Inertial lift takes into account the influence of the fluid flowing around the particles; particle movement follows the pressure gradient over the particle, which is directed toward the centre of the channel. Shear-induced diffusion considers how particles affect the movement of other particles in flow. It is directed towards regions of lower shear (middle of the channel), and various complex relations have been given in literature as will be shown in the model development section.

Which of these mechanisms dominates depends on various parameters, that are incorporated in the dimensionless particle Reynolds number, defined as:

$$
R e_{p}=\frac{v_{r} \cdot a \cdot \rho_{f}}{\eta_{f}}
$$

and the dimensionless Péclet number, defined as:

$$
P e=\frac{\dot{\gamma} \cdot a^{2}}{D_{B}}
$$

In which $v_{r}$ is the relative velocity between the phases $(\mathrm{m} / \mathrm{s}), \dot{\gamma}$ the shear rate $(1 / \mathrm{s})$, a the particle radius $(\mathrm{m}), \rho_{f}$ the fluid density $\left(\mathrm{kg} / \mathrm{m}^{3}\right), \eta_{f}$ the fluid viscosity $(\mathrm{Pa} s)$, and $D_{B}$ the Brownian diffusion coefficient $\left(\mathrm{m}^{2} / \mathrm{s}\right)$ defined as:

$$
D_{B}=\frac{k \cdot T}{6 \pi \cdot \bar{\eta} \cdot a}
$$

Here $\bar{\eta}$ is the suspension viscosity ( $\mathrm{Pa} \mathrm{s}), k$ the Boltzmann constant $(\mathrm{J} / \mathrm{K})$ and $T$ the temperature $(K)$. Inertial lift dominates when $\operatorname{Re}_{p}>1$, and Brownian motion dominates when $\mathrm{Pe}<1$. Hence, for shear induced diffusion to be dominant, $\operatorname{Re}_{\mathrm{p}}<1$ and $\mathrm{Pe}>1$. For particles that are between 1 and 10 micrometre, which are most relevant for microfiltration, shear-induced diffusion is the dominant mechanism and, therefore, this study focuses on this topic. 
As mentioned previously, we will use shear-induced diffusion to segregate particles flowing in a closed channel. Shear induced diffusion is a result of how particles affect the movement of other particles and it scales with the square of the particle size (Table 2.1). With equal volume fractions of large and small particles, the larger particles will move faster towards a region with low shear, which would be the centre of the channel [11]. In this way, the particles can migrate away from the wall in a closed channel before they are exposed to a porous section. It can be expected that this will lead to processes that are environmentally and economically more sustainable.

In summary, for microfiltration flux predictions are based on the build-up of various layers of particles accumulated on the membrane as a result of amongst others convective flow toward the membrane, and cross-flow over the layers that induces back transport. Therefore, Kim and Zydney [12] developed a CFD model that gives good insight in the effect of a number of transport mechanisms, but given the complexity of the filtration process, shear induced diffusivity was not investigated individually. For the flow segregation process that we propose here, shear induced diffusivity needs to be described very accurately since it is the only transport mechanism, and that puts extra weight on the accuracy of our model. To the best of our knowledge, simulation of segregation in flow, as a starting point for novel separation design, using commercially available software has not been covered in literature, which distinguishes our work from that of others.

In order to make use of the flow segregation process, we have designed the system that is shown in Figure 2.1; pre-migration will take place in the closed channel, and liquid can be removed through the pores that are larger than the particles (Figure 2.1) $[9,11]$. This implies that the chances of fouling are reduced, while at the same time higher suspension concentrations can be used (that in turn stimulate shear induced diffusion).

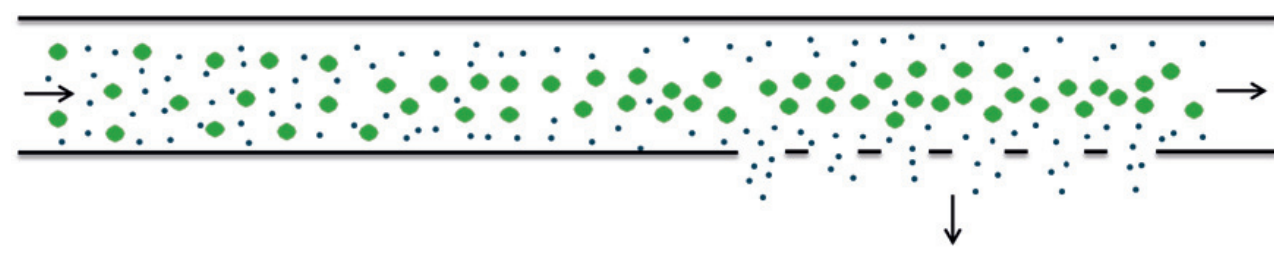

Figure 2.1. Schematic view on fractionation due to shear induced diffusion. Based on [30]. (Reprinted from Modeling Food Processing Operations, R.M. Klaver, C.G.P.H. Schroën, A review of shear-induced particle migration for enhanced filtration and fractionation, 211-233, 2015, with permission from Elsevier) 
As a prerequisite for the design of this novel separation technology, particle migration as a result of shear induced diffusivity needs to be described at a high level of detail and ideally in a flexible way. For this, both experimental work and computer models are needed, and ideally these studies focus on exactly the same system. Previous studies have covered monodisperse [13-16], bidisperse [17-19] or polydisperse [20] suspensions, and have focused on modelling, on experimental work or both, but mostly there are notable discrepancies between experimental data and modelling results.

In case of modelling, most often the particle phase mass balance is rewritten to insert a diffusive flux term $[13,21]$ that describes the principle of shear induced diffusion. However, it should be mentioned that the models that are currently available are mostly the author's own written code and are therefore at a level that is only accessible for experts in the field of modelling and programming. These models generally do not target to capture these effects with commercially available computational fluid dynamics (CFD) programs that are much more accessible. At the same time it should be mentioned that commercially available CFD software is not that flexible to start off with, since the governing equations cannot always be rewritten. Different studies have used CFD to study shear induced diffusivity $[4,5]$, but not to describe flow segregation in a closed channel aiming at the development of new separation technology [22]. We use the commercial CFD software STARCCM+ to describe the diffusive behaviour of monodisperse particles in a closed system which represents the entrance section shown in Figure 2.1. This is a logical starting point for the overall process design that is part of later studies. We validate our results with experiments that were carried out under similar ideal conditions, and compare with available sources from literature, and this forms a solid base for future process design in a user friendly software environment.

\subsection{Model development}

\subsubsection{Governing equations}

In this study the commercial software program STAR-CCM+ was used. The 'Multiphase Segregated Flow Model', that uses an Euler-Euler formulation, was chosen in order to allow fast calculations that we need for extensive parameter studies that are part of future research. In this model the finite volume method is used. The user guide of STAR-CCM+ describes the following about this method: 
"In the finite volume method, the solution domain is subdivided into a finite number of small control volumes, corresponding to the cells of a computational grid. Discrete versions of the integral form of the continuum transport equations are applied to each control volume. The objective is to obtain a set of linear algebraic equations, with the total number of unknowns in each equation system corresponding to the number of cells in the grid. The resulting linear equations are then solved with an algebraic multigrid solver."

The general governing conservation equations, as used in STAR-CCM+, are for continuity:

$$
\begin{aligned}
& \frac{\partial}{\partial t} \int_{V} \alpha_{i} \rho_{i} \chi d V+\oint_{A} \alpha_{i} \rho_{i} \chi\left(v_{i}-v_{g}\right) d a=\int_{V} \sum_{j \neq i}\left(m_{i j}-m_{j i}\right) \chi d V+ \\
& \int_{V} S_{i}^{\alpha} d V
\end{aligned}
$$

and for momentum:

$$
\begin{aligned}
& \frac{\partial}{\partial t} \int_{V} \alpha_{i} \rho_{i} \chi v_{i} d V+\oint_{A} \alpha_{i} \rho_{i} \chi v_{i} \otimes\left(v_{i}-v_{g}\right) d a=-\int_{V} \alpha_{i} \chi \nabla p d V+ \\
& \int_{V} \alpha_{i} \rho_{i} \chi g d V+\oint_{A}\left[\alpha_{i}\left(\tau_{i}+\tau_{i}^{t}\right)\right] \chi d a+\int_{V} M_{i} \chi d V+\int_{V}\left(F_{\text {int }}\right)_{i} \chi d V+ \\
& \int_{V} S_{i}^{v} d V+\int_{V} \sum\left(m_{i j} v_{j}-m_{j i} v_{i}\right) \chi d V
\end{aligned}
$$

In which $\alpha$ is the volume fraction for phase i $(-), \rho$ the density $\left(\mathrm{kg} / \mathrm{m}^{3}\right), \chi$ the void fraction (), $v$ the velocity $(\mathrm{m} / \mathrm{s}), v_{g}$ the grid velocity $(\mathrm{m} / \mathrm{s}), m$ the mass transfer rate $\left(\mathrm{kg} /\left(\mathrm{m}^{3} \cdot \mathrm{s}\right)\right), S_{i}^{\alpha}$ the phase mass source term $\left(\mathrm{kg} /\left(\mathrm{m}^{3} \cdot \mathrm{s}\right)\right), p$ the pressure $(\mathrm{Pa}), g$ the gravity factor $\left(\mathrm{m} / \mathrm{s}^{2}\right), \tau_{i}$ and $\tau_{i}^{t}$ the molecular and turbulent stresses $(\mathrm{Pa}), M_{i}$ the interphase momentum transfer per unit volume $\left(\mathrm{N} / \mathrm{m}^{3}\right), F_{\text {int }}$ the internal forces $\left(\mathrm{N} / \mathrm{m}^{3}\right)$ and $S_{i}^{v}$ the phase momentum source term $\left(\mathrm{N} / \mathrm{m}^{3}\right)$. In addition:

$\sum_{i} \alpha_{i}=1$ and $\sum_{i} M_{i}=0$

The effect of shear induced diffusion was inserted by adding a phase momentum source term. Further, constant density, no mass transfer between phases, no internal forces, no turbulence and no phase mass source term were assumed, which reduces the above equations considerably. These assumptions are justified because of laminar flow conditions; hard, inert particles which do not react or dissolve and prevention of clogging due to pores that are larger than the particles. Below we specify the equations for particles and fluid, for both the continuity and momentum equation. 


\section{Continuity}

Particles:

$$
\frac{\partial}{\partial t} \int_{V} \alpha_{p} d V+\oint_{A} \alpha_{p} v_{p} d a=0
$$

Fluid:

$$
\frac{\partial}{\partial t} \int_{V}\left(1-\alpha_{p}\right) \rho_{f} d V+\oint_{A}\left(1-\alpha_{p}\right) \rho_{f} v_{f} d a=0
$$

\section{Momentum}

Particles:

$$
\begin{aligned}
& \frac{\partial}{\partial t} \int_{V} \alpha_{p} \rho_{p} v_{p} d V+\oint_{A} \alpha_{p} \rho_{p} v_{p} \otimes\left(v_{p}-v_{g}\right) d a=-\int_{V} \alpha_{p} \nabla p d V+ \\
& \int_{V} \alpha_{p} \rho_{p} g d V+\oint_{A} \alpha_{p} \tau_{p} d a+\int_{V} F_{p f}^{D} d V+\int_{V} F^{S I D} d V
\end{aligned}
$$

Fluid:

$$
\begin{aligned}
& \frac{\partial}{\partial t} \int_{V}\left(1-\alpha_{p}\right) \rho_{f} v_{f} d V+\oint_{A}\left(1-\alpha_{p}\right) \rho_{f} v_{f} \otimes\left(v_{f}-v_{g}\right) d a=-\int_{V}(1- \\
& \left.\alpha_{p}\right) \nabla p d V+\int_{V}\left(1-\alpha_{p}\right) \rho_{f} g d V+\oint_{A}\left(1-\alpha_{p}\right) \tau_{f} d a-\int_{V} F_{p f}^{D} d V-\int_{V} F^{S I D} d V
\end{aligned}
$$

Here $F^{D}$ is the drag force $\left(\mathrm{N} / \mathrm{m}^{3}\right)$ and $F^{S I D}$ the force due to shear induced diffusion $\left(\mathrm{N} / \mathrm{m}^{3}\right)$. In literature $[13,14,21]$ the principle of shear induced diffusion is often linked to the governing equations by rewriting the particle phase mass balance, using:

$$
v_{p}=\bar{v}+\left(1-\alpha_{p}\right) w
$$

With $\bar{v}$ the average velocity $(\mathrm{m} / \mathrm{s})$ and $w$ the slip velocity $(\mathrm{m} / \mathrm{s})$. This gives:

$$
\frac{\partial}{\partial t} \int_{V} \alpha_{p} d V+\oint_{A} \alpha_{p} \bar{v} d a=-\oint_{A} \alpha_{p}\left(1-\alpha_{p}\right) w d a=-\oint_{A} j_{d i f f} d a
$$


In which $j_{\text {diff }}$ is the diffusive flux $(\mathrm{m} / \mathrm{s})$. The diffusive flux term is then used to describe the shear induced diffusion effect by using formulations based on either the diffusive flux model $[13,23]$ with the general equation:

$$
j_{\text {diff }}=-\left(D_{\alpha_{p}} \nabla \alpha_{p}+D_{\dot{\gamma}} \nabla \dot{\gamma}\right)
$$

or the suspension balance model $[13,14,21]$, with the following general equation:

$$
j_{d i f f}=-M \nabla \cdot\left(\Pi I+N_{s}\right)
$$

Here $D_{\alpha_{p}}$ is the volume fraction dependent diffusion coefficient $\left(\mathrm{m}^{2} / \mathrm{s}\right), D_{\dot{\gamma}}$ the shear rate dependent diffusion coefficient $\left(\mathrm{m}^{2}\right), M$ the mobility $\left(\mathrm{m}^{2} /(\mathrm{Pa} \cdot \mathrm{s})\right)$, $\Pi$ the particle pressure (Pa) and $N_{s}$ the normal stress differences $(\mathrm{Pa})$. By assuming no normal stress differences, the suspension balance model can be rewritten to $[13,17]$ :

$$
j_{\text {diff }}=-M \nabla \cdot\left(\Pi I+N_{s}\right)=-M \nabla \mu^{*}
$$

In which $\nabla \mu^{*}$ is the excess chemical potential $(\mathrm{Pa} / \mathrm{m})$.

To the best of our knowledge, in STAR-CCM+ the different terms in the governing conservation equations cannot by adjusted, therefore another approach is needed. Since, the different diffusive flux terms are equivalent as shown by Vollebregt et al. [13] it is possible to write the rewritten suspension balance model in terms of the diffusive flux model, and add this as a momentum source term to commercial CFD software:

$$
F^{S I D}=-\nabla \mu^{*}=\frac{\left(D_{\alpha_{p}} \nabla \alpha_{p}+D_{\dot{\gamma}} \nabla \dot{\gamma}\right)}{M}
$$

To complete the model, closure relations were used for the viscosity, mobility and the diffusion coefficients as presented in Table 2.1. 
Table 2.1. Closure relations SID momentum term

\begin{tabular}{cll}
\hline $\begin{array}{c}\text { Closure } \\
\text { relation }\end{array}$ & Reference & Equation \\
\hline$\eta$ & Krieger-Dougherty relation & $\eta_{\mathrm{f}}\left(1-\frac{\alpha_{\mathrm{p}}}{\alpha_{\max }}\right)^{[\eta] \alpha_{\max }}$ \\
$\mathrm{M}$ & Vollebregt et al. [13] & $\frac{2}{9} \frac{\mathrm{a}^{2}}{\eta_{\mathrm{f}}} \alpha_{\mathrm{p}} \mathrm{f}\left(\alpha_{\mathrm{p}}\right)$ \\
$\mathrm{D}_{\alpha_{\mathrm{p}}}$ & Vollebregt et al. [13] & $\frac{2}{9} \dot{\gamma} \mathrm{a}^{2}\left(1-\alpha_{\mathrm{p}}\right)^{2} \cdot 1.5 \frac{\widetilde{\alpha_{\mathrm{p}}}}{\alpha_{\max }}\left(1+\widetilde{\alpha_{\mathrm{p}}}\left(1-\widetilde{\alpha_{\mathrm{p}}}\right)^{-1}\right)$ \\
$\mathrm{D}_{\dot{\gamma}}$ & Vollebregt et al. [13] & $\frac{2}{9} \mathrm{a}^{2}\left(1-\alpha_{\mathrm{p}}\right)^{2} \cdot 0.75 \widetilde{\alpha_{\mathrm{p}}}$ \\
$\mathrm{f}\left(\alpha_{\mathrm{p}}\right)$ & Vollebregt et al. [13] & $\left(1-\alpha_{\mathrm{p}}\right)^{2}\left(1-\widetilde{\alpha_{\mathrm{p}}}\right)^{2}$ \\
$\dot{\gamma}$ & Miller et al. [14] & $\frac{\mathrm{dv}}{\mathrm{dy}}+\frac{\mathrm{a} \cdot v_{\max }}{\mathrm{H}^{2}}$ \\
\hline
\end{tabular}

In addition to the shear induced diffusion momentum term, the drag force also needed to be specified. In STAR-CCM+ the following generic equation is used:

$$
F_{i j}^{D}=A_{i j}^{D}\left(v_{j}-v_{i}\right)
$$

In which $A_{i j}^{D}$ is the linearized drag coefficient (Pa.s $/ \mathrm{m}^{2}$ ) defined as:

$$
A_{i j}^{D}=C_{i j}^{D} \frac{1}{2} \rho_{f}\left|v_{j}-v_{i}\right| \frac{a_{i j}}{4}
$$

Here $C_{i j}^{D}$ is the standard drag coefficient (-) and $a_{i j}$ the interfacial area density $(1 / \mathrm{m})$. The standard drag coefficient is calculated with:

$$
C_{i j}^{D}=f_{i j}^{D} C_{i j \infty}^{D}
$$

Where $C_{i j \infty}^{D}$ is the single particle drag coefficient and $f_{i j}^{D}$ the drag correction factor. Different options are available for the single particle drag coefficient. In this study the SchillerNaumann method was chosen given that hard spherical particles are used, also in the experiments. This correlation is in STAR-CCM+ given by:

$$
C_{i j \infty}^{D}=\left\{\begin{array}{rr}
\frac{24}{R e_{p}}\left(1+0.15 R e_{p}{ }^{0.687}\right) 0<R e_{p}<1000 \\
0.44 & R e_{p}>1000
\end{array}\right.
$$


Richardson Zaki was chosen for the drag correction factor: $\left(1-\alpha_{p}\right)^{n}$, since this gives the most realistic development profile.

\subsubsection{Process conditions}

The simulations were run in steady state and set up for parallel plate geometries, but the method can be applied to other configurations as well. To decrease calculation time 2D simulations were done with channel dimensions as listed in Table 2.2. The relatively low channel height is to assure conditions in which SID is dominant over other transport mechanisms. The channel length is chosen such that the segregation profile is fully developed.

As boundary conditions a velocity inlet, a pressure outlet and a no slip condition at the wall were chosen. Since an Euler-Euler formulation was used, the grid size should be larger than the particle diameter; we carried out a grid refinement study of which the results are shown in Appendix C. To circumvent convergence issues, the nearest neighbour method was used, making the value at the wall equal to the value at the centre of the neighbouring cell. Please note that this implies that if a large grid size is chosen near the wall, this may give a relatively large error in the simulation outcome.

\subsection{Results and discussion}

Vollebregt et al. [13] showed that the different diffusive flux terms are equivalent and that the suspension balance model can be rewritten in terms of the diffusive flux model. In the current paper, we used the relations given by Vollebregt et al., and found that they were in very good agreement for fully developed profiles, as illustrated in Figure $\mathbf{2 . 2}$ for $50 \%$ particles.

There were differences in the development of the profile, as shown in Figure $\mathbf{2 . 3}$ for a $50 \%$ particle volume fraction and the two previously mentioned relations for the diffusion coefficients. The approach of Vollebregt et al. led to faster development of the concentration profile, then that based on Morris and Boulay; this effect will not be discussed further here, but is mentioned to be complete. For now we focus on fully developed flows, using the diffusion coefficients of Vollebregt et al., and compare the model with available experimental results that unfortunately are not very abundant, and differ in regard to the dimensions used. 


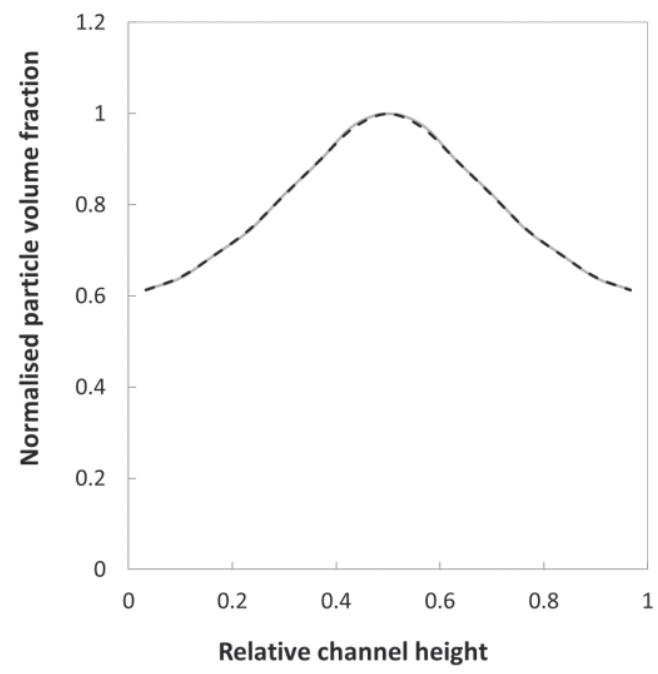

Figure 2.2. Normalised particle volume fraction (relative to the centre value) vs. the relative channel height at steady state conditions $(x / 2 H=1250)$, for $\alpha_{p, f e e d}=0.5$ and $H / a=18$. Model results with rewritten diffusion coefficients of Morris and Boulay by Vollebregt et al.[13] (dashed line), and of Vollebregt et al. (solid line)[13].

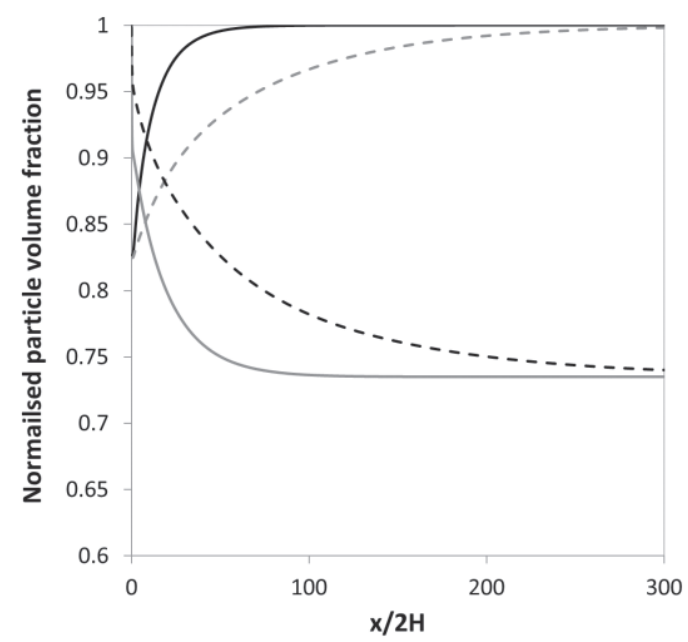

Figure 2.3. Normalised particle volume fraction (relative to the highest value) vs. the relative channel length, for $\alpha_{p, f e e d}=0.5$ and $H / a=18$, for the two diffusion coefficients, both for a position at the wall (bottom two lines), and the centre of the channel (top two lines). Our results with the diffusion coefficients of Vollebregt et al.[13] is indicated by solid lines, our results with the diffusion coefficients of Morris and Boulay adapted by Vollebregt et al.[13] has dashed lines. 
For monodisperse suspensions, Semwogerere et al. [16], Koh et al. [24] and Lyon and Leal [15] have published experimental results, and Semwogerere et al. and Koh et al. have also published modelling results that all could be used for validation. Furthermore, Miller et al. [14] compared their own model to the experimental results of Lyon and Leal and Dbouk et al. [25] compared their CFD model to the model results of Miller et al. [14]. In the next paragraphs all these experimental and modelling data will be compared to our results. To reach a just conclusion, the bulk particle volume fraction and the ratio between channel width and particle radius has been adjusted as much as possible to the actual values used in literature (Table 2.2).

Table 2.2. Process parameters used for comparison of model and literature data. For a grid refinement study see Appendix $C$.

\begin{tabular}{lllll}
\hline Model & $\begin{array}{l}\text { Channel } \\
\text { height }(\mu \mathrm{m})\end{array}$ & $\begin{array}{l}\text { Particle } \\
\text { diameter }(\mu \mathrm{m})\end{array}$ & $\begin{array}{l}\text { Channel } \\
\text { height/particle } \\
\text { diameter }\end{array}$ & $\begin{array}{l}\text { Number of grid } \\
\text { cells in y- } \\
\text { direction } \\
\text { (channel height) }\end{array}$ \\
\hline $\begin{array}{llll}\text { Semwogerere et al. } \\
\text { Our model }\end{array}$ & 50 & 1.4 & 35.7 & 33 \\
Koh et al. & 50 & 1.4 & 35.7 & 25 \\
$\begin{array}{l}\text { Our model } \\
\text { Miller et al. }\end{array}$ & 200 & 7.6 & 26.3 & \\
$\begin{array}{l}\text { Our model } \\
\text { Our experiments }\end{array}$ & 50 & 11.1 & 26.3 & 15 \\
Our model & 50 & 2 & 18 & \\
\hline
\end{tabular}

\subsubsection{Semwogerere et al.}

Semwogerere and colleagues [16] investigated migration of particles inside a channel and compared that to a shear induced diffusion model based on the suspension balance model. In Figure 2.4, our modelling results are shown, together with those of Semwogerere et al., and it is clear that at both entrance lengths the profile is more developed in our model compared to that of Semwogerere et al. 


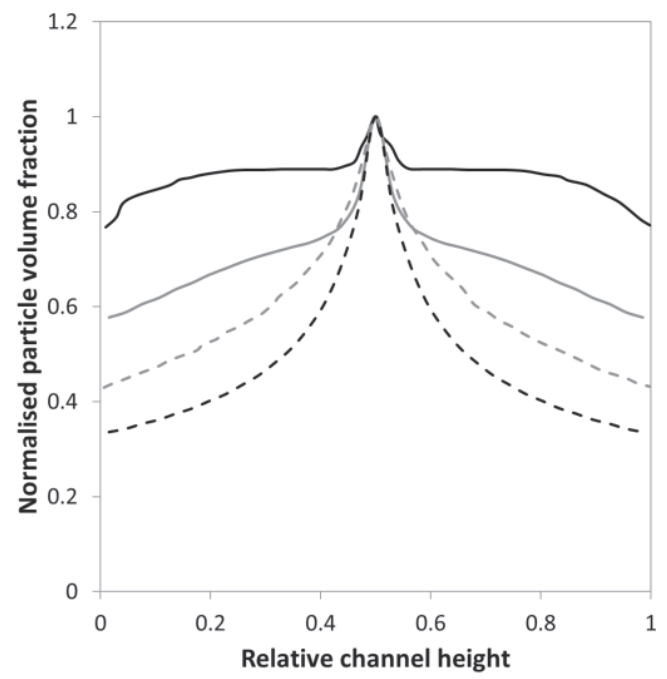

Figure 2.4. Normalised particle volume fraction (relative to the centre value) vs. the relative channel height at two different channel lengths, for $\alpha_{p, f e e d}=0.26$. Model Semwogerere et al. 2007 [16] at $x / H=1360$ (grey dashed line); Model Semwogerere et al. 2007 [16] at $x / H=80$ (black solid line) (Data Semwogerere et al. are taken from Denis Semwogerere, Jeffrey F. Morris and Eric R. Weeks, Development of particle migration in pressure-driven flow of a Brownian suspension, The Journal of Fluid Mechanics, 581, 437-451, reproduced with permission); our study at $x / H=1360$ (black dashed line); our study at $\mathrm{x} / \mathrm{H}=80$ (grey solid line).

When comparing with the experimental results in Figure 2.5, the model of Semwogerere et al. over predicts the rate at which the migration of particles takes place, and in our model migration is even faster. The experimental profile at $x / H=1360$ is in our model reached at $\mathrm{x} / \mathrm{H}=40$ (Figure 2.5). Semwogerere et al. mentioned that particle charge could influence the migration of particles. We also believe that non-ideal particle behaviour could influence particle migration as will be discussed in the last section.

\subsubsection{Koh et al.}

Koh et al. [24] present the steady state profile with the corresponding modelling results based on the suspension balance model. Figure $\mathbf{2 . 6}$ shows that our model is relatively close to the modelling results of Koh et al. Furthermore, it is clear that both models under predict the experimental data. This is in contrast to our analysis of the data of Semwogerere et al. in Figure 2.4 where our model gave an over prediction. As discussed in the previous section, this may be due to non-ideal particle behaviour in the experiments, as will be discussed later. 


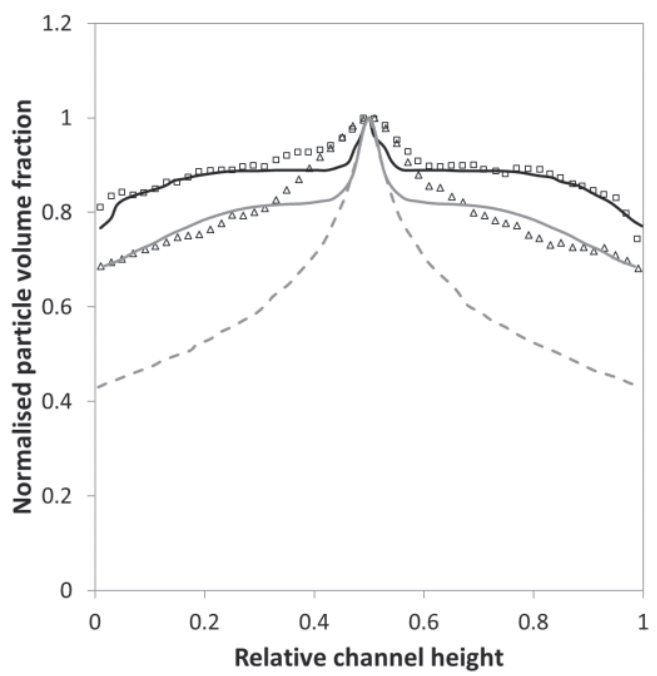

Figure 2.5. Normalised particle volume fraction (relative to the centre value) vs. the relative channel height at different channel lengths, for $\alpha_{p, f e e d}=0.26$. Experimental Semwogerere et al. 2007 [16] at $x / H=1360(\Delta)$; Experimental Semwogerere et al. 2007 [16] at $x / H=80$ (口); Model Semwogerere et al. 2007 [16] at $x / H=1360$ (grey dashed line); Model Semwogerere et al.[16] at $x / H=80$ (black solid line) (Data Semwogerere et al. are taken from Denis Semwogerere, Jeffrey F. Morris and Eric R. Weeks, Development of particle migration in pressure-driven flow of a Brownian suspension, The Journal of Fluid Mechanics, 581, 437-451, reproduced with permission); our results at $\mathrm{x} / \mathrm{H}=40$ (grey solid line).

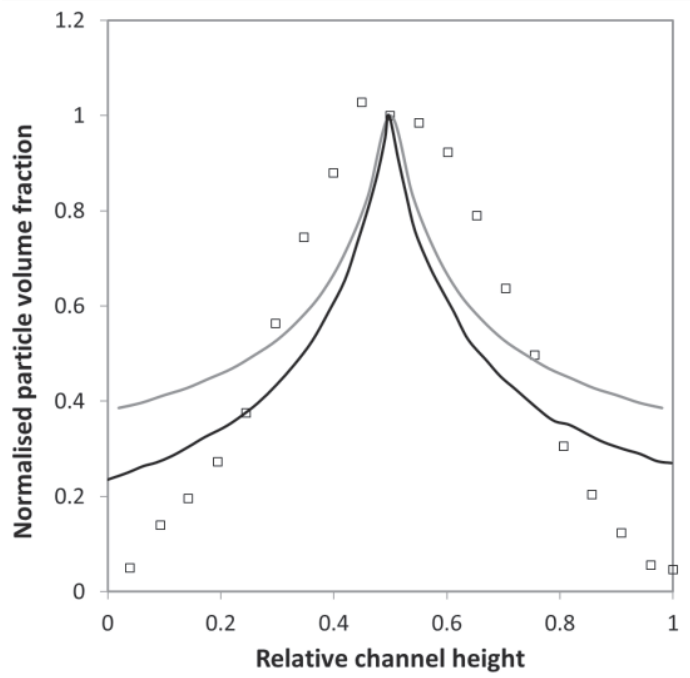

Figure 2.6. Normalised particle volume fraction (relative to the centre value) vs. the relative channel height, for $\alpha_{p, f e e d}=0.3$. Experimental Koh et al. 1994 [24] (ㅁ) ; Model Koh et al. 1994 [24] (black line) (Data Koh et al. are taken from Christopher J. Koh, Philip Hookham and L. G. Leal, An experimental investigation of concentrated suspension flows in a rectangular channel, The Journal of Fluid Mechanics, 266, 1-32, reproduced with permission); Our results (grey line). 


\subsubsection{Miller et al., Dbouk et al. and Lyon and Leal}

In their article Miller et al. [14] used the suspension balance model to describe the effect of shear induced diffusion. They compared their model to the experimental results of Lyon and Leal [15], which is also done by Dbouk et al. for their CFD model. These data are shown in Figure 2.7 along with the results of our model, and it is clear that the modelling results are very comparable. For $0.1 \leq$ relative channel height $\leq 0.9$ the model describes the experimental results well, but outside that range, the models seem to under predict the experimental results, which Miller and co-workers attributed to experimental difficulties. We think this can also be attributed to additional physics close to the wall that are not yet included in the model; this will be put in perspective in the discussion section.

In addition to the fully developed profile, Miller et al. and Dbouk et al. also showed some results on the particle volume fraction as function of the channel length (Figure 2.8). As expected, the results of our model based on the diffusion coefficients of Morris and Boulay $[13,21]$ are comparable to those of Miller et al. and Dbouk et al., who use the same data.

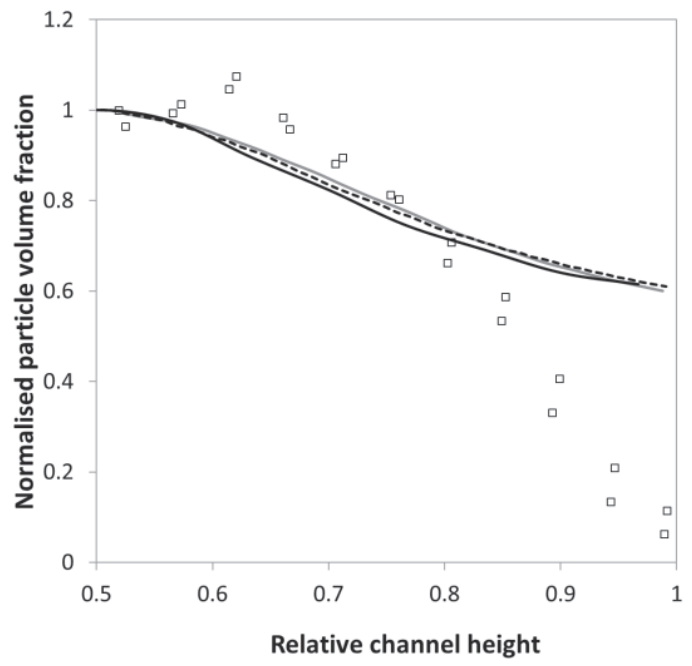

Figure 2.7. Normalised particle volume fraction (relative to the centre value) vs. the relative channel height, for $\alpha_{p, f e e d}=0.5$. Experimental Lyon et al. 1998 [15] taken from Miller et al 2008 [14] ( $\square$ ); Model Miller et al. 2008 [14] (grey line) (Data Miller et al. are reprinted from Journal of Non-Newtonian Fluid Mechanics, 135, Ryan M. Miller, Jeffrey F. Morris, Normal stress-driven migration and axial development in pressure-driven flow of concentrated suspensions, 149-165, 2006, with permission from Elsevier); Model Dbouk et al. 2013 [25] (black dotted line) (Data Dbouk et al. are reprinted from Journal of Non-Newtonian Fluid Mechanics, 198, T. Dbouk, E. Lemaire, L. Lobry, F. Moukalled, Shearinduced particle migration: Predictions from experimental evaluation of the particle stress tensor, 7895, 2013, with permission from Elsevier); Our results (black line). 


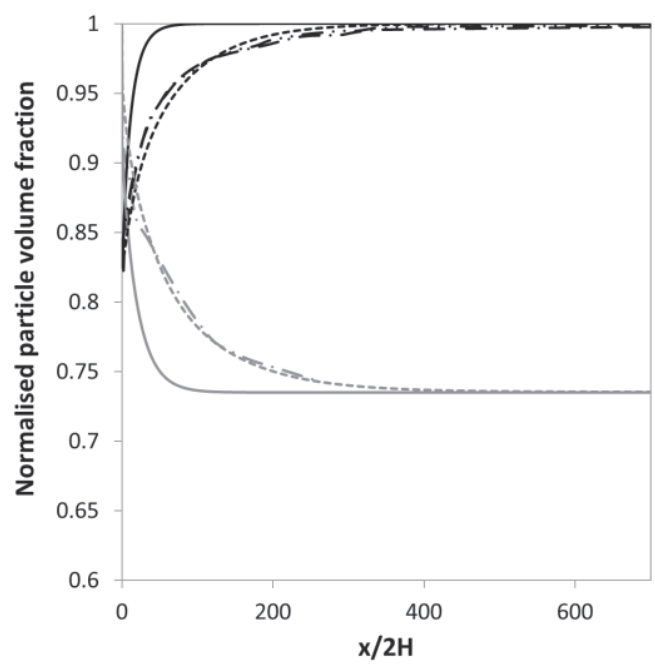

Figure 2.8. Normalised particle volume fraction (relative to the highest value) vs. the relative channel length, for $\alpha_{p, f e e d}=0.5$. The black lines are for the centre of the channel, the grey lines for the wall region. Solid lines are used for our results with the diffusion coefficients of Vollebregt et al. [13]; dashed lines for our results with the diffusion coefficients of Morris and Boulay adapted by Vollebregt et al.[13]; dash dotted lines are for model Miller et al. 2008 [14] (Data Miller et al. are reprinted from Journal of Non-Newtonian Fluid Mechanics, 135, Ryan M. Miller, Jeffrey F. Morris, Normal stress-driven migration and axial development in pressure-driven flow of concentrated suspensions, 149-165, 2006, with permission from Elsevier); dash double dotted line for model Dbouk et al. 2013 [25] (Data Dbouk et al. are reprinted from Journal of Non-Newtonian Fluid Mechanics, 198, T. Dbouk, E. Lemaire, L. Lobry, F. Moukalled, Shear-induced particle migration: Predictions from experimental evaluation of the particle stress tensor, 78-95, 2013, with permission from Elsevier).

\subsubsection{Experimental results}

It is clear that the results from literature are not conclusive. Lyon and Leal and Koh et al. reach particle volume fractions near the wall close to zero while Semwogerere et al. find values far from zero, as is the case in our simulations. Not only the relation for the diffusion coefficients will be of influence (see Figures 2.3 and 2.8) but also other equations will influence the results, such as the equations for viscosity and shear rate. For the shear rate, we used the approach of Miller et al. by adding an extra term that blunts the top of the graph; for a sharp peak to occur in practice the particles have to be highly aligned, which is not likely. The effect is also less pronounced at higher particle volume fractions where continuous interaction between the particles is expected to take place, resulting in a more blunted profile. In order to establish a true validation of the model, it was decided to do an elaborate experiment (see Appendix A), in which particle-particle and particle-wall 
interactions in experiment and simulations are optimally matched, which implies no sticking of particles to the wall or to each other. The results for the particle volume fraction and the velocity are shown in Figure $\mathbf{2 . 9}$ and Figure 2.10.

These results show that there is a very good match, both in regard to velocity and concentration gradient, between the experiments and the model. This confirms that control over experimental conditions is paramount in model validation, and also in pinpointing effects related to shear induced diffusion. These findings make us believe that the differences with literature that we noted in the previous sections are most probably due to non-ideal particle behaviour that is not covered in any model. The nice agreement that we obtained makes us optimistic that we can use this approach to rapidly design processes using commercially available software. For future work we will look into the influence of process parameters on the separation efficiency.

\subsection{Conclusion}

To describe particle migration under flow due to shear induced diffusion, a momentum term is added to commercial CFD software. The model shows an increase in particle volume fraction at the centre of the channel of 1.7 compared to the wall at a bulk particle volume fraction of 50\%. These findings are in very good agreement with our experimental results carried out under ideal conditions in which particle-wall interactions were eliminated. When comparing with experimental results in literature, larger discrepancies were found that are most probably caused by non-ideal particle behaviour.

The description of particle segregation in flow in a closed channel using CFD is the first step toward development of a new separation technology based on this phenomenon, and that is expected to be amongst others less energy consuming due to the laminar flow that is applied. Since commercially available CFD software is used to describe SID, this is an important step towards flexible process design that can be applied in different science areas and disciplines. 


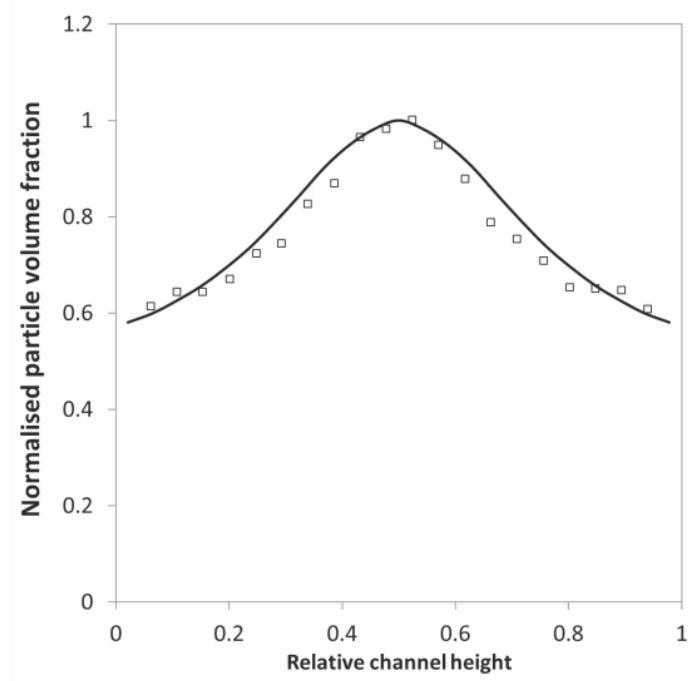

Figure 2.9. Normalised particle volume fraction (relative to the centre value) vs. the relative channel height, for $\alpha_{p, f e e d}=0.5$. Experimental results at $x / H=800$ ( $\square$ ); Model results at $x / H=800$ (line)

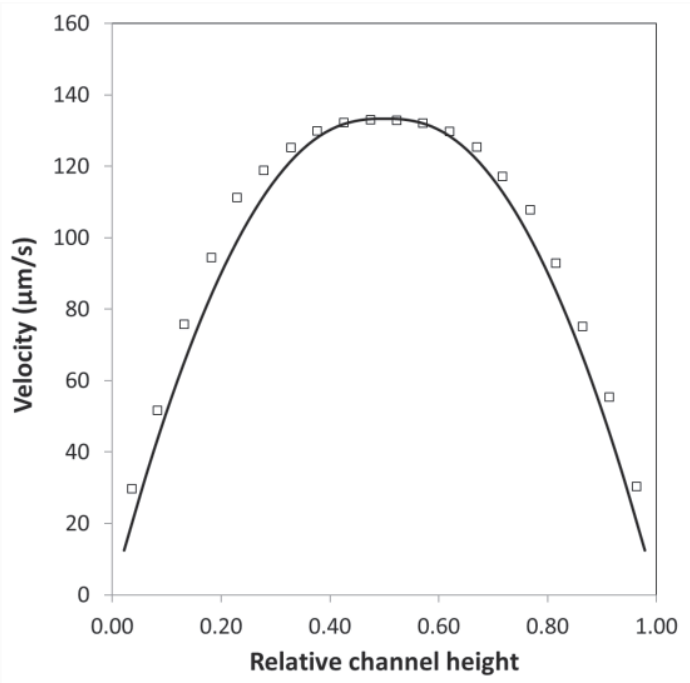

Figure 2.10. Velocity vs. the relative channel height, for $\alpha_{p, f e e d}=0.3$. Experimental results ( $\square$ ); Model results (line). 


\section{Appendix A: Experimental set up}

We synthesize hard sphere colloidal poly(methyl methacrylate)particles, stabilized by poly(hydroxystearic acid) and fluorescently labelled with Nile Red following established methods $[26,27]$. We clean our particle suspension by repeated washing with hexane and finally suspended the particles in an index and density matching mixture of decalin, tetralin and cyclohexyl bromide, saturated with tetrabutylammonium bromide ( $260 \mathrm{nM}$ ) to screen residual charges and ensure hard sphere interactions. The effective volume fraction is quantified by sedimentation and assuming random close packing of this sediment.

We flow these suspensions through glass capillaries with an inner diameter of 50 micron, under controlled pressure, and visualize the flow using high-speed confocal microscopy (movies recorded at $203 \mathrm{fps}$ ). To ensure that we image a fully developed flow profile we image at least $2 \mathrm{~cm}$ away from the start of the channel. The use of confocal microscopy allows us to study the behaviour of each particle separately and with high detail, and we use established particle tracking algorithms to locate and follow each particle individually [28]. From this individual particle information, we can reconstruct velocity profiles accurately by adopting the approach by Duits et al. [29]. To calculate local volume fractions we look at the average number density of particles over the width of the channel, where we subdivide this width in separate bins. The resulting bins are adapted slightly to match the modelling results.

\section{Appendix B: List of symbols}

Symbol

$a$

$a_{i j}$

$A_{i j}^{D}$

$C_{i j}^{D}$

$C_{i j \infty}^{D}$

$D_{\alpha_{p}}$

$D_{\dot{\gamma}}$

$f_{i j}^{D}$

$f\left(\alpha_{p}\right)$

$F_{p f}^{D}$

$\left(F_{\text {int }}\right)_{i}$

\section{Description}

Particle radius

Interfacial area density

Linearized drag coefficient

Standard drag coefficient

Single particle drag coefficient

Volume fraction dependent diffusion coefficient

Shear rate dependent diffusion coefficient

Drag correction factor

Hindered settling function

Drag force on particle phase due to the fluid phase

Internal forces (m)

$(1 / \mathrm{m})$

$\left(\mathrm{Pa} \cdot \mathrm{s} / \mathrm{m}^{2}\right)$

$(-)$

$\left(\mathrm{m}^{2} / \mathrm{s}\right)$

$\left(\mathrm{m}^{2}\right)$

(-)

(-)

$\left(\mathrm{N} / \mathrm{m}^{3}\right)$

$\left(\mathrm{N} / \mathrm{m}^{3}\right)$ 


$\begin{array}{lll}F^{S I D} & \text { Force due to shear induced diffusion } & \left(\mathrm{N} / \mathrm{m}^{3}\right) \\ \mathrm{g} & \text { Gravity factor } & \left(\mathrm{m} / \mathrm{s}^{2}\right) \\ \mathrm{H} & \text { Channel half height } & (\mathrm{m}) \\ j_{\text {diff }} & \text { Diffusive flux } & (\mathrm{m} / \mathrm{s}) \\ m_{i j} & \text { Mass transfer rate to phase i, from phase } \mathrm{j}\left(m_{i j} \geq 0\right) & \left(\mathrm{kg} /\left(\mathrm{m}^{3} \cdot \mathrm{s}\right)\right) \\ m_{j i} & \text { Mass transfer rate to phase j, from phase i }\left(m_{j i} \geq 0\right) & \left(\mathrm{kg} /\left(\mathrm{m}^{3} \cdot \mathrm{s}\right)\right) \\ M_{i} & \text { Interphase momentum transfer per unit volume } & \left(\mathrm{N} / \mathrm{m}^{3}\right) \\ M & \text { Mobility } & (\mathrm{m} 2 /(\mathrm{Pa} \cdot \mathrm{s})) \\ N_{s} & \text { Normal stress differences } & (\mathrm{Pa}) \\ p & \text { Pressure (assumed equal in both phases }) & (\mathrm{Pa}) \\ S_{i}^{\alpha} & \text { Phase mass source term } & \left(\mathrm{kg} /\left(\mathrm{m}^{3} \cdot \mathrm{s}\right)\right) \\ S_{i}^{v} & \text { Phase momentum source term } & \left(\mathrm{N} / \mathrm{m}^{3}\right) \\ v_{g} & \text { Grid velocity } & (\mathrm{m} / \mathrm{s}) \\ v_{i} & \text { Velocity of phase i } & (\mathrm{m} / \mathrm{s}) \\ v_{r} & \text { Relative velocity between phases } & (\mathrm{m} / \mathrm{s}) \\ \bar{v} & \text { Average velocity } & (\mathrm{m} / \mathrm{s}) \\ w & \text { Slip velocity } & (\mathrm{m} / \mathrm{s})\end{array}$

\section{Greek symbols}

\section{Symbol}

$\alpha_{i}$

$a_{f p}$

$\alpha_{\max }$

$\widetilde{\alpha_{p}}$

$\dot{\gamma}$

$\eta_{i}$

$[\eta]$

$\nabla \mu^{*}$

$\Pi$

$\rho_{i}$

$\tau_{i}$ and $\tau_{i}^{t}$

$\chi$

\section{Description}

Volume fraction of phase $i$

$(-)$

Interaction area density between fluid and particle phase

$(1 / \mathrm{m})$

Maximum packing density

$(-)$

Relative volume fraction $\left(\frac{\alpha_{p}}{\alpha_{\max }}\right)$

$(-)$

Shear rate

Viscosity of phase $\mathrm{i}$

Intrinsic viscosity

$(-)$

Excess chemical potential

$(\mathrm{Pa} / \mathrm{m})$

Particle pressure

(Pa)

Density of phase $\mathrm{i}$

$\left(\mathrm{kg} / \mathrm{m}^{3}\right)$

Molecular and turbulent stresses, respectively

Void fraction 


\section{Appendix C: grid refinement study}

To make sure that the grid size does not influence the simulation results a grid refinement study is done. Since the development of the SID profile takes place in the y-direction, different number of grid cells are used in that dimension. The simulations in the current study are compared to different literature data and our own experiments; therefore several grid refinement studies needed to be done. The results are shown in Figures $\mathbf{2 A 1}$ to $\mathbf{2 A 4}$ for the comparison to Semwogerere et al., Koh et al., Miller et al. and our own experiments respectively. There is a slight difference in the relative volume fraction at the centre of the channel but these are all within an acceptable 1.5\%. Near the wall, which is the region that we are interested in, the differences at higher grid cell numbers are negligible. Therefore we can conclude that a fine enough grid is chosen for all simulations.

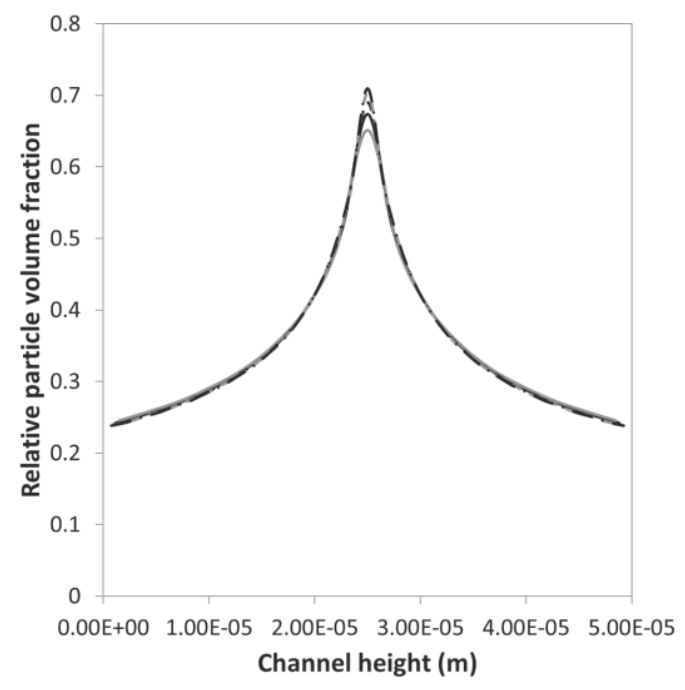

Figure 2A1. Grid refinement study for the comparison to Semwogerere et al. The relative particle volume fraction vs. the channel height at a distance of $3.4 \mathrm{~cm}$ from the entrance is shown. Each line represents a different number of grid cells for the channel height: 17 grid cells (grey solid line); 21 grid cells (black solid line); 25 grid cells (black dashed line); 29 grid cells (grey dashed line) and 33 grid cells (black dashed-dotted line). 


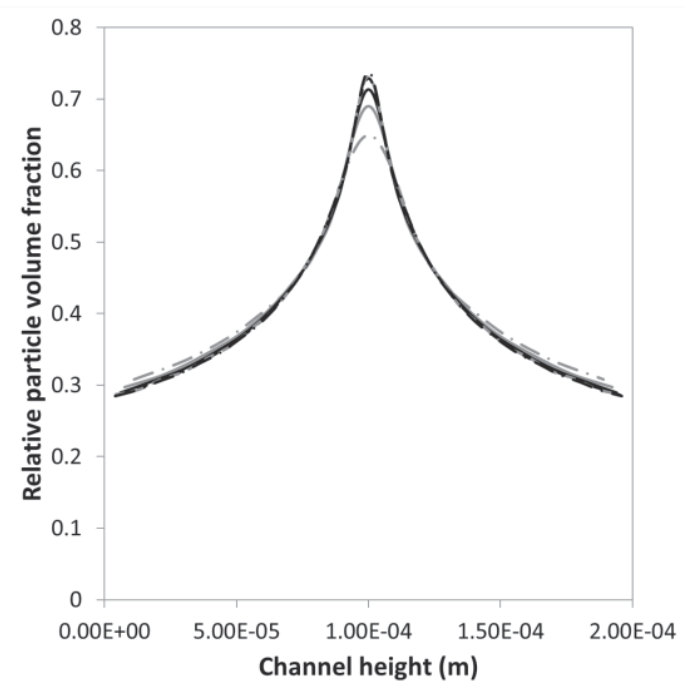

Figure 2A2. Grid refinement study for the comparison to Koh et al. The relative particle volume fraction vs. the channel height at a distance of $10 \mathrm{~cm}$ from the entrance is shown. Each line represents a different number of grid cells for the channel height: 9 grid cells (grey dashed-dotted line); 13 grid cells (grey solid line); 17 grid cells (black solid line); 21 grid cells (black dashed line); 23 grid cells (grey dashed line) and 25 grid cells (black dashed-dotted line).

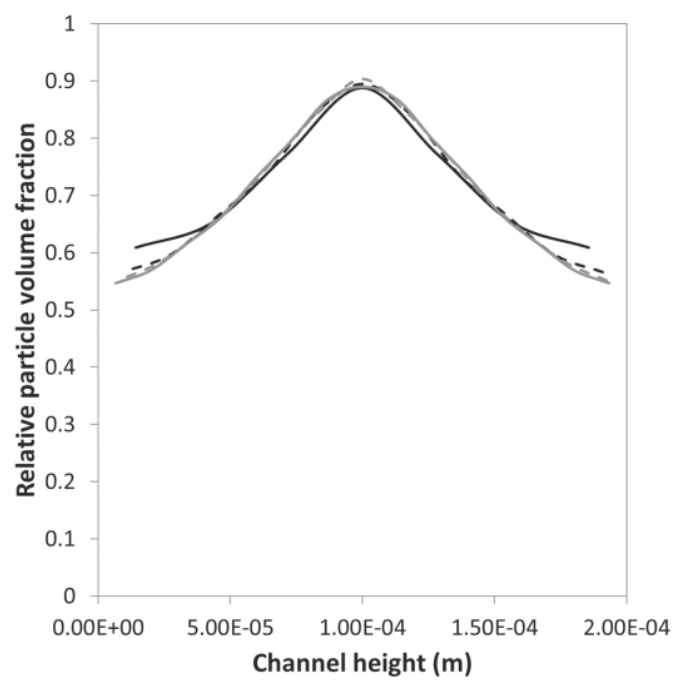

Figure 2A3. Grid refinement study for the comparison to Miller et al. The relative particle volume fraction vs. the channel height at a distance of $10 \mathrm{~cm}$ from the entrance is shown. Each line represents a different number of grid cells for the channel height: 7 grid cells (black solid line); 11 grid cells (black dashed line); 13 grid cells (grey dashed line) and 15 grid cells (grey solid line). 


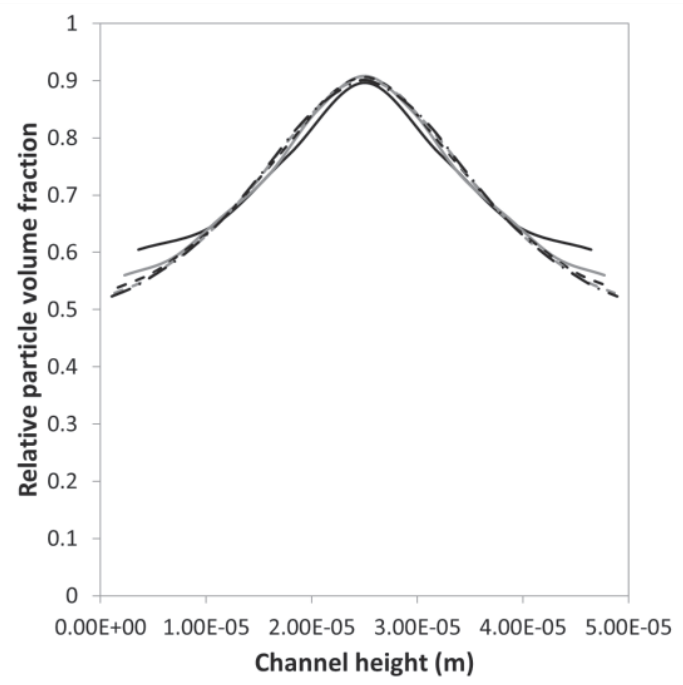

Figure 2A4. Grid refinement study for the comparison to our own experiments. The relative particle volume fraction vs. the channel height at a distance of $2.5 \mathrm{~cm}$ from the entrance is shown. Each line represents a different number of grid cells for the channel height: 7 grid cells (black solid line); 11 grid cells (grey solid line); 15 grid cells (black dashed line); 19 grid cells (grey dashed line) and 23 grid cells (black dashed-dotted line). 


\section{References}

[1] H. Strathmann, Membrane Separation Processes: Current Relevance and Future Opportunities, AIChE J. 47 (2001) 1077-1087.

[2] G. Brans, C.G.P.H. Schroën, R.G.M. van der Sman, R.M. Boom, Membrane fractionation of milk: State of the art and challenges, J. Memb. Sci. 243 (2004) 263-272.

[3] R.G.M. van der Sman, H.M. Vollebregt, A. Mepschen, T.R. Noordman, Review of hypotheses for fouling during beer clarification using membranes, J. Memb. Sci. 396 (2012) 22-31.

[4] P. Tiwari, S.P. Antal, M.Z. Podowski, Modeling shear-induced diffusion force in particulate flows, Comput. Fluids. 38 (2009) 727-737.

[5] A. Asadi Tashvigh, A. Fouladitajar, F. Zokaee Ashtiani, Modeling concentration polarization in crossflow microfiltration of oil-in-water emulsion using shear-induced diffusion; CFD and experimental studies, Desalination. 357 (2015) 225-232. doi:10.1016/j.desal.2014.12.001.

[6] J. Kromkamp, M. Van Domselaar, K. Schroen, R. Van der Sman, R. Boom, Shear-induced diffusion model for microfiltration of polydisperse suspensions, Desalination. 146 (2002) 6368.

[7] G. Belfort, R.H. Davis, A.L. Zydney, The behavior of suspensions and macromolecular solutions in crossflow microfiltration, J. Memb. Sci. 96 (1994) 1-58.

[8] G.H. Goldsztein, Volume of suspension that flows through a small orifice before it clogs, SIAM J. Appl. Math. 66 (2005) 228-236.

[9] A.M.C. van Dinther, C.G.P.H. Schroën, R.M. Boom, Separation process for very concentrated emulsions and suspensions in the food industry, Innov. Food Sci. Emerg. Technol. 18 (2013) 177-182.

[10] V.T. Kuberkar, R.H. Davis, Microfiltration of protein-cell mixtures with crossflushing or backflushing, J. Memb. Sci. 183 (2001) 1-14.

[11] A.M.C. van Dinther, C.G.P.H. Schroën, R.M. Boom, Particle migration leads to deposition-free fractionation, J. Memb. Sci. 440 (2013) 58-66.

[12] M. man Kim, A.L. Zydney, Theoretical analysis of particle trajectories and sieving in a twodimensional cross-flow filtration system, J. Memb. Sci. 281 (2006) 666-675.

[13] H.M. Vollebregt, R.G.M. van der Sman, R.M. Boom, Suspension flow modelling in particle migration and microfiltration, Soft Matter. 6 (2010) 6052-6064.

[14] R.M. Miller, J.F. Morris, Normal stress-driven migration and axial development in pressuredriven flow of concentrated suspensions, J. Nonnewton. Fluid Mech. 135 (2006) 149-165.

[15] M.K. Lyon, L.G. Leal, An experimental study of the motion of concentrated suspensions in two-dimensional channel flow. Part 1. Monodisperse systems, J. Fluid Mech. 363 (1998) 2556.

[16] D. Semwogerere, J.F. Morris, E.R. Weeks, Development of particle migration in pressuredriven flow of a Brownian suspension, J. Fluid Mech. 581 (2007) 437-451.

[17] H.M. Vollebregt, R.G.M. van der Sman, R.M. Boom, Model for particle migration in bidisperse suspensions by use of effective temperature, Faraday Discuss. 158 (2012) 89-103.

[18] M.K. Lyon, L.G. Leal, An experimental study of the motion of concentrated suspensions in two-dimensional channel flow. Part 2. Bidisperse systems, J. Fluid Mech. 363 (1998) 57-77. 
[19] D. Semwogerere, E.R. Weeks, Shear-induced particle migration in binary colloidal suspensions, Phys. Fluids. 20 (2008).

[20] A. Shauly, A. Wachs, A. Nir, Shear-induced particle migration in a polydisperse concentrated suspension, J. Rheol. (N. Y. N. Y). 42 (1998) 1329-1348.

[21] J.F. Morris, F. Boulay, Curvilinear flows of noncolloidal suspensions: The role of normal stresses, J. Rheol. (N. Y. N. Y). 43 (1999) 1213-1237.

[22] K. Schroën, A. van Dinther, R. Stockmann, Particle migration in laminar shear fields: A new basis for large scale separation technology?, Sep. Purif. Technol. 174 (2017) 372-388.

[23] R.J. Phillips, R.C. Armstrong, R.A. Brown, A.L. Graham, J.R. Abbott, A constitutive equation for concentrated suspensions that accounts for shearinduced particle migration A constitutive equation for concentrated for shear-induced particle migration suspensions that accounts, Phys. Fluids A. 4 (1992) 30-40.

[24] C.J. Koh, P. Hookham, L.G. Leal, An experimental investigation of concentrated suspension flows in a rectangular channel, J. Fluid Mech. 266 (1994) 1-32.

[25] T. Dbouk, E. Lemaire, L. Lobry, F. Moukalled, Shear-induced particle migration: Predictions from experimental evaluation of the particle stress tensor, J. Nonnewton. Fluid Mech. 198 (2013) 78-95.

[26] M.T. Elsesser, A.D. Hollingsworth, Revisiting the synthesis of a well-known comb-graft copolymer stabilizer and its application to the dispersion polymerization of poly(methyl methacrylate) in organic media, Langmuir. 26 (2010) 17989-17996.

[27] L. Antl, J.W. Goodwin, R.D. Hill, R.H. Ottewill, S.M. Owens, S. Papworth, J.A. Waters, The preparation of poly(methyl methacrylate) latices in non-aqueous media, Colloids and Surfaces. 17 (1986) 67-78.

[28] V. Pelletier, N. Gal, P. Fournier, M.L. Kilfoil, Microrheology of microtubule solutions and actinmicrotubule composite networks, Phys. Rev. Lett. 102 (2009).

[29] M.H.G. Duits, S. Ghosh, F. Mugele, Measuring advection and diffusion of colloids in shear flow, Langmuir. 31 (2015) 5689-5700.

[30] R.M. Klaver, C.G.P.H. Schroën, A review of shear-induced particle migration for enhanced filtration and fractionation, in: Model. Food Process. Oper., Elsevier, 2015: pp. 211-233. 




\section{Chapter 3}

Modelling shear induced diffusion based particle segregation:

a basis for novel separation technology

This chapter has been published as I. Drijer, K. Schroën, Modelling shear induced diffusion based particle segregation: a basis for novel separation technology, Appl. Sci. 8 (2018) 1008 


\begin{abstract}
Shear induced diffusion based flow segregation is a technique that can be used for concentration and fractionation purposes, and it has the potential to become an economical and sustainable alternative for e.g. membrane separation. When compared to conventional microfiltration, problems related to fouling and cleaning are expected to be minimal.

To make best use of the opportunities that this technique holds, detailed insights in flow and particle behaviour are needed. Modelling this process, allows us to chart particle segregation in flow, as well as the effect of suspension removal through a pore, and restoration of the flow profile after the pore. As a starting point we take the computational fluid dynamics (CFD) model presented in a previous study.

A difference in channel height to particle diameter ratio influences the entrance length of the SID profile as well as its fully developed profile. When extracting liquid through one pore, particles are systematically transmitted at lower concentration (59-78\%) than present in the bulk. The recovery lengths of the SID profile after the pore were short, and thus pores can be placed at realistic distances, which forms a good foundation for further design of this novel separation technology that will ultimately be applied for fractionation of particles taking relatively small differences in diffusive behaviour as a starting point.
\end{abstract}




\subsection{Introduction}

The fractionation and concentration of particles is used in many industries [1-3], for which different methods are available that mostly depend on the size of the particles that need to be separated. Dijkshoorn et al. (2017) distinguish three different categories in their recent review: particles smaller than $10 \mathrm{~nm}$ that can be separated using adsorption or ultrafiltration, particles in the range of 1-10 $\mu \mathrm{m}$ that can be separated by microfiltration or specific microfluidic devices, and particles larger than $10 \mu \mathrm{m}$ that can be separated by centrifugation or settling when having sufficient density difference [4]. In the current paper, we are interested in separating particles in the range of 1-10 $\mu \mathrm{m}$ and focus on a concept that combines insights obtained for microfiltration and microfluidic devices.

In conventional microfiltration particles are carried towards a membrane via convection, where they are then retained creating a concentration polarization layer and, in due time, a cake layer. These layers will have an influence on the trans-membrane pressure, which results in a reduction of the flux $[5,6]$, and changing retention or selectivity of the membrane as function of time $[5,6]$. In micro-structured devices and channels, particle behaviour in flow can also be used to achieve separation or fractionation. For example, deterministic ratchets make use of the displacement of particles around precisely placed objects [7]; based on a critical size, particles will follow a particular streamline, or be displaced [7]. Fluid skimming makes use of fluid flow to carry a particle across a pore (similarly to microfiltration at high cross flow), and is termed an industrially promising technique because of its scalability by some authors [4,8].

In the current paper, we focus on shear induced diffusion based segregation that takes place in relatively narrow channels, and has been suggested for particle fractionation based on experimental observations [9]. Here we use modelling studies to chart process parameter effects (e.g. channel dimensions, flow velocity, concentration profiles, and restoration thereof after a disturbance) and achieve systematic insights in process behaviour.

\subsubsection{Shear induced diffusion based segregation}

Nowadays, industries not only require and demand a high performance at low costs but also look at the environmental impact of their processes. In this sense, making use of the principle of shear induced diffusion is an interesting option since it can be operated at much lower energy impact than e.g. microfiltration that in itself is already not that high in energy impact [9]. Shear induced diffusion (SID) is one of the natural migration mechanisms of 
particles and relies on collective particle behaviour that directs particles away from a channel wall. Next to SID, there is Brownian diffusion and inertial lift [5]; see also Figure 3.1. Brownian diffusion includes the tendency of particles to move in a random direction, and inertial lift includes the effect of the fluid surrounding the particles, which directs individual particles away from the channel wall.

To distinguish the different particle migration mechanisms, the dimensionless particle Reynolds number and Péclet number are used, which are indicative of the ratios between the different forces acting on the particles [10]. SID is dominant for particles in the range of 1 to $10 \mu \mathrm{m}$, with a particle Reynolds number lower than one and a Péclet number higher than one (Figure 3.1).

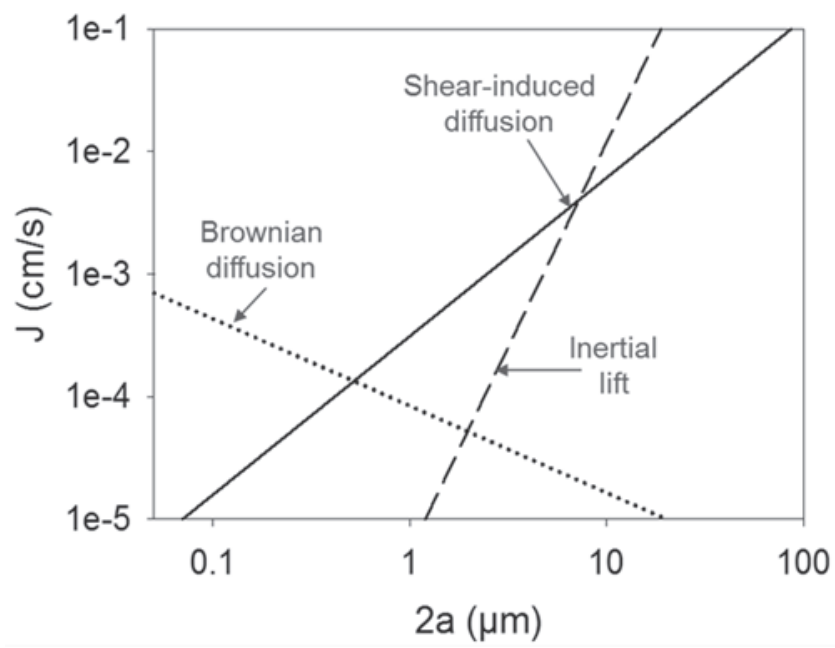

Figure 3.1. Flux versus the particle diameter for different migration mechanisms (Graph is reprinted from Separation and Purification Technology, 174, Karin Schroën; Anna van Dinther and Regine Stockmann, Particle migration in laminar shear fields: A new basis for large scale separation technology?, 372-388, 2017, with permission from Elsevier, original is from Davis [11]).

Considerable effort is put into understanding the principle of shear induced diffusion [1220] that is especially relevant at high volume fractions and causes particles to interact and move towards a region with low shear (i.e. the centre of a channel) [21]. Depending on the size and volume fractions of small and large particles the former or latter will predominantly move towards the centre of the channel when using particles of different sizes [19]. In a monodisperse suspension the particles will concentrate near the centre, which is a lead for 
novel concentration processes based on shear-induced diffusion when removing the particle-free liquid that is close to the wall (Figure 3.2) $[16,17]$.
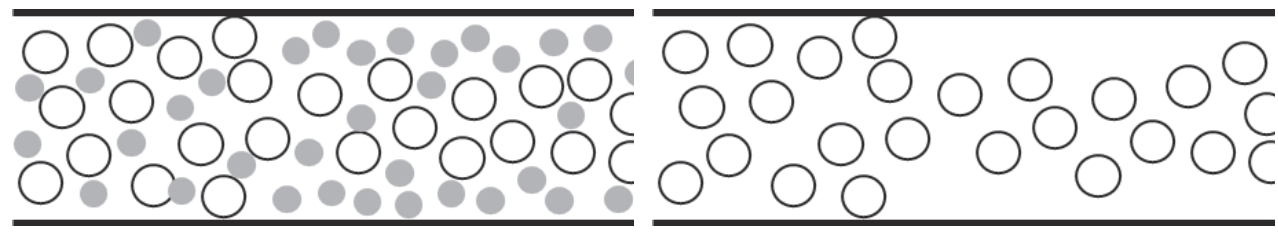

Figure 3.2. Schematic representation of the segregation principle of shear induced diffusion for a bidisperse (left) and monodisperse (right) suspension.

After the segregation of particles has taken place in a closed channel, a porous section can be considered to either concentrate particles, or separate different sized particles in case of a bidisperse or polydisperse suspension [21,22]. Since the segregation already takes place inside the closed channel, the pores in the porous section do not need to have an exclusion effect and can therefore be larger than the size of the particles, unlike regular membrane filtration. The large pores have much lower tendency to block, and the formation of a cake layer is much less likely to occur, even while working with high particle volume fractions [21]. This allows for process intensification, and will reduce cleaning costs, which in turn is expected to reduce the environmental impact of the process considerably [22].

The effect of SID has been experimentally investigated by Van Dinther and coworkers [2123], and they found high separation efficiency of a bidisperse suspension in a system consisting of a non-porous channel and a porous region, depending on the process conditions used. In order to facilitate process design, we have set up and validated a CFD model, which describes the effect of SID in a non-porous channel only, for a monodisperse suspension in earlier work [10]. In the current study, this CFD model will be used as a starting point for the description of the whole process that also consists of a porous section (Figure 3.3). The particle profile near the pore, and the re-constitution of the concentration profile after the pore are of core importance to this novel process; therefore, we focus on these aspects. This information will in later studies be used as a basis for fractionation of particles that are similar in size. 


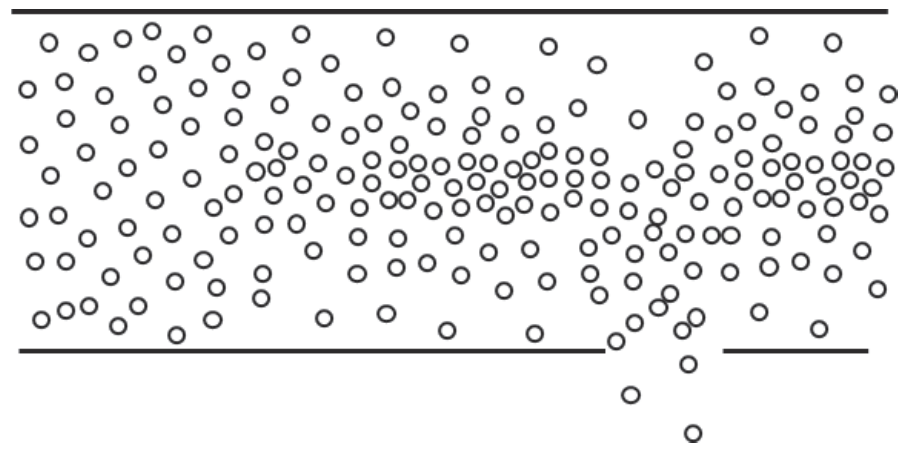

Figure 3.3. Schematic view of the process considered in this study; please note the change in concentration profile close to the pore that will be discussed in detail in the results section.

\subsection{Model development}

The interested reader is referred to a previous study [10] for the details of the CFD model that describes the SID process and its validation; here, we limit ourselves to a summary, and highlight the additions made to the previously established model. The 'Multiphase Segregated Flow Model' of the commercial CFD software STAR-CCM+ (CD-adapco, London, UK) is applied, which uses an Euler-Euler type of formulation that enables us to do the fast calculations needed for parameter studies.

\subsubsection{Governing equations}

Because of the Euler-Euler formulation separate equations are used for the particle and fluid phase for both momentum and mass. A phase momentum source term describes SID for the main channel in these equations. To make use of the principle of SID the flow needs to be laminar (turbulence will destroy the concentration profiles). Furthermore, nonreactive hard and inert particles are used that do not dissolve, and do not stick to the walls. The above mentioned conditions allow us to assume that there are no internal forces and phase mass source terms. Also, a constant density and an absence of mass transfer between phases can be assumed. This results in the equations given next.

Continuity equation for the fluid:

$$
\frac{\partial}{\partial t} \int_{V}\left(1-\alpha_{p}\right) \rho_{f} d V+\oint_{A}\left(1-\alpha_{p}\right) \rho_{f} v_{f} d a=0
$$


Continuity equation for the particles:

$$
\frac{\partial}{\partial t} \int_{V} \alpha_{p} d V+\oint_{A} \alpha_{p} v_{p} d a=0
$$

Momentum equation for the fluid:

$$
\begin{aligned}
& \frac{\partial}{\partial t} \int_{V}\left(1-\alpha_{p}\right) \rho_{f} v_{f} d V+\oint_{A}\left(1-\alpha_{p}\right) \rho_{f} v_{f} \otimes\left(v_{f}-v_{g}\right) d a=-\int_{V}(1- \\
& \left.\alpha_{p}\right) \nabla p d V+\int_{V}\left(1-\alpha_{p}\right) \rho_{f} g d V+\oint_{A}\left(1-\alpha_{p}\right) \tau_{f} d a-\int_{V} F_{p f}^{D} d V- \\
& \int_{V} F^{S I D} d V
\end{aligned}
$$

Momentum equation for the particles:

$$
\begin{aligned}
& \frac{\partial}{\partial t} \int_{V} \alpha_{p} \rho_{p} v_{p} d V+\oint_{A} \alpha_{p} \rho_{p} v_{p} \otimes\left(v_{p}-v_{g}\right) d a=-\int_{V} \alpha_{p} \nabla p d V+ \\
& \int_{V} \alpha_{p} \rho_{p} g d V+\oint_{A} \alpha_{p} \tau_{p} d a+\int_{V} F_{p f}^{D} d V+\int_{V} F^{S I D} d V
\end{aligned}
$$

Here $\alpha_{i}$ is the volume fraction of phase i (-) $\left(\sum_{i} \alpha_{i}=1\right), \rho_{i}$ the density of phase $\mathrm{i}\left(\mathrm{kg} / \mathrm{m}^{3}\right)$, $v_{i}$ the velocity of phase $\mathrm{i}(\mathrm{m} / \mathrm{s}), v_{g}$ the grid velocity $(\mathrm{m} / \mathrm{s}), p$ the pressure $(\mathrm{Pa}), g$ the gravity vector $\left(\mathrm{m} / \mathrm{s}^{2}\right), \tau_{i}$ the molecular stresses of phase $\mathrm{i}(\mathrm{Pa}), F^{D}$ the drag force $\left(\mathrm{N} / \mathrm{m}^{3}\right)$ and $F^{S I D}$ the shear induced diffusion force $\left(\mathrm{N} / \mathrm{m}^{3}\right)$. The shear induced diffusion force is given below in equation 5 for which the closure relations are given in Table 3.1.

$$
F^{S I D}=\frac{\left(D_{\alpha_{p}} \nabla \alpha_{p}+D \dot{\gamma} \nabla \dot{\gamma}\right)}{M}
$$

With $\dot{\gamma}$ the shear rate $(1 / \mathrm{s}), D_{\alpha_{p}}$ the volume fraction dependent diffusion coefficient $\left(\mathrm{m}^{2} / \mathrm{s}\right)$, $D_{\dot{\gamma}}$ the shear rate dependent diffusion coefficient $\left(\mathrm{m}^{2}\right)$ and $M$ the mobility $\left(\mathrm{m}^{2} /(\mathrm{Pa} \cdot \mathrm{s})\right)$. The drag force is described by the following generic relation:

$$
F_{i j}^{D}=A_{i j}^{D}\left(v_{j}-v_{i}\right)
$$

Here, $A_{i j}^{D}$ is the linearized drag coefficient $\left(\mathrm{Pa} \cdot \mathrm{s} / \mathrm{m}^{2}\right)$. For more details about the drag force see Table 3.2. 
To make the key points of our numerical model clearer, a flow chart is presented in Figure $\mathbf{3 . 4}$ that gives the most important points used in our model.

Table 3.1. Closure relations needed for the shear induced diffusion force

\begin{tabular}{cll}
\hline $\begin{array}{c}\text { Closure } \\
\text { relation }\end{array}$ & Reference & Equation \\
\hline$\eta$ & Krieger-Dougherty relation & $\eta_{\mathrm{f}}\left(1-\frac{\alpha_{\mathrm{p}}}{\alpha_{\max }}\right)^{[\eta] \alpha_{\max }}$ \\
$\mathrm{M}$ & Vollebregt et al. [15] & $\frac{2}{9} \frac{\mathrm{a}^{2}}{\eta_{\mathrm{f}}} \alpha_{\mathrm{p}} \mathrm{f}\left(\alpha_{\mathrm{p}}\right)$ \\
$\mathrm{D}_{\alpha_{\mathrm{p}}}$ & Vollebregt et al. [15] & $\frac{2}{9} \dot{\gamma} \mathrm{a}^{2}\left(1-\alpha_{\mathrm{p}}\right)^{2} \cdot 1.5 \frac{\widetilde{\alpha_{\mathrm{p}}}}{\alpha_{\max }}\left(1+\widetilde{\alpha_{\mathrm{p}}}\left(1-\widetilde{\alpha_{\mathrm{p}}}\right)^{-1}\right)$ \\
$\mathrm{D}_{\dot{\gamma}}$ & Vollebregt et al. [15] & $\frac{2}{9} \mathrm{a}^{2}\left(1-\alpha_{\mathrm{p}}\right)^{2} \cdot 0.75 \widetilde{\alpha_{\mathrm{p}}}$ \\
$\mathrm{f}\left(\alpha_{\mathrm{p}}\right)$ & Vollebregt et al. [15] & $\left(1-\alpha_{\mathrm{p}}\right)^{2}\left(1-\widetilde{\alpha_{\mathrm{p}}}\right)^{2}$ \\
$\dot{\gamma}$ & Miller et al. [17] & $\frac{\mathrm{dv}}{\mathrm{dy}}+\frac{\mathrm{a} \cdot \mathrm{v}_{\max }}{\mathrm{H}^{2}}$ \\
\hline
\end{tabular}

Table 3.2. Relations used for the drag force

\begin{tabular}{|c|c|c|}
\hline $\begin{array}{l}\text { Closure } \\
\text { relation }\end{array}$ & Reference & Equation \\
\hline$A_{i j}^{D}$ & & $C_{i j}^{D} \frac{1}{2} \rho_{f}\left|v_{j}-v_{i}\right| \frac{a_{i j}}{4}$ \\
\hline$C_{i j}^{D}$ & & $f_{i j}^{D} C_{i j \infty}^{D}$ \\
\hline$C_{i j \infty}^{D}$ & Schiller-Naumann method & $\left\{\begin{array}{c}\frac{24}{R e_{p}}\left(1+0.15 R e_{p}^{0.687}\right) 0<R e_{p}<1000 \\
0.44 \quad R e_{p}>1000\end{array}\right.$ \\
\hline$f_{i j}^{D}$ & Richardson Zaki & $\left.1-\alpha_{p}\right)^{n}$ \\
\hline
\end{tabular}

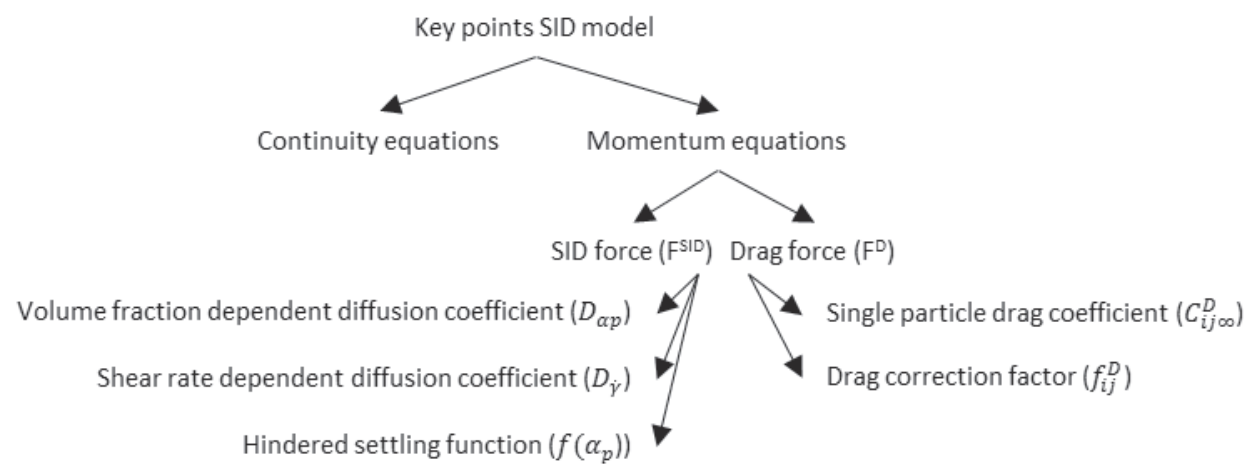

Figure 3.4. Flow chart of the most important steps taken in our shear induced diffusion model. 


\subsubsection{Process conditions}

In the STAR-CCM+ software, we make use of two-dimensional (2D) steady state simulations, which decreases the calculation time considerably. Parallel plate geometries are used that have a no slip boundary condition at the wall. Furthermore, by using a velocity inlet and a negative velocity outlet, we have the option to set the trans-membrane flux to a desired value. The nearest neighbour method, in which the two neighbouring values adjacent to the wall are set equal, is used to prevent convergence issues.

The exact dimensions of the channel are different for the parameter studies that were carried out (see Table 3.3), but all channels are narrow in order for SID to occur. Typically, the pore size is much smaller than the length of the channel. Therefore, the grid size chosen for the height of the channel and dimensions of the pore are adjusted such that the process can be captured accurately (see grid refinement study in Appendix B). An overview of the dimensions is given in Table 3.3.

Table 3.3. Overview of the different dimensions used in the parameter studies.

\begin{tabular}{llll}
\hline & & Particle diameter $(\mu \mathrm{m})$ & Grid cell number \\
\hline Channel height & $50 \mu \mathrm{m}$ & 2 & 23 \\
Channel height & $100 \mu \mathrm{m}$ & 2 & 47 \\
Channel height & $100 \mu \mathrm{m}$ & 4 & 23 \\
Pore length & $20 \mu \mathrm{m}$ & 2 & 9 \\
\hline
\end{tabular}

\subsection{Results and discussion}

In order to arrive at a complete process, the three parts of the overall system are first discussed below in individual sections: the non-porous entrance section, the porous section, and the recovery section in which the SID profile restores after being disturbed in the porous section.

\subsubsection{Entrance Section}

\subsubsection{Friction factor}

In our previous study [10], it was shown that different diffusion coefficients can have a large influence on the development length of the SID profile, but not on the fully developed SID 
profile. It is expected that the friction factor that is used for both the drag force and the SID force has similar effects; therefore, this was tested first. In our model, we use the function: $f\left(\alpha_{p}\right)=\left(1-\alpha_{p}\right)^{2}\left(1-\widetilde{\alpha_{p}}\right)^{2}$ for the SID force (based on Vollebregt et al. [14]), and: $f_{i j}^{D}=\left(1-\alpha_{p}\right)^{n}$ for the drag force (standard in STAR-CCM+), and we investigated the sensitivity of the model for the functions used.

Figure 3.5 shows that a difference in friction factor does not influence the fully developed profile, but it does change the length needed to reach this profile. This was also observed by Miller et al. who changed the exponents in their function for $f\left(\alpha_{p}\right)$ [16]. In Figure 3.5, it can be seen that the position at which the particle volume fraction reaches its' equilibrium value is much shorter when using $f\left(\alpha_{p}\right)$ as compared to $f_{i j}^{D}$, and that is even more strongly so when used in conjunction with the SID force that as expected has a bigger influence on the development profile when compared to the drag force.
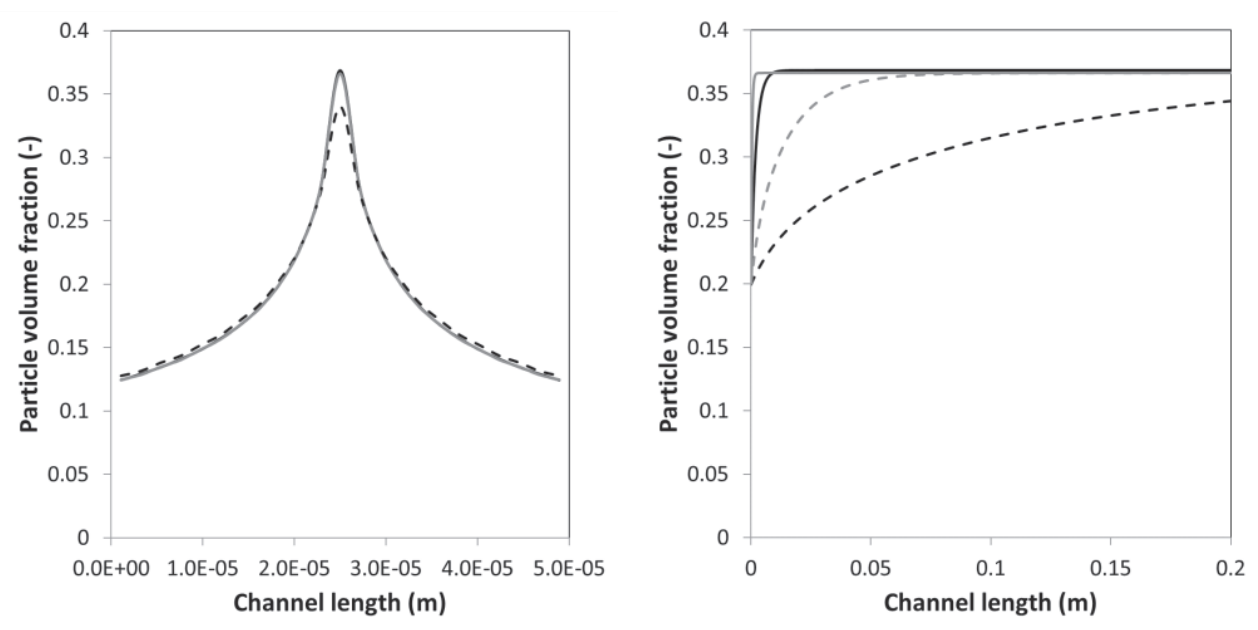

Figure 3.5. Particle volume fraction versus the channel height (left) and the particle volume fraction in the centre of the channel versus the channel length (right) for different friction factors for both the drag and SID force: $f\left(\alpha_{p}\right)$ for SID and $f_{i j}^{D}$ for drag (black solid line); $f\left(\alpha_{p}\right)$ for both SID and drag (grey solid line); $f_{i j}^{D}$ for both SID and drag (black dashed line) and $f_{i j}^{D}$ for SID and $f\left(\alpha_{p}\right)$ for drag (grey dashed line)

The choice of the friction coefficient is thus only of influence on the development length, but as Vollebregt and coworkers already mentioned there are many different expressions for the friction factor in literature [14]. For the process that we eventually want to design, 
it is important to compare various situations, and we express our results in section 3.3.3 relative to the entrance length.

\subsubsection{Parameter case study}

The four case studies shown in Table 3.4 were carried out to test the influence of velocity, channel height, particle diameter and ratio between channel height and particle diameter. Table 3.5 shows the parameter ratios that are varied in the different cases.

Table 3.4. Four different case studies to look at the influence of different parameters.

\begin{tabular}{llllll}
\hline Case & $\begin{array}{l}\text { Channel height } \\
(\mathbf{H})(\boldsymbol{\mu m})\end{array}$ & Velocity $(\mathrm{mm} / \mathbf{s})$ & $\begin{array}{l}\text { Particle diameter } \\
\left(\mathbf{D}_{\mathbf{p}}\right)(\boldsymbol{\mu m})\end{array}$ & $\begin{array}{l}\text { Ratio } \\
\mathbf{H} / \mathbf{D}_{\mathbf{p}}\end{array}$ & $\begin{array}{l}\text { Channel } \\
\text { length } \\
(\mathbf{c m})\end{array}$ \\
\hline 1 & 50 & 1.0 & 2 & 25 & 4 \\
2 & 100 & 1.0 & 2 & 50 & 10 \\
3 & 100 & 1.0 & 4 & 25 & 8 \\
4 & 50 & 0.5 & 2 & 25 & 4 \\
\hline
\end{tabular}

Table 3.5. Parameter ratios that can be compared between the cases as shown in Table 3.4

\begin{tabular}{ll}
\hline Comparison between cases & Parameters compared \\
\hline 1 and 2 & Difference in $H / D_{p}$ ratio \\
1 and 3 & Difference in $H$ and $D_{p}$ at equal $H / D_{p}$ ratio \\
1 and 4 & Difference in velocity \\
\hline
\end{tabular}

The results for a $30 \%$ bulk particle volume fraction are shown in Figure 3.6; the concentration at the centre of the channel increases with increasing channel length till it reaches a maximum, while the concentration at the wall decreases, which is indicative of shear induced diffusion taking place. Taking case 1 as our base case, an increase in channel height (case 2), and thus a change in $H / D_{p}$ ratio, results in reaching a different fully developed profile, as was also reported by Miller and coworkers [16]. Although the average particle volume fraction stays the same, the absolute number of particles is higher in case 2, which allows for more particle migration, leading to more particles in the centre, and less particles near the wall. Besides, we see that the length needed to develop the SID profile changes, because particles need to travel further in case 2 , which is in line with findings by Miller et al. [16]. Interestingly, at equal channel height/particle diameter ratio (comparison 
between case 1 and 3) the entrance length changes while the fully developed profile does not differ, indicating the relative importance of these factors. Last, we checked the change in velocity but this did not influence the profile (case 1 and 4 in Figure $\mathbf{3 . 6}$ overlap), and indicates that the total number of interactions determines the concentration profile that is formed.
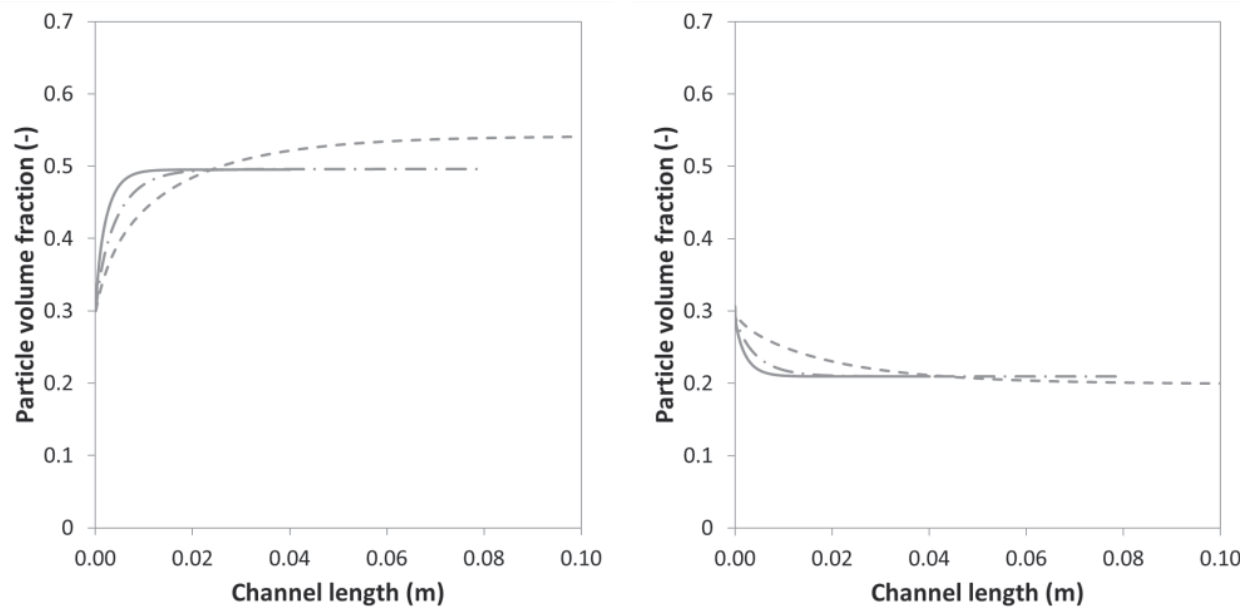

Figure 3.6. Particle volume fraction versus the channel length at the channel centreline (left) and at $10 \%$ from the wall (right). Results are shown for a bulk particle volume fraction of $30 \%$ and for the cases as given in Table 3.4: case 1 (solid line); case 2 (dashed line); case 3 (dashed-dotted line) and case 4 (dotted line). Note that case 1 and 4 overlap.

Furthermore, if we compare different bulk particle volume fractions (Figure 3.7), we conclude that the profiles develop faster at higher concentrations, and the differences in concentration at the centreline decrease with an increasing bulk particle volume fraction, while the opposite is true for the region near the wall. We believe this is caused by the limited freedom of movement that particles have at higher particle volume fractions; the increase in particle concentration that can be achieved in the centre is a function of the initial particle concentration, as illustrated in Figure 3.8. At high volume fractions, the particle concentration in the centre may be very close to the maximum packing density $\left(\alpha_{\max }=0.68\right)$, while the concentration at the wall is considerably reduced when compared to the average concentration. Both effects are beneficial for the novel process that we investigate, but they are only useful if the concentration profile re-establishes fast after being disturbed by a pore, as is investigated next. It is good to mention that these 
effects are directly related to pore placement design, which is discussed in the concluding section.
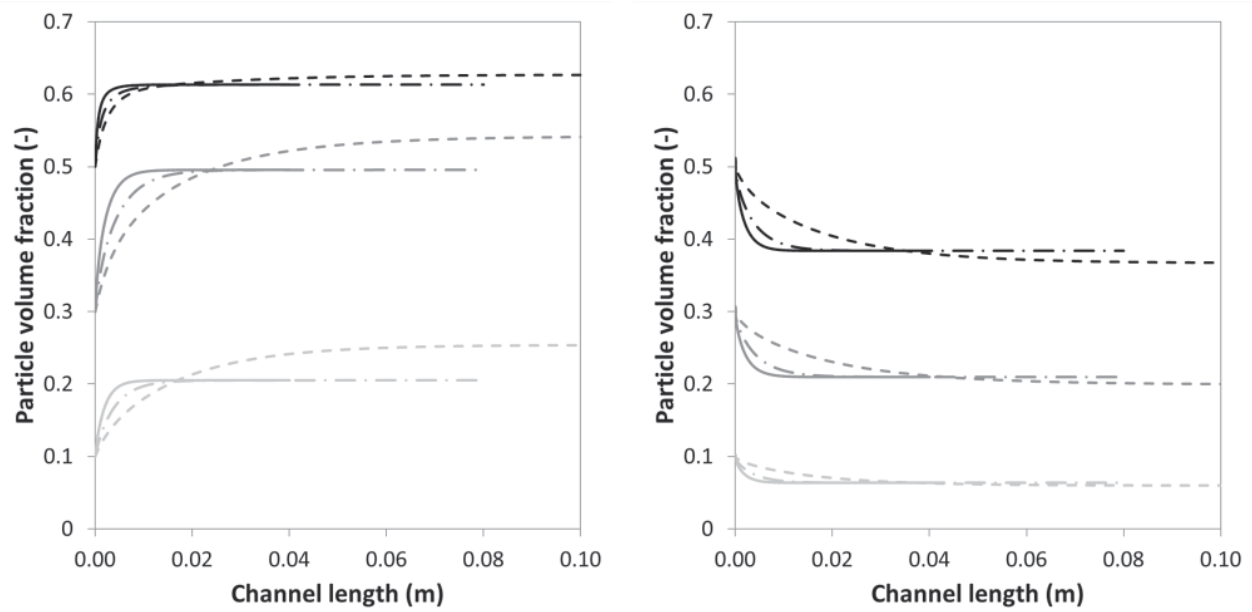

Figure 3.7. Particle volume fraction versus the channel length at the channel centreline (left) and at $10 \%$ from the wall (right). Results are shown for three different bulk particle volume fractions: 0.1 (light grey); 0.3 (dark grey); 0.5 (black) and for the cases as given in Table 3.4: case 1 (solid line); case 2 (dashed line); case 3 (dashed-dotted line) and case 4 (dotted line). Note, case 1 and 4 overlap.

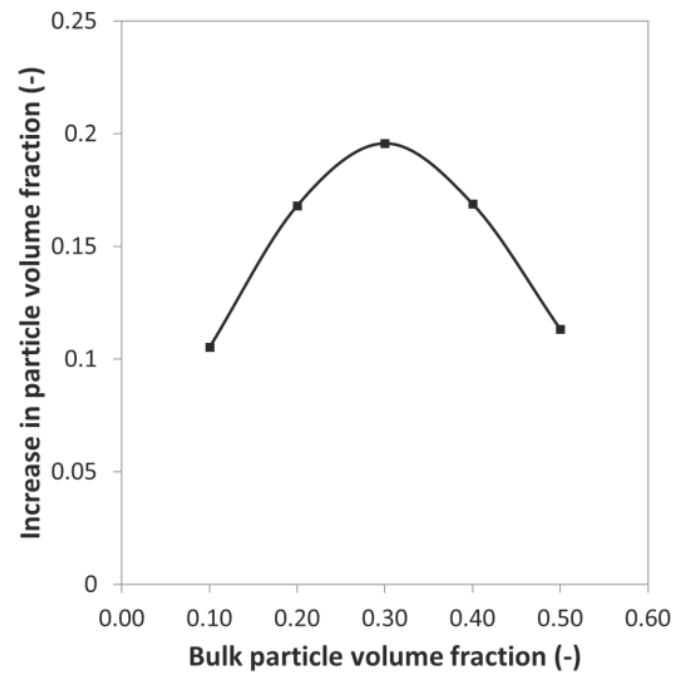

Figure 3.8. Increase in particle volume fraction at the centre versus the bulk particle volume fraction for fully developed profiles for case 4 given in Table 3.4 . 


\subsubsection{Porous section}

A pore of $20 \mu \mathrm{m}$ length is added to the simulation grid. To compare separation efficiency the transmission $(T)$ is determined, which is defined as:

$$
T=\frac{F_{m, p, \text { permeate }} / F_{m, p, \text { feed }}}{\text { Volume fraction extracted }}
$$

With $F_{m, p}$ the particle mass flux $\left(\mathrm{kg} / \mathrm{m}^{2} / \mathrm{s}\right)$. The results are shown in Figure $\mathbf{3 . 9}$ for two different channel heights and for permeate volumes that are between 2.5 and $10 \%$ of the feed, which are realistic values for membrane processes (albeit that for a single pore these are impressive amounts). The transmission, ranges from $59 \%$ to $78 \%$ for different channel heights and particle concentrations in the feed. For higher channels, the transmission will be slightly lower, which is consistent with the findings discussed in section 3.3.1.2. At high feed volume fraction, the concentration in the centre of the channel is close to the maximum packing density, and therefore relatively more particles will be present near the wall. This results in a higher transmission, as was also expected based on the results shown in Figure 3.6.

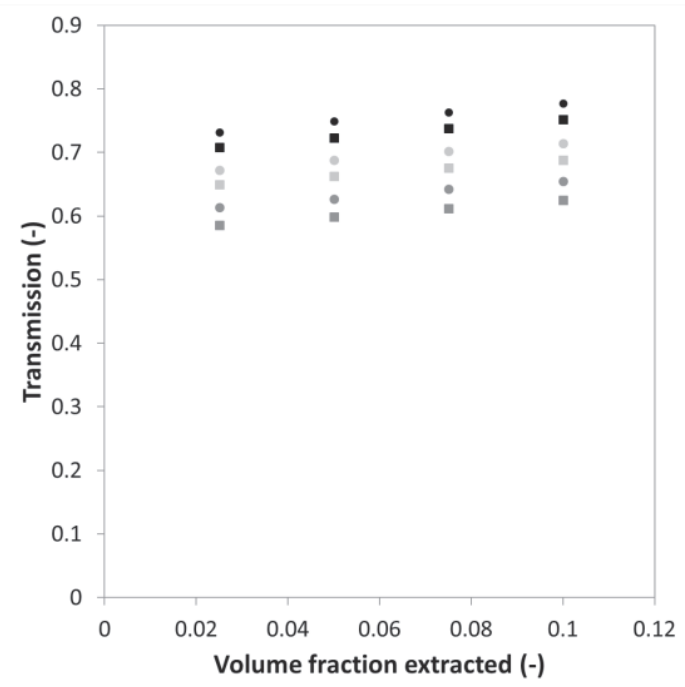

Figure 3.9. Transmission versus the volume fraction taken form the inlet. Results are shown for a channel height of 50 (circles) and 100 (squares) $\mu \mathrm{m}$ and for three different bulk particle volume fractions: 0.1 (dark grey); 0.3 (light grey); 0.5 (black). 


\subsubsection{Recovery section}

For a single pore, the results are encouraging, and the next question that needs to be answered is how fast the concentration profile re-establishes after the pore, since it is disturbed by the porous section, see Figure $\mathbf{3 . 1 0}$ for an illustration. The results are shown in Figure 3.11; the method with which the recovery was characterized can be found in Appendix C. The centre of the channel is taken as a reference point. Please note, the reference point chosen and the extent to which the SID profile is disturbed will have an influence on the results, therefore detailed analysis of membrane design are part of ongoing research.

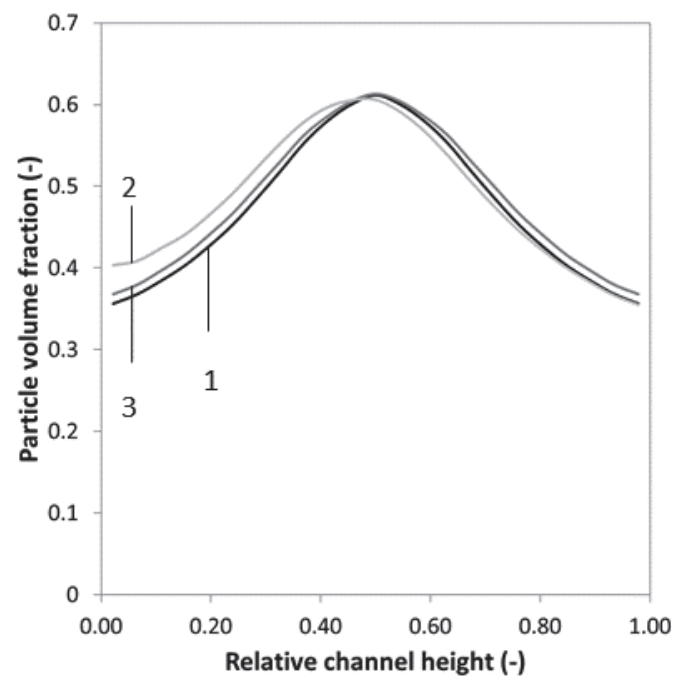

Figure 3.10. Particle volume fraction versus the relative channel height. The graph gives an indication of the shift in the SID profile of a suspension with a 50\% bulk particle volume fraction: fully developed SID profile before the pore at $9.5 \mathrm{~cm}$ (black line, 1); disturbed SID profile just after the pore at $10 \mathrm{~cm}$ (light grey line, 2) and the restored SID profile after the pore at $19.5 \mathrm{~cm}$ (dark grey line, 3).

Figure 3.11 shows the relative development length after the pore when compared to the entrance section for different volume fractions extracted, and for bulk particle volume fractions of 10 and 30 percent. The values for reaching $95 \%$ of the fully developed profile for a bulk particle volume fraction of 50 percent were zero, indicating that the profiles reestablish extremely fast, which is essential for process design.

For lower bulk particle volume fractions, a higher development length is needed but never exceeded $42 \%$ of that of the closed channel, even if as much as $10 \%$ of the liquid was 
removed. The trends that we see are as expected, with higher concentrations reestablishing faster, and this is also the case if less liquid is removed. In brief, extraction of more volume gives a greater disturbance of the SID profile, which therefore needs longer to recover.

The channel height does not have a great effect on the result; the narrower channels need, relative to the development length of the entrance section, slightly longer to re-establish but this effect is not as much as expected from Figure 3.7. This is caused by the fact that the profile is still rather established after the pore (and near the wall), while it needs to form from scratch at the entrance. When looking in the centre of the channel, the effect of channel height is much clearer, since more particles need to be moved to re-establish the entire profile, as shown in Figure 3.12. For process design this is not very relevant since liquid is removed near to the wall, but we show the results here to illustrate that the extent to which the profile is distorted and recovers is a strong function of the position in the channel.
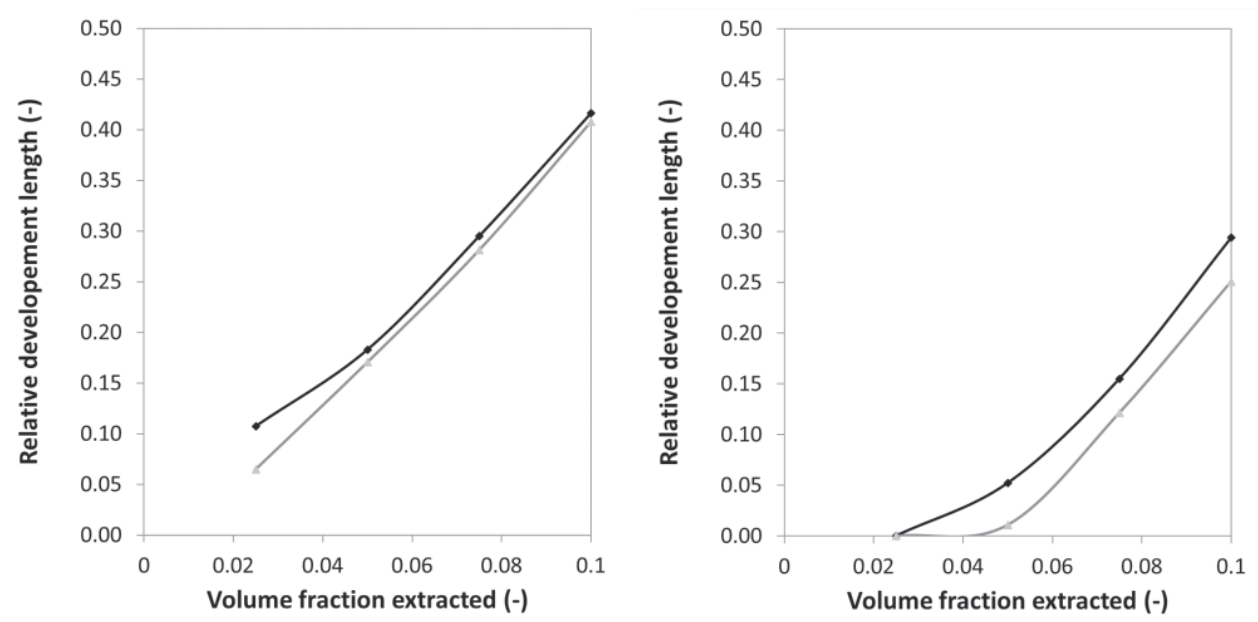

Figure 3.11. Relative development length at the centre of the channel (95\%) between the recover section and the entrance section versus the volume fraction extracted from the inlet for a bulk particle volume fraction of 10\% (left) and 30\% (right). Each graph shows 2 different lines for the different channel heights: $50 \mu \mathrm{m}$ (black) and $100 \mu \mathrm{m}$ (grey). 


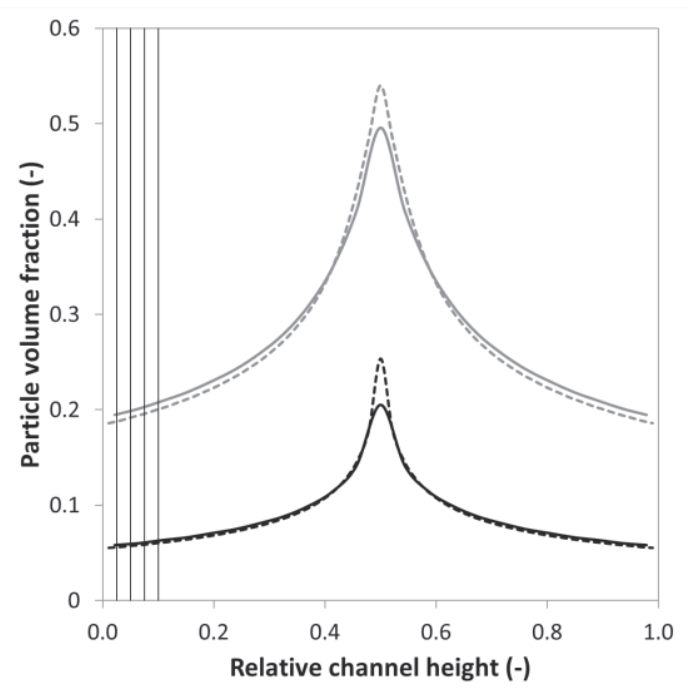

Figure 3.12. Relative particle volume fraction versus the relative channel height at a fully developed profile before the porous region for two different bulk particle volume fractions: $10 \%$ (black) and 30\% (grey) and two different channel heights: $50 \mu \mathrm{m}$ (solid line) and $100 \mu \mathrm{m}$ (dashed line). Vertical lines indicate the amount of volume extracted, from left to right: $2.5 \%, 5 \%, 7.5 \%$ and $10 \%$.

\subsubsection{Implications for design}

The various aspects presented here are now related to process design in rather general terms. In order for the SID technology to work, the concentration profile needs to be established fast and within reasonable distance after entering the system. For all the conditions investigated here (10-50\% particles, channel heights 50 and $100 \mu \mathrm{m})$, this requirement is met. The transmissions that are achieved in our systems were for monodisperse particles. We expect that if applied for fractionation of bi- or polydisperse dispersions the system will become even more interesting. Last but not least, the concentration profile re-established fast after the pore, and this indicates that in a full process, multiple pores can be placed within realistic distances from each other. Therewith, the overall productivity of the process can be enhanced considerably, as we hope to establish in future work that is directed toward the simulation of multiple pores leading to detailed design of porous regions.

\subsection{Conclusions}

Through simulations we showed that shear induced diffusion can be used in novel technology for concentration of suspensions. The ratio of channel height and particle 
diameter was found to influence the channel length that is needed for the concentration profile to establish. Similar trends were found when a pore was added to the simulation grid. Particles are transmitted through the pores at concentrations that are considerably lower than the bulk concentration, and it is expected that these effects are going to be more prominent for bi- or polydisperse suspensions. After the pore, the concentration profile reestablished fast, and in all cases, convincing values were found indicating that pores can be positioned at realistic distances from each other as also discussed in the previous section. This leads us to conclude that the results that are obtained here form a good foundation for more detailed design studies of the porous region, and the process as a whole. 


\section{Appendix A. List of symbols}

Symbol

$a$

$a_{i j}$

$A_{i j}^{D}$

$C_{i j}^{D}$

$C_{i j \infty}^{D}$

$D_{\alpha_{p}}$

$D_{\dot{\gamma}}$

$f_{i j}^{D}$

$f\left(\alpha_{p}\right)$

$\mathrm{F}_{\mathrm{m}, \mathrm{p}}$

$F_{p f}^{D}$

$F^{S I D}$

g

M

$p$

$T$

$v_{g}$

$v_{i}$

\section{Greek symbols}

Symbol

$\alpha_{i}$

$\alpha_{\max }$

$\widetilde{\alpha_{p}}$

$\dot{\gamma}$

$\eta_{i}$

[n]

$\rho_{i}$

$\tau_{i}$

\section{Description}

Particle radius

(m)

Interfacial area density

(1/m)

Linearized drag coefficient

Standard drag coefficient

$\left(\mathrm{Pa} \cdot \mathrm{s} / \mathrm{m}^{2}\right)$

$(-)$

$(-)$

Single particle drag coefficient

$\left(\mathrm{m}^{2} / \mathrm{s}\right)$

Shear rate dependent diffusion coefficient

$\left(\mathrm{m}^{2}\right)$

Drag correction factor

$(-)$

Hindered settling function

$(-)$

Particle mass flux

$\left(\mathrm{kg} /\left(\mathrm{m}^{2} \cdot \mathrm{s}\right)\right)$

Drag force on particle phase due to the fluid phase

$\left(\mathrm{N} / \mathrm{m}^{3}\right)$

Force due to shear induced diffusion

$\left(\mathrm{N} / \mathrm{m}^{3}\right)$

Gravity vector

$\left(\mathrm{m} / \mathrm{s}^{2}\right)$

Mobility

Pressure (assumed equal in both phases)

$\left(\mathrm{m}^{2} /(\mathrm{Pa} \cdot \mathrm{s})\right)$

(Pa)

$(-)$

$(\mathrm{m} / \mathrm{s})$

$(\mathrm{m} / \mathrm{s})$

Transmission

Grid velocity

Velocity of phase i

\section{Description}

Volume fraction of phase $i$

$(-)$

Maximum packing density

$(-)$

Relative volume fraction $\left(\frac{\alpha_{p}}{\alpha_{\max }}\right)$

Shear rate

Viscosity of phase $i$

Intrinsic viscosity

(-)

Density of phase i

$\left(\mathrm{kg} / \mathrm{m}^{3}\right)$

Molecular stresses

(Pa) 


\section{Appendix B. Grid refinement study}

Different pore geometries are considered for the parameter studies (Table 3A1) and therefore several grid refinement studies needed to be done, of which the results can be found in Figures 3A1-3A4. Note that for both the length and height of the pore grid refinement was tested. It can be concluded that the grid sizes given in Table $\mathbf{3 . 3}$ are chosen appropriately.

Table 3A1. Overview of the different dimensions used in the parameter studies.

\begin{tabular}{llll}
\hline Case & Channel height $(\mu \mathrm{m})$ & $\begin{array}{l}\text { Pore height and } \\
\text { length }(\boldsymbol{\mu m})\end{array}$ & $\begin{array}{l}\text { Particle diameter } \\
(\boldsymbol{\mu m})\end{array}$ \\
\hline 1 & 50 & - & 2 \\
2 & 100 & - & 2 \\
3 & 100 & - & 4 \\
4 & - & 20 & 2 \\
\hline
\end{tabular}

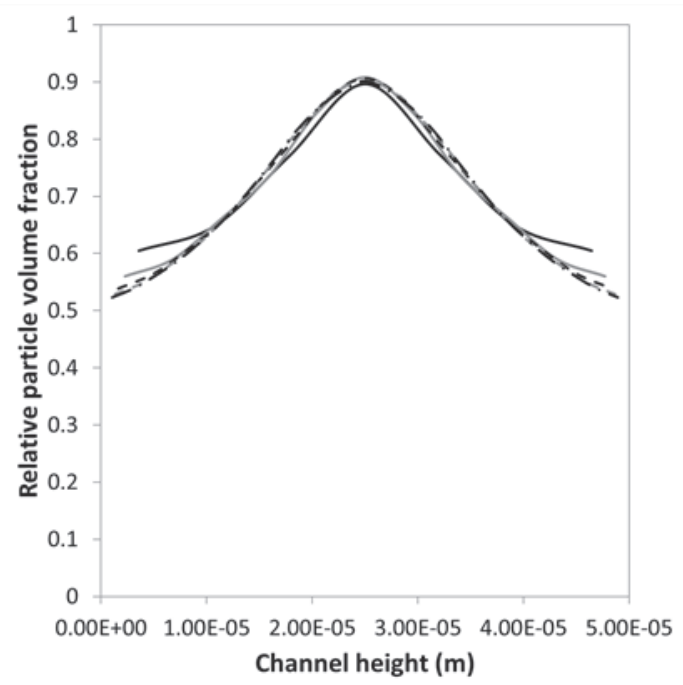

Figure 3A1. Grid refinement study for case 1. The relative particle volume fraction versus the channel height, measured $2.5 \mathrm{~cm}$ from the channel entrance. The grid cell number of the channel height is changed: 7 grid cells (black solid line); 11 grid cells (grey solid line); 15 grid cells (black dashed line); 19 grid cells (grey dashed line) and 23 grid cells (black dashed-dotted line) (Graph is reprinted from Separation and Purification Technology, 192, I. Drijer; T. van de Laar; H.M. Vollebregt and C.G.P.H. Schroën, From highly specialised to generally available modelling of shear induced particle migration for flow segregation based separation technology, 99-109, 2018, with permission from Elsevier). 


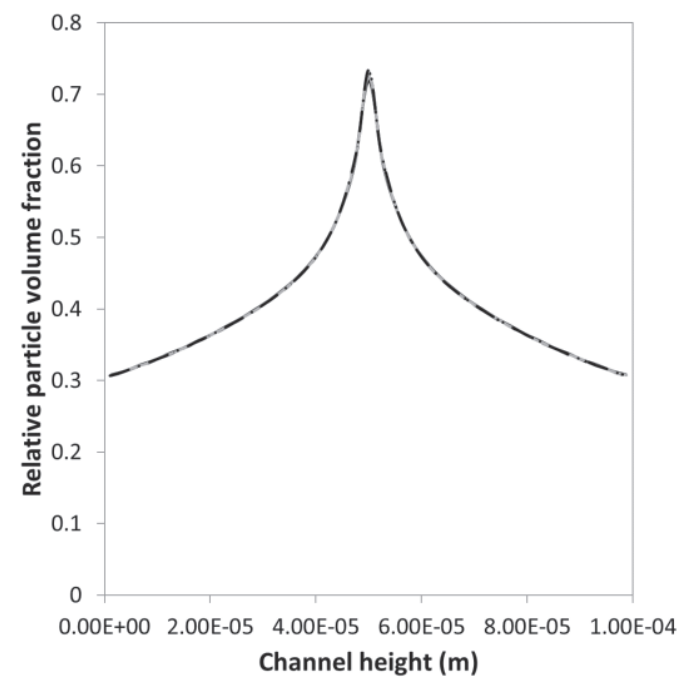

Figure 3A2. Grid refinement study for case 2. The relative particle volume fraction versus the channel height, measured $2.5 \mathrm{~cm}$ from the channel entrance. The grid cell number of the channel height is changed: 37 grid cells (black solid line); 41 grid cells (grey solid line); 45 grid cells (black dashed line); 47 grid cells (grey dashed line) and 49 grid cells (black dashed-dotted line).

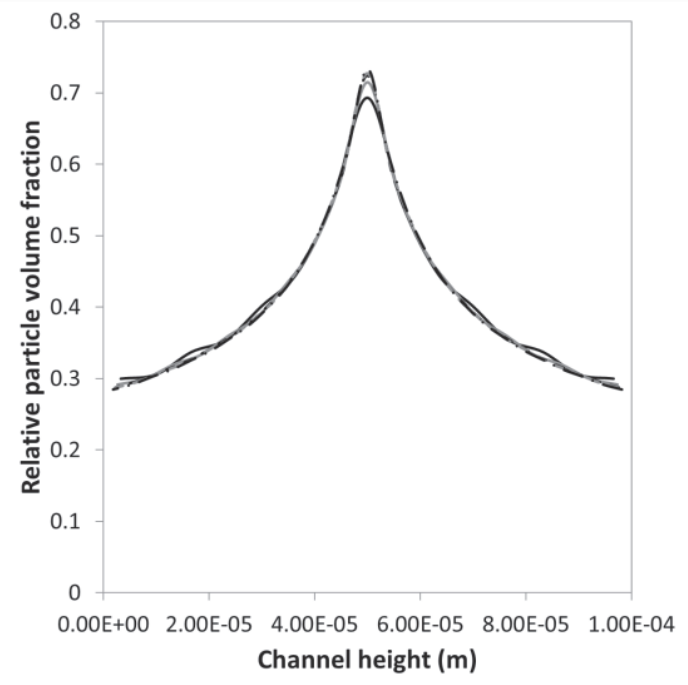

Figure 3A3. Grid refinement study for case 3. The relative particle volume fraction versus the channel height, measured $2.5 \mathrm{~cm}$ from the channel entrance. The grid cell number of the channel height is changed: 15 grid cells (black solid line); 19 grid cells (grey solid line); 21 grid cells (black dashed line); 23 grid cells (grey dashed line) and 27 grid cells (black dashed-dotted line). 

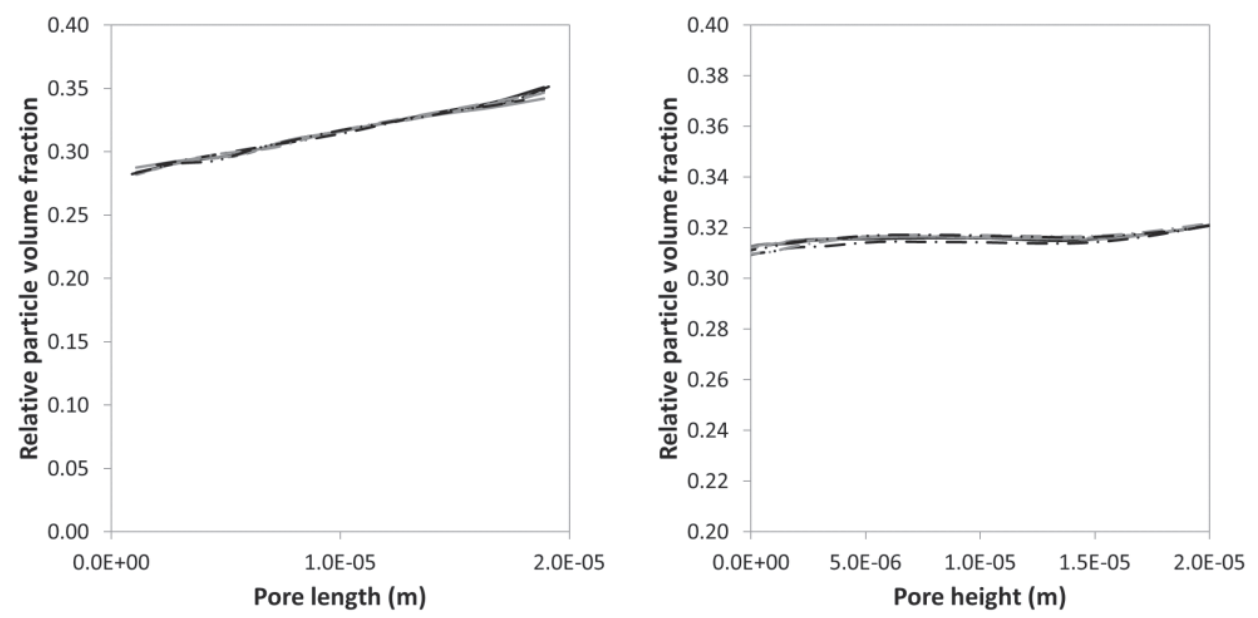

Figure 3A4.Grid refinement study for case 4: the length and height of the pore. The relative particle volume fraction versus the channel height, measured at the centre of the pore in the vertical (left) and horizontal (right) direction. The grid cell number for both the height ( $h)$ and the length (I) is changed: $h=5$ and $I=9$ (black solid line); $h=7$ and $I=9$ (grey solid line); $h=9$ and $l=9$ (black dashed line); $h=11$ and $I=9$ (grey dashed line); $h=9$ and $l=5$ (black dashed-dotted line), $h=9$ and $I=7$ (grey dashed-dotted line) and $h=9$ and $l=7$ (black dashed-double dotted line).

\section{Appendix C. Characterization of recovery length}

The development length for both the entrance section and recovery section are determined at the centre of the channel using 95\% of the value for a fully developed profile as a target (Figure 3A5); we chose this value because this profile is sufficiently developed to be used in practice. To be complete, we used a different method than the method introduced by Hampton and coworkers [24] because high correlations between the different parameters were obtained when using their method. 


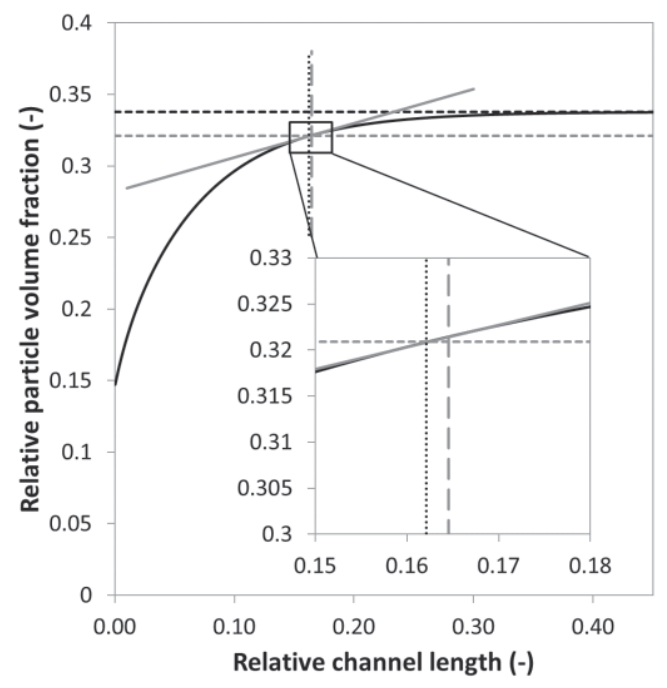

Figure 3A5. Schematic overview of how the entrance length is determined at the centre of the channel and at $95 \%$ of the fully developed value. SID profile (black solid line); relative particle volume fraction for a fully developed profile (horizontal black dotted line); relative particle volume fraction at $95 \%$ (grey horizontal dotted line); tangent at 95\% of the fully developed profile (grey solid line). 


\section{References}

[1] H. Strathmann, Membrane Separation Processes: Current Relevance and Future Opportunities, AIChE J. 47 (2001) 1077-1087.

[2] G. Brans, C.G.P.H. Schroën, R.G.M. van der Sman, R.M. Boom, Membrane fractionation of milk: State of the art and challenges, J. Memb. Sci. 243 (2004) 263-272.

[3] R.G.M. van der Sman, H.M. Vollebregt, A. Mepschen, T.R. Noordman, Review of hypotheses for fouling during beer clarification using membranes, J. Memb. Sci. 396 (2012) 22-31.

[4] J.P. Dijkshoorn, M.A.I. Schutyser, R.M. Wagterveld, C.G.P.H. Schroën, R.M. Boom, A comparison of microfiltration and inertia-based microfluidics for large scale suspension separation, Sep. Purif. Technol. 173 (2017) 86-92.

[5] G. Belfort, R.H. Davis, A.L. Zydney, The behavior of suspensions and macromolecular solutions in crossflow microfiltration, J. Memb. Sci. 96 (1994) 1-58.

[6] M.Y. Jaffrin, Hydrodynamic Techniques to Enhance Membrane Filtration, Annu. Rev. Fluid Mech. 44 (2012) 77-96.

[7] Y.S. Lubbersen, M.A.I. Schutyser, R.M. Boom, Suspension separation with deterministic ratchets at moderate Reynolds numbers, Chem. Eng. Sci. 73 (2012) 314-320.

[8] A.M.C. Van Dinther, C.G.P.H. Schroën, R.M. Boom, High-flux membrane separation using fluid skimming dominated convective fluid flow, J. Memb. Sci. 371 (2011) 20-27.

[9] K. Schroën, A. van Dinther, R. Stockmann, Particle migration in laminar shear fields: A new basis for large scale separation technology?, Sep. Purif. Technol. 174 (2017) 372-388.

[10] I. Drijer, T. van de Laar, H.M. Vollebregt, C.G.P.H. Schroen, From highly specialised to generally available modelling of shear induced particle migration for flow segregation based separation technology, Sep. Purif. Technol. 192 (2018) 99-109.

[11] R.H. Davis, Modeling of fouling of crossflow microfiltration membranes, Sep. Purif. Methods. 21 (1992) 75-126.

[12] P. Tiwari, S.P. Antal, M.Z. Podowski, Modeling shear-induced diffusion force in particulate flows, Comput. Fluids. 38 (2009) 727-737.

[13] A. Asadi Tashvigh, A. Fouladitajar, F. Zokaee Ashtiani, Modeling concentration polarization in crossflow microfiltration of oil-in-water emulsion using shear-induced diffusion; CFD and experimental studies, Desalination. 357 (2015) 225-232.

[14] H.M. Vollebregt, R.G.M. van der Sman, R.M. Boom, Suspension flow modelling in particle migration and microfiltration, Soft Matter. 6 (2010) 6052-6064.

[15] H.M. Vollebregt, R.G.M. van der Sman, R.M. Boom, Model for particle migration in bidisperse suspensions by use of effective temperature, Faraday Discuss. 158 (2012) 89-103.

[16] R.M. Miller, J.F. Morris, Normal stress-driven migration and axial development in pressuredriven flow of concentrated suspensions, J. Nonnewton. Fluid Mech. 135 (2006) 149-165.

[17] M.K. Lyon, L.G. Leal, An experimental study of the motion of concentrated suspensions in two-dimensional channel flow. Part 2. Bidisperse systems, J. Fluid Mech. 363 (1998) 57-77.

[18] M.K. Lyon, L.G. Leal, An experimental study of the motion of concentrated suspensions in two-dimensional channel flow. Part 1. Monodisperse systems, J. Fluid Mech. 363 (1998) 2556. 
[19] D. Semwogerere, E.R. Weeks, Shear-induced particle migration in binary colloidal suspensions, Phys. Fluids. 20 (2008).

[20] A. Shauly, A. Wachs, A. Nir, Shear-induced particle migration in a polydisperse concentrated suspension, J. Rheol. (N. Y. N. Y). 42 (1998) 1329-1348.

[21] A.M.C. van Dinther, C.G.P.H. Schroën, R.M. Boom, Particle migration leads to deposition-free fractionation, J. Memb. Sci. 440 (2013) 58-66.

[22] A.M.C. van Dinther, C.G.P.H. Schroën, R.M. Boom, Separation process for very concentrated emulsions and suspensions in the food industry, Innov. Food Sci. Emerg. Technol. 18 (2013) 177-182.

[23] A.M.C. van Dinther, C.G.P.H. Schroën, A. Imhof, H.M. Vollebregt, R.M. Boom, Flow-induced particle migration in microchannels for improved microfiltration processes, Microfluid. Nanofluidics. 15 (2013) 451-465.

[24] R.E. Hampton, A.A. Mammoli, A.L. Graham, N. Tetlow, S.A. Altobelli, Migration of particles undergoing pressure-driven flow in a circular conduit, J. Rheol. (N. Y. N. Y). 41 (1997) 621640 . 



\section{Chapter 4}

Computational evaluation of membrane pore placement for novel shear-induced diffusion based separation processes

This chapter has been submitted as I. Drijer, P. Hazelhoff, C.G.P.H. Schroen, Computational evaluation of membrane pore placement for novel shear-induced diffusion based separation processes 


\begin{abstract}
Shear-induced diffusion based separation processes can be used to concentrate and fractionate suspensions. In a closed channel, particles segregate while in flow, and the liquid close to the wall can subsequently be siphoned off through a porous region to obtain various fractions. In this paper we investigate the design of this porous region (placement of membrane pores) in relation to concentration and fractionation efficiency.

It was found that when pores are placed on both sides of the channel and as much as 0.1 volume fraction was extracted, the pore size, the pore distance, and the number of pores don't affect transmission. Typically, at a permeate split ratio of $10 \%$, using a $30 \%$ feed concentration, the transmission is around 0.68. For pores that are placed at only one side of the channel the shear induced diffusion profile is disturbed extensively, which is not desired. For the ultimate process design, large double-sided pores are recommended, since they allow for minimal disturbance and fast recovery of the shear-induced diffusion profile, and better control over extraction of the layers close to the wall.
\end{abstract}




\subsection{Introduction}

Since 1960, industrial interest for membrane separation grew rapidly [1,2] and different types of membrane processes were explored, using gradients in pressure, concentration or electrical potential [3]. In this study we focus on the processes based on a pressure gradient across the membrane, but contrary to regular process design, we make use of a natural migration mechanism that micron-sized particles display.

\subsubsection{Pressure driven membrane separation}

Pressure driven membrane separation can be operated in dead-end and cross-flow mode, using the pore size as a gate keeper for component retention. In dead-end filtration the membrane is placed perpendicular to the feed flow forcing most of the feed through the membrane. In cross-flow filtration, only a small amount of the feed is removed, the socalled permeate (split), which ranges typically between 1 and $10 \%$ of the feed volume; the rest of the feed becomes the retentate. The advantage of cross flow filtration is that the membrane is less prone to fouling resulting in a more constant flux and less need of cleaning. Nevertheless, fouling will still occur and ways to prevent or minimize it need to be applied i.e. back flushing [4] and diluting the suspension [5,6] etc. In this study we look at an alternative process in which we make use of particle migration in flow to mitigate fouling.

\subsubsection{Flow based separation}

Brownian diffusion, inertial lift and shear induced diffusion are natural migration mechanisms based on random movement, influences of the surrounding fluid, and the interactions with other particles, respectively [7]. The high cross-flow velocity that induces turbulence, as well as the back flushing strategies that are applied in cross-flow filtration disturb and even completely cancel out concentration profiles that are the result of natural migration processes of particles. This implies that these natural migration mechanisms can only be taken as a starting point for design of membrane systems if process conditions are chosen that allow for the concentration profiles to persist. Since we are interested in concentration and fractionation of particles in the range of 1 to 10 micrometre at high particle volume fraction we focus on shear induced diffusion $[8,9]$ and use this mechanism to allow migration to occur, so to 'pre-fractionate' particles in laminar flow. 


\subsubsection{Shear induced diffusion}

Shear induced diffusion is a result of particle interactions; therefore at high particle volume fraction the diffusivity is higher [6]. The particles will migrate towards a region with lower shear [10]; which implies that in laminar flow particles will move from the channel wall towards the channel centre, as schematically shown for a monodisperse suspension in the first part of Figure 4.1. Through the pores that are also shown in Figure 4.1, a certain feed volume can be removed with lower particle concentration than overall present in the feed. These pores can be relatively large, which reduces the propensity of fouling. The interested reader is referred through to literature on shear induced diffusion for monodisperse suspensions [11-15].

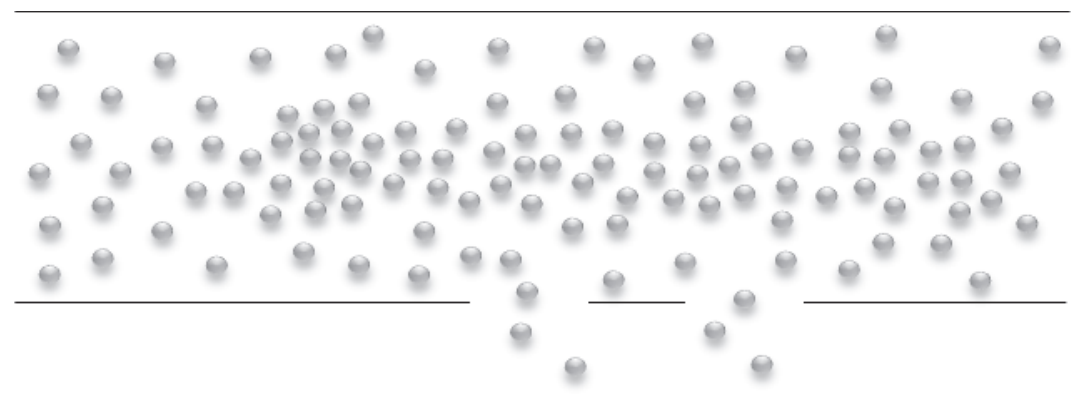

Figure 4.1. The principle of shear induced diffusion illustrated for a monodisperse suspension.

Next to the particle volume fraction, also the particle size has a large influence on the rate of migration $[6,12]$ : the larger the particles the higher their migration velocity. This is an important effect for concentration processes, but the situation becomes even more relevant for fractionation processes. For bidisperse suspensions [16-18] the difference in migration velocity between differently sized particles enables size segregation in the channel, and the specific removal of for example small particles [10].

\subsubsection{Membrane design}

Although the new process that we propose revolves around separation inside a closed channel, the permeate split, and the size and placement of pores are expected to influence separation efficiency. Due to the trans-membrane flux, the shear induced diffusion profile will be affected, and we are interested to which extent this happens, and how much closed channel would be needed to restore the profile after a pore. To chart these effects we 
model monodisperse suspensions. Please keep in mind that the membrane design proposed in the current paper is rather different from conventional filtration processes since we take shear induced diffusion as a starting point.

\subsection{Shear induced diffusion model}

This study adds to computational findings that we published earlier $[15,19]$; therefore, we briefly recapture the main features of the model in this section.

\subsubsection{Model equations}

Separate equations are used for both phases in the suspension, which is indicative of an Euler-Euler type of model. This Euler-Euler formulation is implemented by using the 'Multiphase Segregated Flow Model' of the CFD software STAR-CCM+ where shear induced diffusion for the main channel is included in a momentum source term. This results in the following equations (for nomenclatures see Appendix A):

Continuity equation for the fluid:

$$
\frac{\partial}{\partial t} \int_{V}\left(1-\alpha_{p}\right) \rho_{f} d V+\oint_{A}\left(1-\alpha_{p}\right) \rho_{f} v_{f} d a=0
$$

Continuity equation for the particles:

$$
\frac{\partial}{\partial t} \int_{V} \alpha_{p} d V+\oint_{A} \alpha_{p} v_{p} d a=0
$$

Momentum equation for the fluid:

$$
\begin{aligned}
& \frac{\partial}{\partial t} \int_{V}\left(1-\alpha_{p}\right) \rho_{f} v_{f} d V+\oint_{A}\left(1-\alpha_{p}\right) \rho_{f} v_{f} \otimes\left(v_{f}-v_{g}\right) d a=-\int_{V}(1- \\
& \left.\alpha_{p}\right) \nabla p d V+\int_{V}\left(1-\alpha_{p}\right) \rho_{f} g d V+\oint_{A}\left(1-\alpha_{p}\right) \tau_{f} d a-\int_{V} F_{p f}^{D} d V- \\
& \int_{V} F^{S I D} d V
\end{aligned}
$$


Momentum equation for the particles:

$$
\begin{aligned}
& \frac{\partial}{\partial t} \int_{V} \alpha_{p} \rho_{p} v_{p} d V+\oint_{A} \alpha_{p} \rho_{p} v_{p} \otimes\left(v_{p}-v_{g}\right) d a=-\int_{V} \alpha_{p} \nabla p d V+ \\
& \int_{V} \alpha_{p} \rho_{p} g d V+\oint_{A} \alpha_{p} \tau_{p} d a+\int_{V} F_{p f}^{D} d V+\int_{V} F^{S I D} d V
\end{aligned}
$$

In which $F^{S I D}=\frac{\left(D_{\alpha_{p}} \nabla \alpha_{p}+D_{\dot{\gamma}} \nabla \dot{\gamma}\right)}{M}$ and $F_{i j}^{D}=A_{i j}^{D}\left(v_{j}-v_{i}\right)$ (for closure relations see Table 4.1). In these equations it is assumed that internal forces, mass transfer as well as mass source terms can be omitted and that both phases have a constant density. This assumption is made because non-soluble, non-deformable and non-reactive/inert particles are used to emulate a filtration system in which laminar flow is needed to create the shear induced diffusion profile.

Table 4.1. Closure relations for the shear induced diffusion and drag force term.

\begin{tabular}{cll}
\hline $\begin{array}{c}\text { Closure } \\
\text { relation }\end{array}$ & Reference/Description & Equation \\
\hline$\eta$ & $\begin{array}{l}\text { Krieger-Dougherty } \\
\text { relation }\end{array}$ & $\eta_{f}\left(1-\frac{\alpha_{p}}{\alpha_{\text {max }}}\right)^{[\eta] \alpha_{\max }}$ \\
$M$ & Vollebregt et al. [12] & $\frac{2}{9} \frac{a^{2}}{\eta_{f}} \alpha_{p} f\left(\alpha_{p}\right)$ \\
$D_{\alpha_{p}}$ & Vollebregt et al. [12] & $\frac{2}{9} \dot{\gamma} a^{2}\left(1-\alpha_{p}\right)^{2} \cdot 1.5 \frac{\widetilde{\alpha_{p}}}{\alpha_{\max }}\left(1+\widetilde{\alpha_{p}}\left(1-\widetilde{\alpha_{p}}\right)^{-1}\right)$ \\
$D_{\dot{\gamma}}$ & Vollebregt et al. [12] & $\frac{2}{9} a^{2}\left(1-\alpha_{p}\right)^{2} \cdot 0.75 \widetilde{\alpha_{p}}{ }^{2}$ \\
$f\left(\alpha_{p}\right)$ & Vollebregt et al. [12] & $\left(1-\alpha_{p}\right)^{2}\left(1-\widetilde{\alpha_{p}}\right)^{2}$ \\
$\dot{\gamma}$ & Miller et al. [11] & $\frac{d \mathrm{v}}{d y}+\frac{a \cdot v_{\max }}{H^{2}}$ \\
$A_{i j}^{D}$ & & $C_{i j}^{D} \frac{1}{2} \rho_{f}\left|v_{j}-v_{i}\right| \frac{a_{i j}}{4}$ \\
$C_{i j}^{D}$ & & $f_{i j}^{D} C_{i j \infty}^{D}$ \\
$C_{i j \infty}^{D}$ & Schiller-Naumann method & $\left\{\frac{24}{R e_{p}}\left(1+0.15 R e_{p}{ }^{0.687}\right) 0<R e_{p}<1000\right.$ \\
$f_{i j}^{D}$ & Richardson Zaki & $\left(1-\alpha_{p}\right)^{n}$ \\
\hline
\end{tabular}




\subsubsection{Process conditions}

The model is applied to rectangular channels that are converted to $2 \mathrm{D}$, and is run at steady state conditions. The channel height was 50 micrometre, the channel entrance length 4 centimetre, the feed particle volume fraction $30 \%$ and the particle diameter 2 micrometre. The permeate was $10 \%$ of the feed; this value was chosen since it is a realistic flow split for a regular membrane process, but challenging given the number of pores that are used. Furthermore, a $10 \%$ flow split is expected to lead to disturbance of the shear induced diffusion profile, which we need to quantify. As boundary conditions, a velocity inlet of 1.0 $\mathrm{mm} / \mathrm{s}$, and a negative velocity outlet were chosen which enables us to specify the transmembrane flux. To investigate the pore and pitch size and the number of pores, the different geometries listed in Table $\mathbf{4 . 2}$ were used.

Because the permeate is $10 \%$ of the feed, irrespective of the number of pores used, the average pore velocity varies with pore size and number of pores. The permeate velocity is calculated with:

$$
v_{\text {permeate }}=-v_{\text {feed }} \cdot \text { fraction extracted } \cdot \frac{H}{\text { Total length permeate outlet }}
$$

From previous studies it was known that the number of grid cells for the pores and the height of the channel need to comply with equation 6 to have a fine enough mesh:

$$
\text { Number of grid cells }=\text { first odd number }<\frac{\text { domain length }(\mu m)}{2}
$$

Furthermore, a no-slip boundary condition was used at the wall, and the value for the wall was taken equal to its neighbouring cell to ensure good convergence. 
Table 4.2. Overview of geometries used at $10 \%$ permeate extracted from the feed.

\begin{tabular}{|c|c|c|c|}
\hline Case & $\begin{array}{l}\text { Pore } \\
\text { length } \\
(\mu \mathrm{m})\end{array}$ & $\begin{array}{l}\text { Distance } \\
\text { between } \\
\text { pores }(\mu \mathrm{m})\end{array}$ & Schematic view of the geometry \\
\hline 1 & 10 & N.A. & \\
\hline 2 & 20 & N.A. & \\
\hline 3 & 30 & N.A. & $\longrightarrow$ \\
\hline 4 & 40 & N.A. & \\
\hline 5 & 80 & N.A. & \\
\hline 6 & 160 & N.A. & \\
\hline 7 & 10 & N.A. & \\
\hline 8 & 20 & N.A. & \\
\hline 9 & 30 & N.A. & $\longrightarrow$ \\
\hline 10 & 40 & N.A. & \\
\hline 11 & 80 & N.A. & \\
\hline 12 & 160 & N.A. & \\
\hline 13 & 20 & 40 & \\
\hline 14 & 20 & 60 & \\
\hline 15 & 20 & 120 & \\
\hline 16 & 20 & 240 & \\
\hline 17 & 20 & 550 & \\
\hline 18 & 20 & 2090 & $\longrightarrow$ \\
\hline 19 & 20 & 4000 & \\
\hline 20 & 20 & 7000 & \\
\hline 21 & 10 & 7000 & \\
\hline 22 & 40 & 7000 & \\
\hline 23 & 80 & 7000 & \\
\hline 24 & 20 & 120 & \\
\hline 25 & 20 & 240 & \\
\hline 26 & 20 & 500 & $\longrightarrow$ \\
\hline 27 & 20 & 2090 & \\
\hline 28 & 20 & 4000 & \\
\hline 29 & 20 & 7000 & \\
\hline
\end{tabular}

\subsection{Results and discussion}

In this study, we investigate pore design through their size, the distance between the pores and the number of pores as discussed in the following sections. 


\subsubsection{Pore size}

In this section we vary the pore size of single and double sided pores (pores on one wall or on both walls) at $10 \%$ permeate split and present effects on transmission (cases 1 to 12 from Table 4.2) in Figure 4.2. Note that we zoomed in on the y-axis, and that transmission is defined relative to the original feed concentration, so $30 \%$.

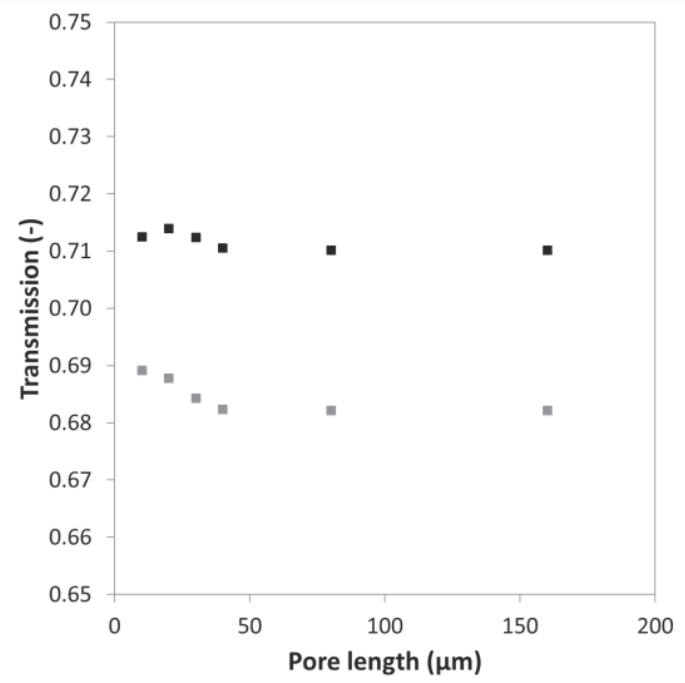

Figure 4.2. Transmission versus pore length for a single pore (cases 1 to 6 in Table 4.2, black squares) and for two pores, one on each side of the channel (cases 7 to 12 in Table 4.2, grey squares).

Figure 4.2 shows that at equal total permeate split similar transmissions are found for all pore sizes, which is expected if the shear induced diffusion profile is not disturbed too much. Furthermore, placement of pores on both sides of the channels lowers transmission, which is caused by the shear induced diffusion profile inside the channel (Figure 4.3). The particle volume fraction increases with the distance from the wall, and for cases 1 to 6, 10\% permeate is extracted from one side of the channel (grey vertical line; see Figure 4.3), whereas for cases 7 to 12 , only $5 \%$ permeate is extracted from both sides (black lines). The particle volume fraction at the $10 \%$ position is higher than at the $5 \%$ position which explains the difference in Figure 4.2. Figure 4.3 also shows that the shear induced diffusion profile gets more disturbed for single sided pores, which is undesirable for the process we envision, therefore we only use double sided pores in the rest of our study. 


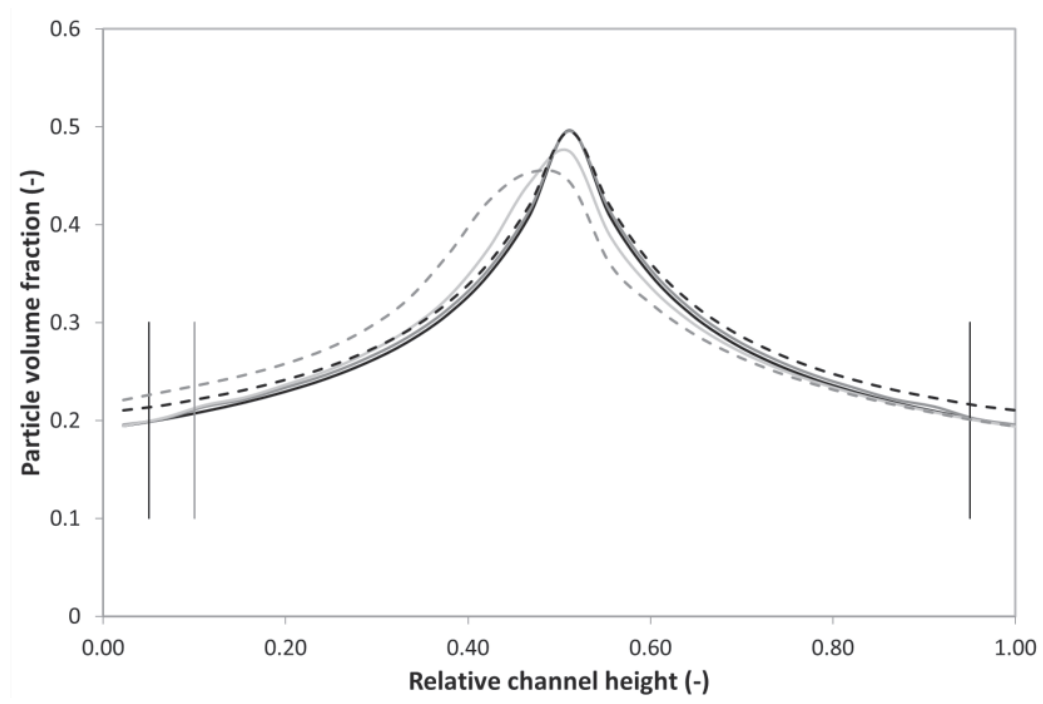

Figure 4.3. Particle volume fraction versus the relative channel height at $10 \mu \mathrm{m}$ before the pore for cases 1 to 6 (light grey line) and cases 7 to 12 (dark grey line). The steady state profile is also given (black line). The profiles $10 \mu \mathrm{m}$ after the pore are given for cases 2 (grey dashed line) and 6 (black dashed line). The vertical grey line represents the 10\% position, the vertical black lines $5 \%$.

\subsubsection{Profile recovery}

We vary the distance between the pores, at a pore size of $20 \mu \mathrm{m}$ (cases 13 to 20 from Table 4.2), and determine the transmission, relative to the initial feed, through the first and second pore as shown in Figure 4.4. Note that also here we zoomed in on the y-axis.

Figure 4.4 shows that the distance between the pores hardly influences transmission, and that the transmission through the first pore is only slightly lower than through the second pore. The concentration profile near the wall is disturbed minimally resulting in a very fast recovery as also shown in Figure 4.3. The transmission values for the first pore are slightly lower than shown in Figure $\mathbf{4 . 2}$ for one double sided pore, since per pore typically 'only' $2.5 \%$ of the feed is removed, which corresponds to lower particle concentrations in the permeate (see Figure 4.3). The second pore will have a slightly higher transmission due to a small effect caused by the slightly increased feed concentration after the first pore, which results in a small change of the shear induced diffusion profile.

In a previous study [19] we showed that the recovery lengths for single sided pores, were up to $42 \%$ of the initial entrance length when taking the middle of the channel as a reference point. For single sided pores the entire concentration profile is distorted (see Figure 4.3), and in this sense the use of double sided pores leads to minimal disturbance of the profile 
that can restore very fast without the need for unrealistically large pore spacing. The restoration length is also a function of other parameters such as the particle volume fraction, and the particle size distribution, which need to be taken into account in process design. It should be noted that there is a small inconsistency in the recovery profile, but for the cases we tested we found an acceptable deviation of around $1 \%$.

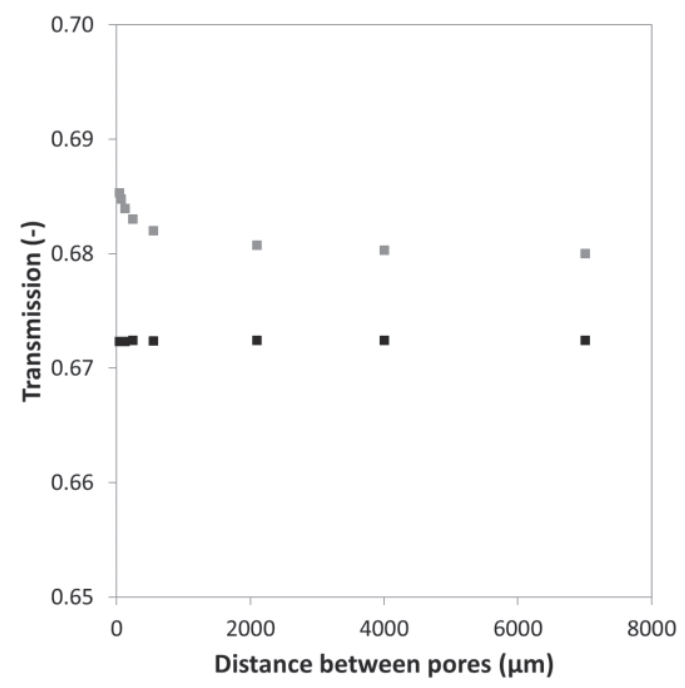

Figure 4.4. Transmission, relative to the initial feed, through the first (black squares) and second pore (grey squares) versus the distance between the pores (cases 13 to 20 in Table 4.2).

\subsubsection{One versus two double-sided pores}

To compare one and two double-sided pores in more detail we compare cases 8, 10-12, and 20-23. In Figure 4.5, the transmission is plotted as function of the total pore length where we again zoomed in on the y-axis; in Figure $\mathbf{4 . 6}$ detailed flow profiles are shown.

Figure 4.5 shows that transmission decreases with pore length. The flow profile through the pores is shown in Figure 4.6, and it is clear that at the beginning of a pore more water than particles enter the pore, which lowers transmission. This effect remains visible for the second pore, although the effect seems to lessen which is most likely caused by the previously mentioned slight change in shear induced diffusion profile. Furthermore, shear induced-diffusion may lead to a slight positive effect on migration of particles toward the middle of the channel while crossing the pore, allowing for reduced transmission for larger pore length. 


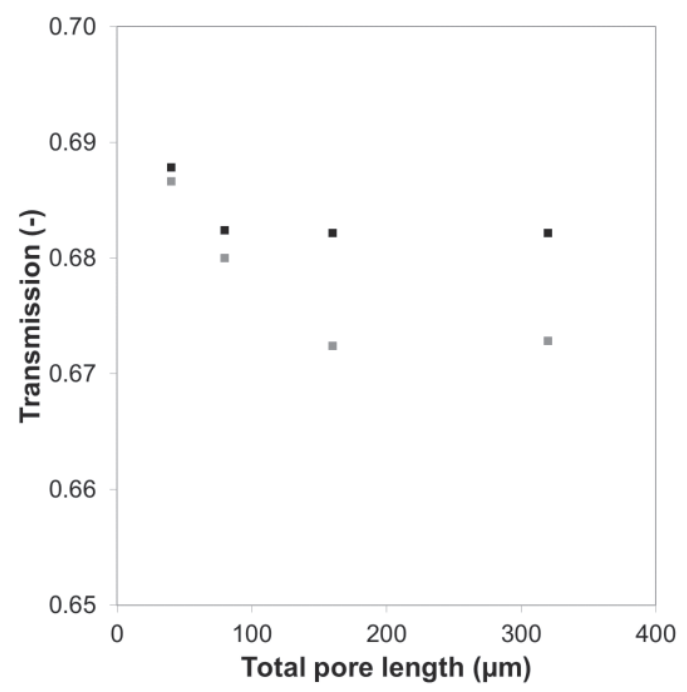

Figure 4.5. Transmission versus the total pore length for the following cases as given in Table 4.2: 8, 10-12 (black squares: one double-sided pores) and 20-23 (grey squares; two double-sided pores)

\subsubsection{Multiple double-sided pores}

In order to evaluate if more pores can be used, or if the effects described before are only valid for the first two pores, we consider the use of in total 6 pores (cases 24 to 29 of Table 4.2, Figure 4.7) where we look at the transmission through each pore relative to the initial feed. As in section 4.3.2, it can be seen that the transmission through the first pore is slightly lower than through the second pore and the same holds for the second pore compared to the third pore; please keep in mind that we zoomed in on the y-axis. As explained before this is due to the lower permeate volume extracted per pore (typically $1.67 \%$ ) and the changed shear induced diffusion profile after every pore. It also shows that the transmission doesn't change with increased pore spacing, therewith showing that multiple pores can effectively be used, given the pore distances that were investigated. Please remember that the porous areas are very small (at most centimetres long), and they only contain few pores, whereas $10 \%$ of the feed is effectively removed through them. This is in stark contrast to microfiltration membranes of e.g. 1 meter long that typically would have $>10^{6}$ pores per membrane length (porosity 50\%, pore size 0.1 micrometre). 


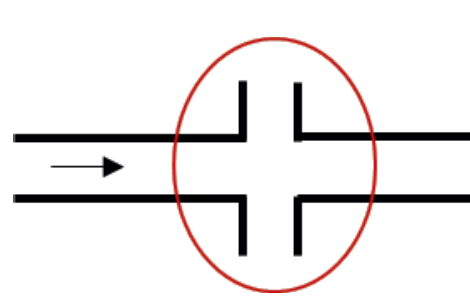

Region depicted in flow profiles for one double sided pore

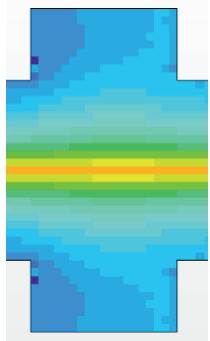

Case 10

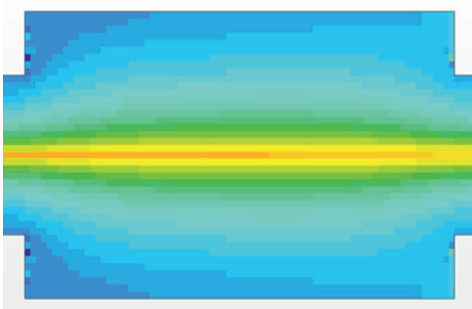

Case 12

\subsection{0}

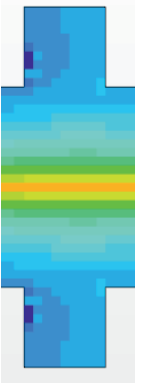

Case 20, first pore

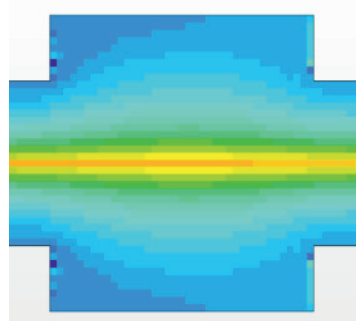

Case 23, first pore

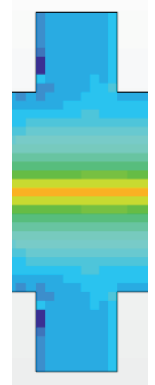

Case 20, second pore

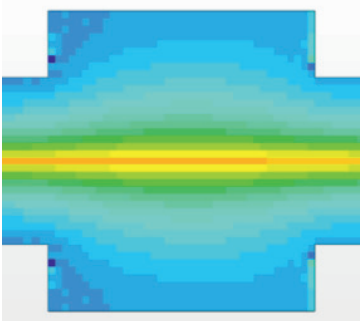

Case 23, second pore pores 


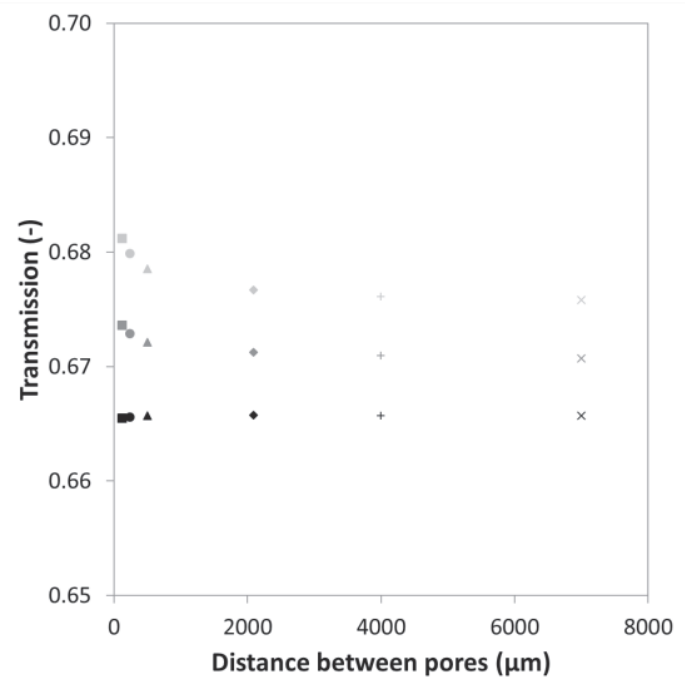

Figure 4.7. Transmission versus the distance between the pores for cases 24 to 29 of Table 4.2 (indicated with squares, circles, triangles, chequers, plusses and crosses respectively). The black symbols give the transmission of the first pore, the dark grey symbols that of the second pore and the light grey symbols that of the third pore, all relative to the initial feed.

\subsection{Conclusion}

In this study we looked at the effect of pore placement on the transmission of particles in a separation system that uses shear-induced diffusion as an underlying mechanism. When using a permeate split ratio of $10 \%$, the overall transmission of particles is around 0.68 at a feed concentration of $30 \%$. For pores present on both sides of the channel only a small to negligible effect on the transmission was found when changing the pore size, the distance between the pores, and the number of pores. This is due to the minimal disturbance of the shear induced diffusion profile in combination with its fast recovery after the pore. When pores are only present on one side we see a small change in transmission, and a large disturbance of the shear induced diffusion profile.

In this study we used a constant permeate split ratio of $10 \%$. We expect a higher transmission when more volume is extracted, due to a change in the shear induced diffusion profile in the channel that is expected to be steeper further from the wall. A change in transmission, can also be expected for the fractionation of bidisperse and/or polydisperse suspensions, although the actual profiles are much harder to predict than for the monodisperse suspensions investigated here. 


\section{Appendix A. List of symbols}

\section{Symbol}

$a$

$a_{i j}$

$A_{i j}^{D}$

$C_{i j}^{D}$

$C_{i j \infty}^{D}$

$D_{\alpha_{p}}$

$D_{\dot{\gamma}}$

$f_{i j}^{D}$

$f\left(\alpha_{p}\right)$

$\mathrm{F}_{\mathrm{m}, \mathrm{p}}$

$F_{p f}^{D}$

$F^{S I D}$

g

$\mathrm{H}$

M

$p$

$T$

$v_{g}$

$v_{i}$

\section{Greek symbols}

Symbol

$\alpha_{i}$

$\alpha_{\max }$

$\widetilde{\alpha_{p}}$

$\dot{\gamma}$

$\eta_{i}$

$[\eta]$

$\rho_{i}$

$\tau_{i}$

\section{Description}

Particle radius

(m)

Interfacial area density

$(1 / \mathrm{m})$

Linearized drag coefficient

Standard drag coefficient

$\left(\mathrm{Pa} \cdot \mathrm{s} / \mathrm{m}^{2}\right)$

$(-)$

Single particle drag coefficient

$(-)$

Volume fraction dependent diffusion coefficient

$\left(\mathrm{m}^{2} / \mathrm{s}\right)$

Shear rate dependent diffusion coefficient

$\left(\mathrm{m}^{2}\right)$

Drag correction factor

$(-)$

Hindered settling function

$(-)$

Particle mass flux

$\left(\mathrm{kg} /\left(\mathrm{m}^{2} \cdot \mathrm{s}\right)\right)$

Drag force on particle phase due to the fluid phase

$\left(\mathrm{N} / \mathrm{m}^{3}\right)$

Force due to shear induced diffusion

$\left(\mathrm{N} / \mathrm{m}^{3}\right)$

Gravity vector

$\left(\mathrm{m} / \mathrm{s}^{2}\right)$

Channel height

Mobility

Pressure (assumed equal in both phases)

$\mathrm{m}$

$\left(\mathrm{m}^{2} /(\mathrm{Pa} \cdot \mathrm{s})\right)$

(Pa)

Transmission

$(-)$

Grid velocity

$(\mathrm{m} / \mathrm{s})$

$(\mathrm{m} / \mathrm{s})$

Velocity of phase i
$(-)$

$(-)$

$(-)$

(Pa s)

$(-)$

$\left(\mathrm{kg} / \mathrm{m}^{3}\right)$

(Pa) 


\section{References}

[1] H. Strathmann, Membrane Separation Processes: Current Relevance and Future Opportunities, AIChE J. 47 (2001) 1077-1087.

[2] C.J.M. Van Rijn, Membrane Science and Technology: Nano and Micro Engineered Membrane Technology, Volume 10, Elsevier, 2004.

[3] K. Nath, Membrane separation processes, PHI Learning Private Limited, Delhi, 2017.

[4] V.T. Kuberkar, R.H. Davis, Microfiltration of protein-cell mixtures with crossflushing or backflushing, J. Memb. Sci. 183 (2001) 1-14.

[5] G.H. Goldsztein, Volume of suspension that flows through a small orifice before it clogs, SIAM J. Appl. Math. 66 (2005) 228-236.

[6] A.M.C. van Dinther, C.G.P.H. Schroën, R.M. Boom, Separation process for very concentrated emulsions and suspensions in the food industry, Innov. Food Sci. Emerg. Technol. 18 (2013) 177-182.

[7] G. Belfort, R.H. Davis, A.L. Zydney, The behavior of suspensions and macromolecular solutions in crossflow microfiltration, J. Memb. Sci. 96 (1994) 1-58.

[8] R.H. Davis, Modeling of fouling of crossflow microfiltration membranes, Sep. Purif. Methods. 21 (1992) 75-126.

[9] A.M.C. van Dinther, C.G.P.H. Schroën, A. Imhof, H.M. Vollebregt, R.M. Boom, Flow-induced particle migration in microchannels for improved microfiltration processes, Microfluid. Nanofluidics. 15 (2013) 451-465.

[10] A.M.C. van Dinther, C.G.P.H. Schroën, R.M. Boom, Particle migration leads to deposition-free fractionation, J. Memb. Sci. 440 (2013) 58-66.

[11] R.M. Miller, J.F. Morris, Normal stress-driven migration and axial development in pressuredriven flow of concentrated suspensions, J. Nonnewton. Fluid Mech. 135 (2006) 149-165.

[12] H.M. Vollebregt, R.G.M. van der Sman, R.M. Boom, Suspension flow modelling in particle migration and microfiltration, Soft Matter. 6 (2010) 6052-6064.

[13] M.K. Lyon, L.G. Leal, An experimental study of the motion of concentrated suspensions in two-dimensional channel flow. Part 1. Monodisperse systems, J. Fluid Mech. 363 (1998) 2556.

[14] D. Semwogerere, J.F. Morris, E.R. Weeks, Development of particle migration in pressuredriven flow of a Brownian suspension, J. Fluid Mech. 581 (2007) 437-451.

[15] I. Drijer, T. van de Laar, H.M. Vollebregt, C.G.P.H. Schroen, From highly specialised to generally available modelling of shear induced particle migration for flow segregation based separation technology, Sep. Purif. Technol. 192 (2018) 99-109.

[16] H.M. Vollebregt, R.G.M. van der Sman, R.M. Boom, Model for particle migration in bidisperse suspensions by use of effective temperature, Faraday Discuss. 158 (2012) 89-103.

[17] M.K. Lyon, L.G. Leal, An experimental study of the motion of concentrated suspensions in two-dimensional channel flow. Part 2. Bidisperse systems, J. Fluid Mech. 363 (1998) 57-77.

[18] D. Semwogerere, E.R. Weeks, Shear-induced particle migration in binary colloidal suspensions, Phys. Fluids. 20 (2008). 
[19] I. Drijer, K. Schroën, Modelling shear induced diffusion based particle segregation: a basis for novel separation technology, Appl. Sci. 8 (2018) 1008. 



\section{Chapter 5}

The flow induced particle segregation principle applied to the separation of a polydisperse cream suspension

This chapter has been submitted as I. Drijer, R. van Zwieten, C.G.P.H. Schroen, The flow induced particle segregation principle applied to the separation of a polydisperse cream suspension 


\begin{abstract}
Concentration of particles is carried out at large scale in industry. For membrane concentration processes a pore size that would retain all particles can be chosen, but for membrane fractionation one range of particles needs to be able to permeate freely while others are retained. Fractionation is in general possible if the particles are sufficiently different in size, but for particles that are relatively close in size this is impossible using classic membrane filtration. That is why we use flow induced particle segregation to allow particles to segregate while in flow, and later fractionate them with a sieve with pores that largely exceed the particle sizes.

The aim of this paper is to show that shear induced segregation is more than a theoretical framework, which is why we apply it to complex polydisperse suspensions, more specifically milk fat globules with a typical size range between 1 and 10 micrometre. We found that the concentration of small particles could be increased to $26 \%$ ( $35 \%$ increase relative to the initial concentration of small particles of $19 \%)$; at a total fat content of approximately $38 \%$.

This clearly indicates that shear induced diffusion occurs very effectively in polydisperse suspensions, and can be applied while fractionating highly concentrated feeds. When comparing these results with a computational fluid dynamics model of a monodisperse suspension, we see a similar trend, which makes us confident that the model can be used to make basic predictions for the novel separation process that we describe.
\end{abstract}




\subsection{Introduction}

To obtain safe products, separation of different-sized components often needs to be carried out. For example, in both water treatment [1], clarification of beer and for the sterilization of pharmaceutical products, separation is needed [2]. In the latter case, unwanted components such as bacteria and viruses need to be removed. Often, this is relatively easy, because the components are rather different in size, but that is not always the case. For example, during milk production [3], bacteria would need to be removed from a liquid that contains milk fat globules that are larger than the bacteria, and casein proteins that are slightly smaller, and this is not possible when using classic membrane technology.

On the other hand, it would be truly beneficial if it were possible to fractionate these components that are close together in size, as this could e.g. lead to enriched starting materials for food product design. For instance, if we could increase the amount of small fat globules, this increases the digestibility of milk, enhances creaminess, and lends beneficial properties to cheese and butter [4].

\subsubsection{Filtration technology}

When talking about membranes and milk, two processes that are often mentioned are ultrafiltration (UF) and microfiltration (MF), which both apply a pressure gradient, and differ in pore size used, typically 0.005 to $0.1 \mu \mathrm{m}$ for UF and 0.05 to $5 \mu \mathrm{m}$ for MF [5]. The size range of the 'particles' that are present in milk approximately cover the pore size range of both membranes, and the propensity to clog is thus very high, leading to flux decrease, and changes in selectivity. To prevent this as much as possible e.g. backflushing is used to (partially) remove the cake layer by reversing the pressure gradient across the membrane [6]. Despite this, it is inevitable that regular cleaning is needed, or even that the process needs to be carried out under conditions where the feed is first diluted, leading to an increase in production costs [7].

As an alternative, several migration mechanisms like Brownian motion, inertial lift and shear induced diffusion $[2,8]$ can be considered as means to mitigate the previously described effects (to some extent). To achieve this, the process conditions need to be tuned to these mechanisms, as will be discussed next. 


\subsubsection{Particle migration}

The three natural mechanisms that can cause the migration of particles are Brownian motion (random movement), inertial lift (due to particle-fluid interactions) and shear induced diffusion (as a result of particle-particle interactions). Depending on several parameters, which are included in the dimensionless Péclet number $\left(P e=\frac{\dot{\gamma} \cdot a^{2}}{D_{B}}\right.$, with $D_{B}=$ $\left.\frac{k \cdot T}{6 \pi \cdot \bar{\eta} \cdot a}\right)$ and particle Reynolds number $\left(R e_{p}=\frac{\mathrm{v}_{\mathrm{r}} \cdot a \cdot \rho_{f}}{\eta_{f}}\right)$, one of these mechanisms will overrule the others [9]. Here, $\dot{\gamma}$ is the shear rate $(1 / \mathrm{s}), a$ the particle radius $(m), k$ the Boltzmann constant $(\mathrm{J} / \mathrm{K}), T$ the temperature $(\mathrm{K}), \bar{\eta}$ the suspension viscosity $(\mathrm{Pa} \cdot \mathrm{s}), v_{r}$ the relative velocity $(\mathrm{m} / \mathrm{s})$ and $\rho_{f}\left(\mathrm{~kg} / \mathrm{m}^{3}\right)$ and $\eta_{f}(\mathrm{~Pa} \cdot \mathrm{s})$ the density and viscosity of the fluid respectively. In both dimensionless numbers, the particle size is present, so whichever mechanism dominates is highly dependent on this parameter. Inertial lift dominates when $\operatorname{Re}_{p}>1$, which in general is the case for particles $>10$ micrometre, and Brownian motion dominates when $\mathrm{Pe}<1$, which is most relevant for particles below 0.5 micrometre. For the current study, we use intermediately sized particles (1-10 micrometre) at a high concentration, and we focus on shear induced diffusion. This mechanism is dominant when $\operatorname{Re}_{\mathrm{p}}<1$ and $\mathrm{Pe}>1$, and the most important migration mechanism for these particles as was shown by Davis [10].

Shear induced diffusion revolves around particle-particle interactions, and higher particle volume fractions lead to a higher number of interactions, and faster diffusion. As mentioned, shear induced diffusion is also strongly dependent on the particle size [7,11], which results in different migration velocities. Overall, particles tend to move from a region with high shear (channel wall) towards a region with low shear (channel centre).

When different-sized particles are present, it depends on the particle size and volume fraction which particles will move towards the centre of the channel [12]. If the volume fractions of small and large particles (in case of a bi-disperse suspension) are equal, the larger particles will preferentially move towards the channel centre, leaving the smaller particles closer to the wall [12] (Figure 5.1). This process occurs in a closed channel, which makes the gate keeper function of pores, around which membrane processes normally revolve, obsolete. Instead, the pre-fractionation that takes place in the closed channel allows us to use a ratio between pore size and particle size that is much higher than one (Figure 5.1). Because of the pre-fractionation effect, smaller particles can be separated rather easily, while larger particles are not even close to the pores if the process conditions are chosen appropriately. Due to the high pore to particle size ratio the membrane module 
is also less prone to fouling, and combined with the laminar flow conditions that are used this results in a more energy efficient process.

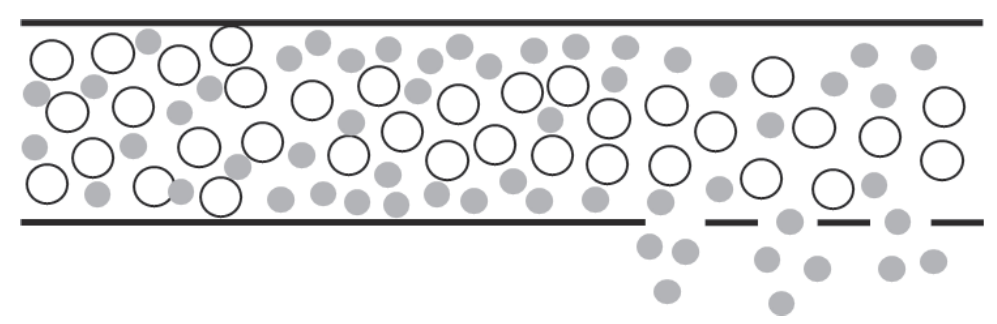

Figure 5.1. Illustration of the principle of shear induced diffusion for a bi-disperse suspension

\subsubsection{Practical application}

In order to be able to design such an innovative process, various aspects need to be investigated. In literature, the principle of shear induced diffusion in a nonporous channel has been studied extensively. Amongst others, Drijer et al. [9], Vollebregt et al. [11,13] and Dbouk and co-workers [14] focused on modelling while Lyon and Leal $[15,16]$ focused on experimental work. Sieving processes using a pore to particle size ratio above 1, were investigated in our group by Drijer et al. $[9,17,18]$ who worked on modelling, and by Van Dinther and coworkers $[7,19,20]$ who did extensive experimental studies on separation of bi-disperse suspensions. To the best of our knowledge, no other groups have investigated this.

In the current paper, we apply the knowledge gained from modelling and experimental studies, to the separation of polydisperse suspensions. We first describe an experimental study aimed at fractionating milk fat globules using shear induced diffusion. These results will then be compared to modelling results obtained for a monodisperse suspension to see if these studies can be used to describe trends, and ideally predict fractionation efficiency.

\subsection{Materials and methods}

The experiments were performed using concentrated cream ( $\sim 0 \%$ ) generously donated by FrieslandCampina, Wageningen, the Netherlands. The skim milk (Campina, purchased in a local supermarket) that was used to obtain the desired concentrations, and cream were stored at $4{ }^{\circ} \mathrm{C}$. The same batch of cream was used for all the experiments. 


\subsubsection{Sample preparation}

To obtain homogeneous samples, the cream was heated to $40{ }^{\circ} \mathrm{C}$ and stirred continuously. Also the skim milk was heated to $40{ }^{\circ} \mathrm{C}$. To be able to look at the separation of differently sized fat globules the casein micelles needed to be dissociated and for this $\mathrm{Na}_{2} \mathrm{EDTA} \bullet 2 \mathrm{H}_{2} \mathrm{O}$ (Sigma-Aldrich) was added to the cream (4g/100g, $100 \mathrm{mM}$ ). During EDTA addition the $\mathrm{pH}$ was kept at 6.7 by adding $\mathrm{NaOH}(1 \mathrm{~N})$. In total $1 \mathrm{~L}$ of feed was prepared.

\subsubsection{Experimental set-up}

The fat globules are separated in a membrane module similar to the setup used by van Dinther and coworkers $[7,19,20]$ and is shown in Figure 5.2. The feed enters the set-up by the use of a positive displacement pump (VG1000digit, Verdergear, Germany) at a velocity of approximately 0.07 m/s. A pressure sensor (EL-PRESS P-502C, Bronkhorst High-Tech B.V., the Netherlands) was placed in front of the membrane module, and pressure was registered with Bronkhorst High-Tech software.

The trans-membrane flux at the permeate outlet was regulated using an elastic tube with an adjustable screw, such that 0.6, 4.0, 5.6, 9.0 and 11.6 percent of the feed volume was extracted. The mass of the permeate, and retentate was determined using balances (CP4202S and QUINTIX612-1S, Sartorius, Germany). It is assumed that the density of all samples equals $1000 \mathrm{~g} / \mathrm{L}$ at $40{ }^{\circ} \mathrm{C}$ [21]. The system was cleaned before every experiment with $1 \mathrm{~L}$ of water $\left(20^{\circ} \mathrm{C}, \mathrm{v}=0.15 \mathrm{~m} / \mathrm{s}\right), 0.5 \mathrm{~L}$ of household cleaning solution $(0.2 \% \mathrm{vol} / \mathrm{vol}, \mathrm{v}$ $=0.15 \mathrm{~m} / \mathrm{s})$, and $0.5 \mathrm{~L}$ of water $\left(20^{\circ} \mathrm{C}, \mathrm{v}=0.15 \mathrm{~m} / \mathrm{s}\right)$.

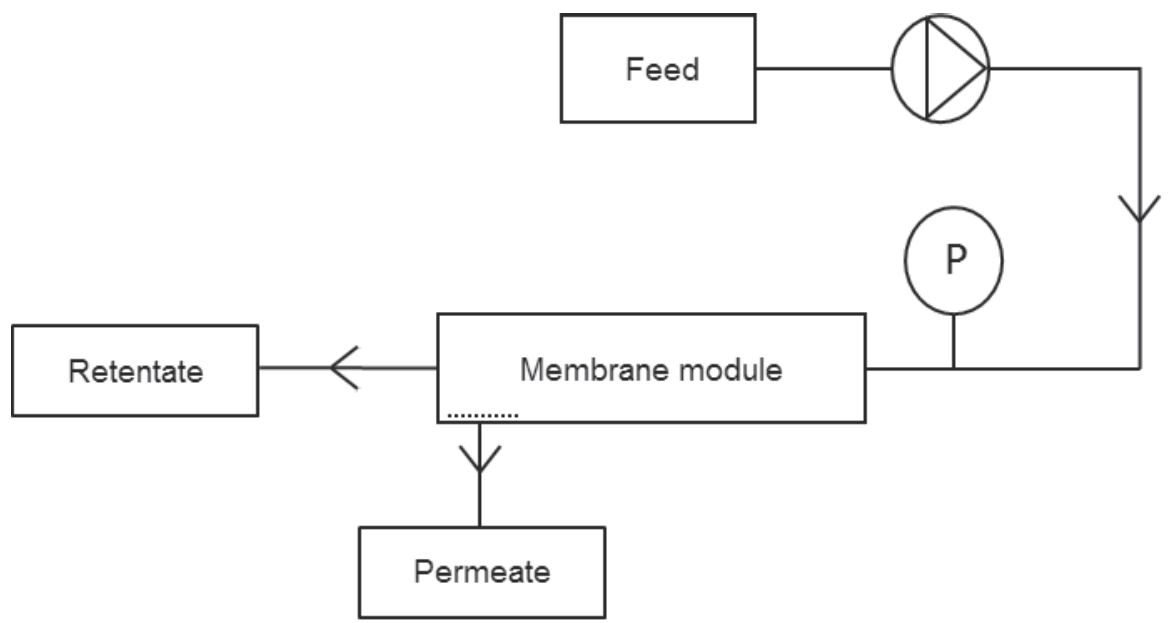

Figure 5.2. Schematic view of the experimental set-up 


\subsubsection{Membrane module}

The height of the membrane module was $200 \mu \mathrm{m}$, and the length $40.5 \mathrm{~cm}$. The module contains a closed entrance section in which the shear induced diffusion profile establishes. After $34.5 \mathrm{~cm}$ a round nickel sieve (Veconic sieve, Veco B.V., the Netherlands) of $1.39 \mathrm{~cm}^{2}$ is placed to fractionate the fat globules. The sieve contains elongated pores that are all identical in size (190 by $10 \mu \mathrm{m}$, see Figure $\mathbf{5 . 3}$ ). The sieve is positioned such that the pores are lengthwise perpendicular to the direction of the feed flow.
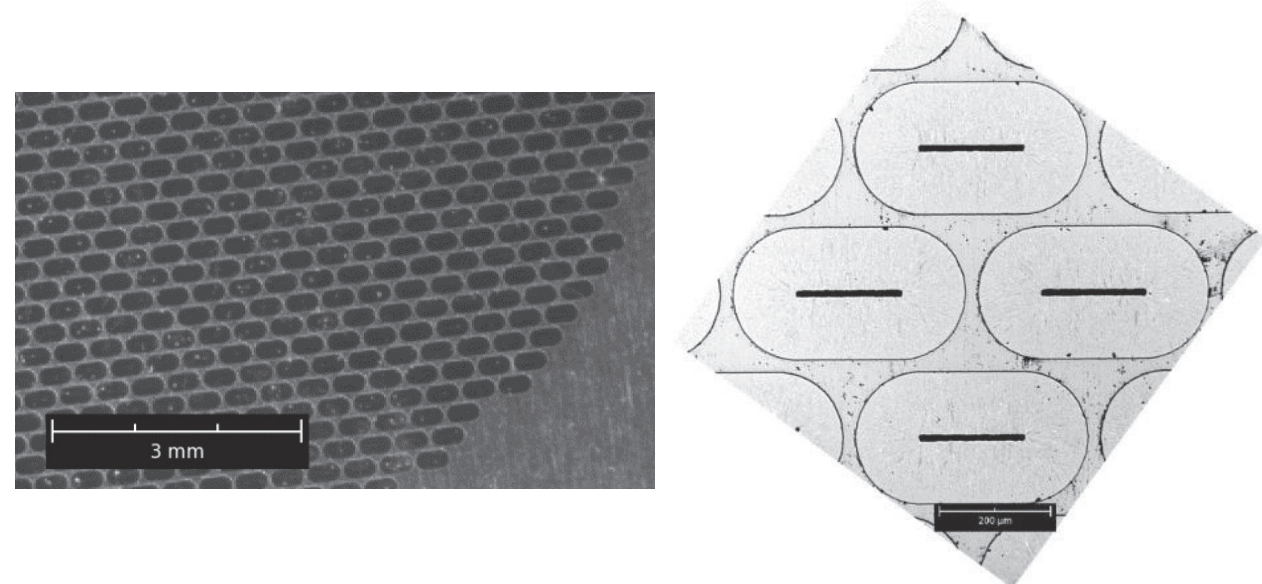

Figure 5.3. SEM images of the sieves used; left, back view of the sieve, black areas are pore fields. The black slits (right) visible in the front view are the actual pores.

\subsubsection{Characterization of fat globules}

The fat globule size as well as the fat content were measured for the initial feed and for each permeate sample. If the feed is no longer enough to do a measurement, the retentate is added to the feed; because we only extract small amounts of permeate, it is safe to assume that this will have negligible influence on the composition of the feed (1 litre in total).

\subsubsection{Fat globule size distribution}

The size of the fat globules of the permeate, and the initial feed were determined in triplicate by light scattering. For this the Mastersizer3000 (Malvern Instrument Ind.) was used in which the refractive index of the fat globules and the dispersant (Millipore water, Millipore Q-Gard 2 and PureLab Ultra) were set at 1.46 and 1.33 respectively, while keeping the concentration of the sample below the multiple scattering limit. 


\subsubsection{Fat content measurement}

The permeate cream samples were mixed with heated skim milk (approximately $40^{\circ} \mathrm{C}$ ) in a ratio of $1: 12$. Fat content was measured at least five times in duplicate by infrared spectroscopy with MilkoScan 134 A/B (Foss Electric Denmark) and as prescribed we excluded the first two duplicate measurements when determining the average values. Because of the low fat percentage after dilution (typically $3-5 \%$ which is customary for milk), all samples were measured using the 'milk' settings of the apparatus, rather than the cream settings.

\subsection{Results and discussion}

First the experimental results are discussed, after which they are compared to the modelling results of a monodisperse suspension $[9,17,18]$.

\subsubsection{Experimental output}

The particle size distribution of the feed and the different permeate samples were measured three times of which the averages are shown in Figure 5.4.

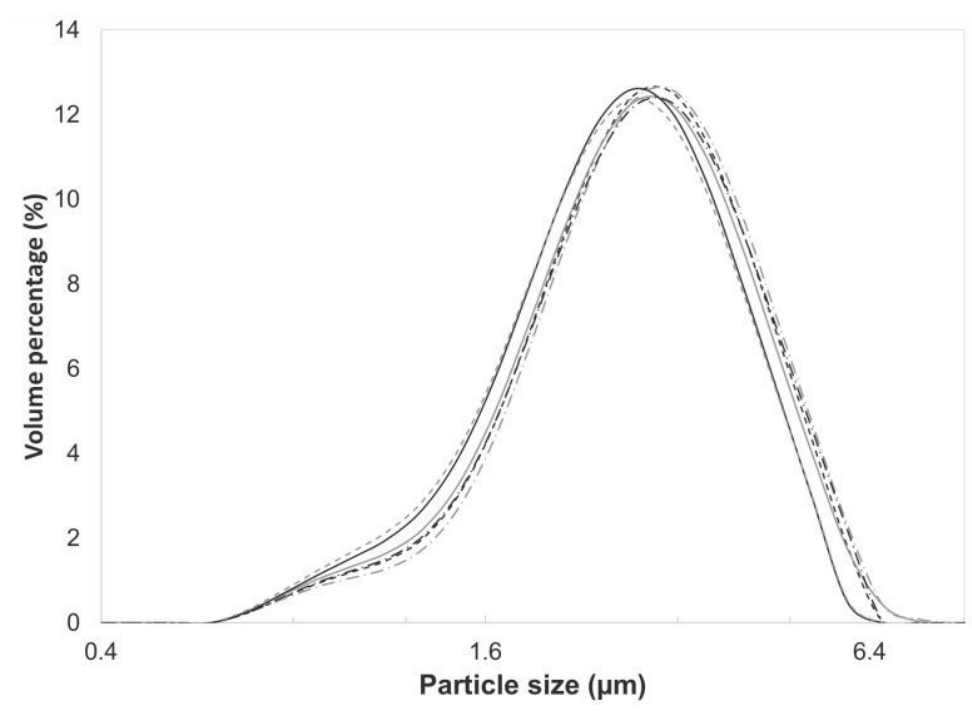

Figure 5.4. Particle size distribution of the feed (grey dashed dotted line) and samples taken at various permeate splits: $0.6 \%$ (black solid line); $4 \%$ (grey dashed line); 5,6\% (grey solid line); 9\% (black dashed dotted line) and $11.6 \%$ (black dashed line). 
Although the differences may look small, Figure $\mathbf{5 . 4}$ shows that there is a systematic difference between feed and permeate at low permeate split, especially when taking the small differences in particle size into account. There are more small and less large particles in the permeate compared to the feed which is indicative of shear induced diffusion taking place. When more permeate is extracted the composition of the permeate sample approaches that of the feed. This is also clear when looking at the total fat percentage (Figure 5.5). At lower permeate split the fat percentage is lower; the larger particles most probably moved away faster than the small ones that are captured in the permeate, and depending on how much permeate is removed, the overall concentration will be influenced. Please note that one data point at approximately $4 \%$ is off; during the experiments accidentally the pressure over the membrane changed, which illustrates the sensitivity of the method.

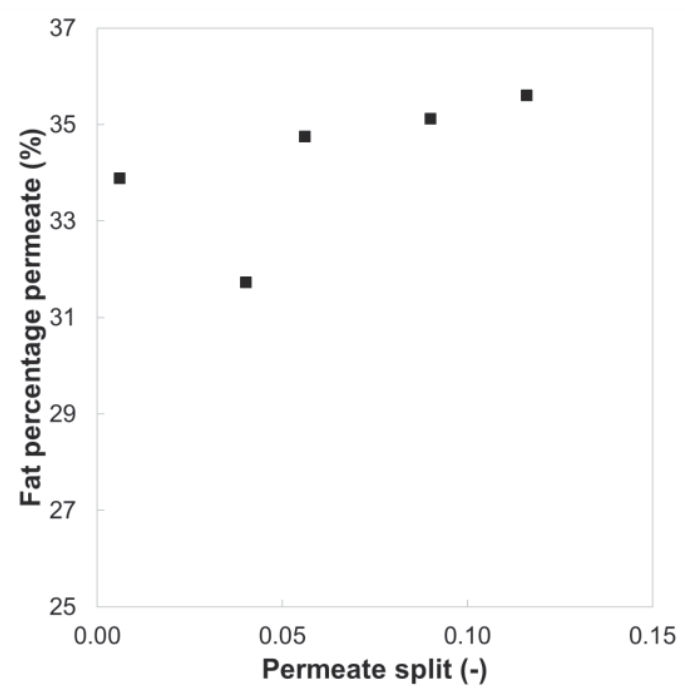

Figure 5.5. The fat percentage in the permeate versus the permeate split $(0.10$ means $10 \%$ of the feed is removed as permeate).

For further analysis we define the "small" particles as those that are less than $25 \%$ of the largest particles. When distinguishing between small $(0-1.9 \mu \mathrm{m})$ and large $(1.9-10 \mu \mathrm{m})$ particles we observe specific differences in transmission (Figure 5.6). Figure $\mathbf{5 . 6}$ shows that at low permeate split, the transmission of small particles is above one, so higher than the total volume fraction in the feed, whereas the transmission of larger particles is below one. This implies that shear induced migration has taken place resulting in more smaller particles close to the wall compared to larger particles. At a higher permeate split, the transmission of both particles approaches one indicating that the composition of the permeate is similar 
to that of the feed as was shown in Figure 5.4. These findings are in line with Van Dinther and co-workers [21] who studied filtration of bi-disperse particles with two distinct particles sizes unlike our polydisperse cream, using 20 micrometre round pores. They found an enrichment in small particles with a transmission of around 1.2 at low permeate split, leading to a significant shift in composition. Interestingly, the loss of this effect took place at a permeate split of around $0.02 \%$ (for slightly different flow conditions), whereas in our experiment transmission remains at 1.2 till close to a permeate split of $5 \%$, therewith illustrating that shear-induced migration is more effective when applied to a polydisperse system.

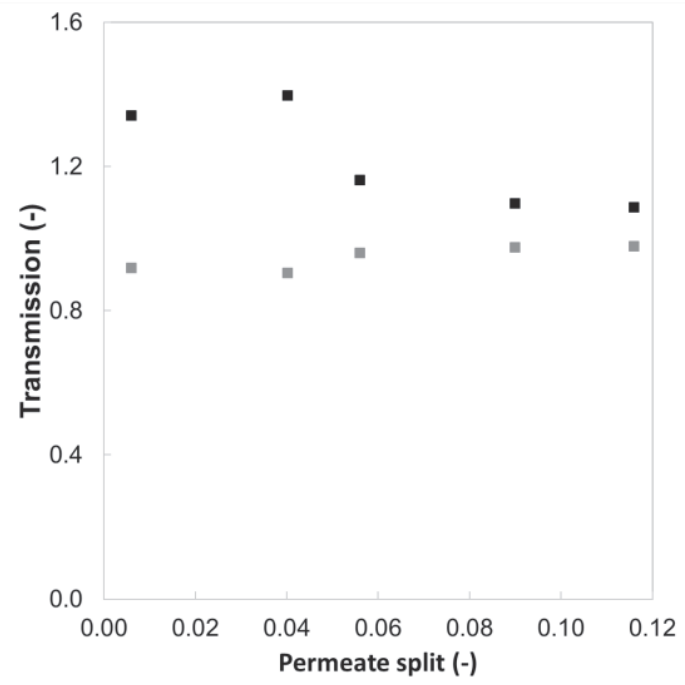

Figure 5.6. Transmission based on total fat volume versus the permeate split $(0.1$ means $10 \%$ of the feed is removed as permeate) for 0-1.9 $\mu \mathrm{m}$ particles (black squares) and 1.9-10 $\mu \mathrm{m}$ particles (grey squares).

To put these effects into perspective, the effect basically vanishes (slowly) at $5 \%$ permeate split, which may not sound that impressive. At the same time, please realize that the sieve that we are using is only $1.3 \mathrm{~cm}$ long (and wide), so we take out $5 \%$ of the feed using this small membrane, which corresponds to fluxes that are as high as $30-500 \mathrm{~L} / \mathrm{m}^{2} / \mathrm{h}$ (based on total membrane area), which is comparable to classic microfiltration processes [22-29].

What we expect to have happened is that the shear induced diffusion profile is disturbed when high amounts of permeate are extracted. In that sense, it would be advisable to design the system in such a way that after the sieving area another closed area [22] is used prior to the next sieving area, in order to allow shear induced diffusion to re-establish the 
concentration profile. The technology used to make the sieves would also allow the inclusion of non-porous regions, so technically this is possible. Alternatively, a recycle loop can be used.

\subsubsection{Model comparison}

In previous studies we have developed a computational fluid dynamics (CFD) model for monodisperse suspension filtration based on the system that we use here for the experiments. Now, we compare the model and the experiments, and see if it captures observed effects. For the details of the model we refer to Drijer and coworkers $[9,17,18]$. The essential parameters are listed in Table 5.1, and resemble the experimental work as close as possible. The average diameter of the particles is the same as measured, but the entrance length used in the model is shorter than that used in the experimental work to save computing time. It is known that the profile is almost fully developed at $10 \mathrm{~cm}$, and therefore the influence on the results will be minimal. Furthermore, in the model only one pore of $400 \mu \mathrm{m}$ is used compared to the multi-pore sieve that is used in the experiments. Please keep in mind that the actual sieve has an accumulative pore width (so over the entire length of the sieve) that approximately agrees with $400 \mu \mathrm{m}$; we previously showed [18] that the effect in transmission is minimal for different pore sizes, as long as the permeate split stays the same.

Table 5.1. Parameters used in the CFD model to compare to experimental results.

\begin{tabular}{ll}
\hline Parameter & Value \\
\hline Channel height & $200 \mu \mathrm{m}$ \\
Particle diameter & $3 \mu \mathrm{m}$ \\
Cross flow velocity & $0.07 \mathrm{~m} / \mathrm{s}$ \\
Pore length & $400 \mu \mathrm{m}$ \\
Particle volume fraction feed & 0.38 \\
Entrance length & $0.1 \mathrm{~m}$ \\
\hline
\end{tabular}

In Figure 5.7, the fat percentage in the permeate is plotted versus the permeate split, and compared with the experimental data (earlier presented in Figure 5.5, and it is clear that 
the trends are similar. The concentration profile in the channel just before the pore is shown in Figure 5.8, and the lines indicate the portion that would be removed given a certain permeate split. From this it is clear that higher concentrations can be expected at a higher permeate split. However, the model values are different from the measured ones. This could be related to the actual area used to take the permeate from, which may be smaller than the sieve dimensions that we use. The sieve has non-porous support structures that make the sieve mechanically more stable (see Figure 5.3), and also a non-porous area near the outside. Both effects lead to a reduction of effective sieving area, or when translating to Figure 5.8, to higher local permeate flux to compensate for the non-porous areas. From Figure 5.8, it is immediately clear that in those cases, the fat percentage in the permeate would increase.

Although the effective sieving area is something to consider, we think that the differences in Figure $\mathbf{5 . 7}$ are thus large that this cannot explain the total effect. It is known that special effects occur in bi- and most probably also in poly-dispersions. In case of a poly-disperse suspension it can be expected that the particle size and volume fraction affect the migration of particles, and either the smaller or the larger particles will move preferentially towards the channel centre resulting in a similar profile as also shown by van Dinther and coworkers for a bi-disperse suspension that is reproduced in Figure 5.9 [20]. In this specific case, the larger particles move towards the centre while the smaller particles move towards the side, which is in line with experiments carried out by for example Semwogerere and Weeks [12] who experimentally also showed the difference between a monodisperse and a bi-disperse suspension. We expect to have a similar situation in our experiments, resulting in a higher overall small particle volume fraction near the wall.

The model for a monodisperse suspension does capture the trends and can be used to get an indication on the effects of certain process and membrane parameters. Obviously, to capture the differences in transmission for differently sized particles, a model for bidisperse or poly-disperse systems is needed, but this requires a different calculation method compared to the one that we use for monodisperse suspensions. We therefore conclude that the trends that the model generates can be used to guide the design of the sieving systems. 


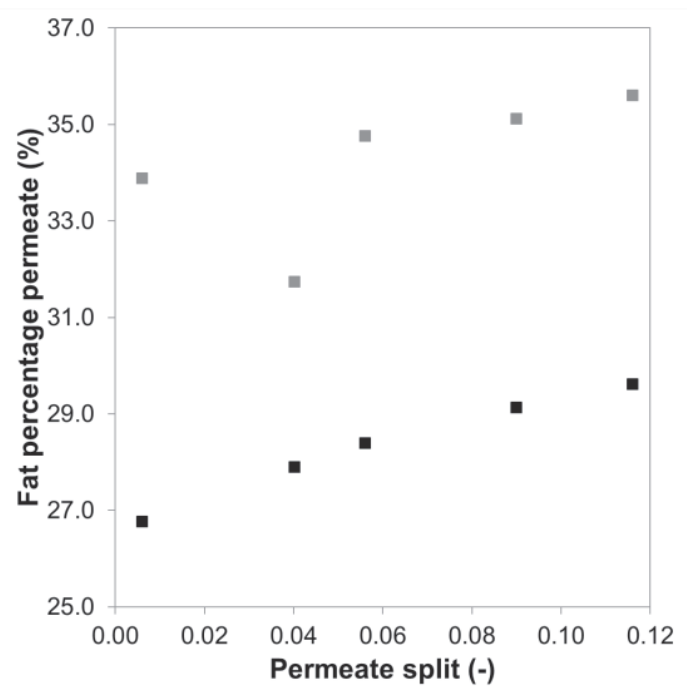

Figure 5.7. The fat percentage in the permeate versus the permeate split $(0.1$ means $10 \%$ of the feed is removed as permeate) for the model (black squares) and the experiment (grey squares).

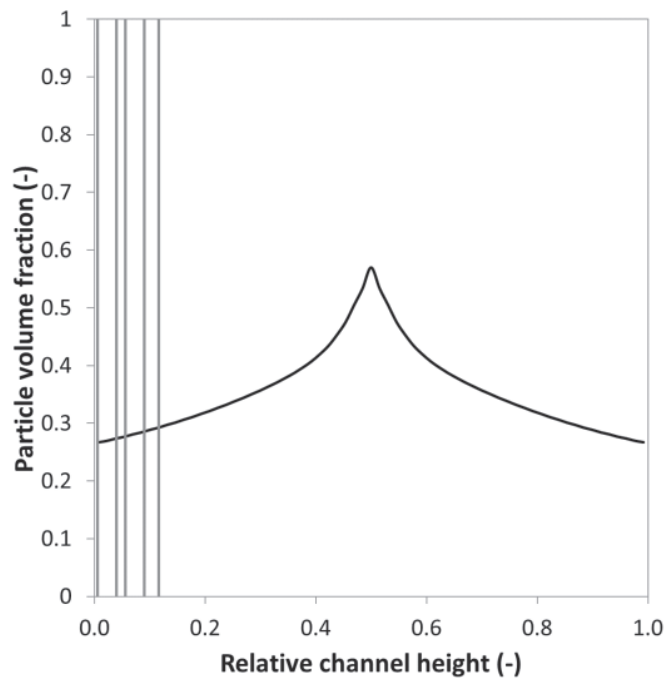

Figure 5.8. Particle volume fraction versus the relative channel height for the model results of a monodisperse suspension (black line). The grey lines indicate the different percentages of volume extracted. From left to right: $0.6 \% ; 4 \% ; 5,6 \% ; 9 \%$ and $11.6 \%$. 


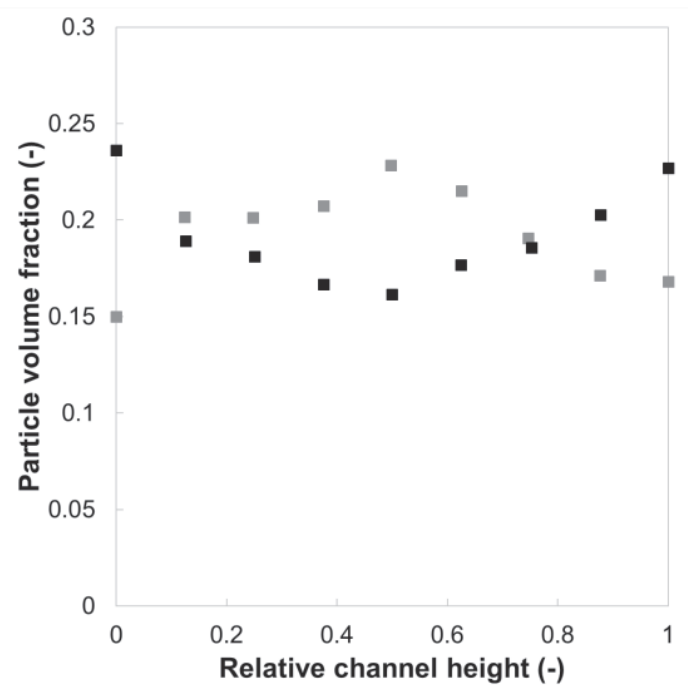

Figure 5.9 Particle volume fraction plotted against the relative channel height at a distance of $24 \mathrm{~cm}$ from the entrance of the channel and for $2.65 \mu \mathrm{m}$ (circles) and $1.53 \mu \mathrm{m}$ (triangles) particles. Total particle volume fraction of the feed is 0.38 , the channel height is $50 \mu \mathrm{m}$, velocity is $20.8 \mu \mathrm{m} / \mathrm{s}$ and ratio between large and small particles is 0.5. (Reprinted from Journal of Membrane Science, 440, A.M.C. van Dinther; C.G.P.H. Schroën; R.M.Boom, Particle migration leads to deposition free fractionation, 5866, 2013, with permission from Elsevier.)

\subsection{Conclusion}

In this study we showed that shear induced diffusion can be used to fractionate polydisperse milk cream particles using sieves with pores that are much larger than the particle size. The small cream particles ( $<1.9$ micrometre), have a transmission of around 1.3 at $0.5-5 \%$ permeate split, indicating that they can be removed at a higher concentration than present in the feed. The transmission of large particles (>1.9 micrometre) is typically around $\mathbf{0 . 8}$, so their concentration is lower than in the feed. These effects are lost at a permeate split > 5\%. This shows that shear-induced migration is effective for the fractionation of polydisperse systems, and not just for bi-disperse ones that are known from literature, albeit that the effect breaks down at much lower permeate split. The fluxes at which the process can be carried out are high, especially when considering that the fractionation is carried out with 38 volume $\%$ cream.

The experimental results were compared with a model for a monodisperse suspension, and a similar trend for fat volume fraction as function of the permeate split was found. The differences in actual values are most probably due to specific effects occurring in bi-disperse and poly-disperse systems, leading to smaller particles being present at higher 
concentration near the wall. We suggest that the model for a monodisperse suspension is useful to chart the effects of process conditions, and sieve dimensions, and facilitate overall process design. 


\section{References}

[1] P. Le-Clech, V. Chen, T.A.G. Fane, Fouling in membrane bioreactors used in wastewater treatment, J. Memb. Sci. 284 (2006) 17-53.

[2] G. Belfort, R.H. Davis, A.L. Zydney, The behavior of suspensions and macromolecular solutions in crossflow microfiltration, J. Memb. Sci. 96 (1994) 1-58.

[3] G. Brans, C.G.P.H. Schroën, R.G.M. van der Sman, R.M. Boom, Membrane fractionation of milk: State of the art and challenges, J. Memb. Sci. 243 (2004) 263-272.

[4] G. Gésan-Guiziou, Liquid Milk Proccessing, in Membrane Processing: Dairy and Beverage Applications, Blackwell Publishing Ltd, Oxford, UK, 2013.

[5] C.J.M. Van Rijn, Membrane Science and Technology: Nano and Micro Engineered Membrane Technology, Volume 10, Elsevier, 2004.

[6] V.T. Kuberkar, R.H. Davis, Microfiltration of protein-cell mixtures with crossflushing or backflushing, J. Memb. Sci. 183 (2001) 1-14.

[7] A.M.C. van Dinther, C.G.P.H. Schroën, R.M. Boom, Separation process for very concentrated emulsions and suspensions in the food industry, Innov. Food Sci. Emerg. Technol. 18 (2013) 177-182.

[8] R.H. Davis, D.T. Leighton, Shear-induced transport of a particle layer along a porous wall, Chem. Eng. Sci. 42 (1987) 275-281.

[9] I. Drijer, T. van de Laar, H.M. Vollebregt, C.G.P.H. Schroen, From highly specialised to generally available modelling of shear induced particle migration for flow segregation based separation technology, Sep. Purif. Technol. 192 (2018) 99-109.

[10] R.H. Davis, Modeling of fouling of crossflow microfiltration membranes, Sep. Purif. Methods. 21 (1992) 75-126.

[11] H.M. Vollebregt, R.G.M. van der Sman, R.M. Boom, Suspension flow modelling in particle migration and microfiltration, Soft Matter. 6 (2010) 6052-6064.

[12] D. Semwogerere, E.R. Weeks, Shear-induced particle migration in binary colloidal suspensions, Phys. Fluids. 20 (2008).

[13] H.M. Vollebregt, R.G.M. van der Sman, R.M. Boom, Model for particle migration in bidisperse suspensions by use of effective temperature, Faraday Discuss. 158 (2012) 89-103.

[14] T. Dbouk, E. Lemaire, L. Lobry, F. Moukalled, Shear-induced particle migration: Predictions from experimental evaluation of the particle stress tensor, J. Nonnewton. Fluid Mech. 198 (2013) 78-95. doi:10.1016/j.jnnfm.2013.03.006.

[15] M.K. Lyon, L.G. Leal, An experimental study of the motion of concentrated suspensions in two-dimensional channel flow. Part 2. Bidisperse systems, J. Fluid Mech. 363 (1998) 57-77.

[16] M.K. Lyon, L.G. Leal, An experimental study of the motion of concentrated suspensions in two-dimensional channel flow. Part 1. Monodisperse systems, J. Fluid Mech. 363 (1998) 2556 .

[17] I. Drijer, K. Schroën, Modelling shear induced diffusion based particle segregation: a basis for novel separation technology, Appl. Sci. 8 (2018) 1008.

[18] I. Drijer, P. Hazelhoff, C.G.P.H. Schroen, Computational evaluation of membrane pore placement for novel shear-induced diffusion based separation processes, Unpublished. 
(2018).

[19] A.M.C. van Dinther, C.G.P.H. Schroën, A. Imhof, H.M. Vollebregt, R.M. Boom, Flow-induced particle migration in microchannels for improved microfiltration processes, Microfluid. Nanofluidics. 15 (2013) 451-465.

[20] A.M.C. van Dinther, C.G.P.H. Schroën, R.M. Boom, Particle migration leads to deposition-free fractionation, J. Memb. Sci. 440 (2013) 58-66.

[21] P. Walstra, J.T.M. Wouters, T.J. Geurts, Dairy Science and Technology, 2nd ed., Taylor \& Francis Group, Boca Raton, FL, 2006.

[22] A. Guerra, G. Jonsson, A. Rasmussen, E. Waagner Nielsen, D. Edelsten, Low cross-flow velocity microfiltration of skim milk for removal of bacterial spores, Int. Dairy J. 7 (1997) 849-861.

[23] K.S. S. Holm, R. Malmberg, Method for producing milk with a lowered bacterial content, 1989.

[24] M. Pouliot, Y. Pouliot, M. Britten, On the conventional cross-flow microfiltration of skim milk for the production of native phosphocaseinate, Int. Dairy J. 6 (1996) 105-111.

[25] P.K. Vadi, S.S.H. Rizvi, Experimental evaluation of a uniform transmembrane pressure crossflow microfiltration unit for the concentration of micellar casein from skim milk, J. Memb. Sci. 189 (2001) 69-82.

[26] P. Punidadas, S.S.H. Rizvi, Separation of milk proteins into fractions rich in casein or whey proteins by cross flow filtration, Food Res. Int. 31 (1998) 265-272.

[27] D.M. Krstić, M.N. Tekić, M.Đ. Carić, S.D. Milanović, The effect of turbulence promoter on cross-flow microfiltration of skim milk, J. Memb. Sci. 208 (2002) 303-314.

[28] L. V. Saboya, J. Maubois, Development of Microfiltration Technology in the Dairy Industry, Lait. 80 (2000) 541-553.

[29] C.J.M. van Rijn, M.C. Elwenspoek, Micro filtration membrane sieve with silicon micro machining for industrial and biomedical applications, in: Proc. Micro Electro Mech. Syst., Amsterdam, the Netherlands, 1995: pp. 83-87. 



\section{Chapter 6}

General discussion 


\subsection{Introduction}

Conventional membrane filtration techniques suffer from 'fouling', which is an overall term indicating that the flux decreases in time, and is an unwanted result. In order to keep the flux constant, the trans-membrane pressure needs to be increased and next to that, turbulence is used to enhance mass transfer to mitigate the effects of fouling [1]. These measures increase the energy demand and therefore the costs of the process, whereas 'fouling' can never be prevented completely. This leads to undesired selectivity changes of the membrane as function of time, because fouling is an accumulative process.

It is clear that if changes in flux and selectivity could be prevented, this would lead to a process that is more sustainable, and has better control over product quality. In order to do so, we used an alternative approach to the classic 'membrane' separation process that has the advantages of conventional filtration like upscaling but at the same time can mitigate the problems related to fouling. We took shear induced diffusion as a basis for this novel separation, which revolves around allowing the fouling particles to move away from the porous area using one of their natural diffusive mechanisms. This chapter gives an overview of the findings of previous chapters and extrapolates these findings to a much wider range of process options.

\subsection{Main findings}

In Chapter 2 a computational fluid dynamics (CFD) model was set up for the shear induced diffusion of a monodisperse suspension in a nonporous channel. This is the starting point for the innovative separation method that we investigate, and needs to be in good agreement with experimental data. We noted that experimental results from literature were only in moderate agreement with our simulations, whereas they compared better to other computer models. When we carried out a highly idealized experiment ourselves, we found that the results were in very good agreement with the model. It is good to note, that in literature less ideal conditions were used, and results of others may have been influenced to a large extent by channel wall / particle interactions.

From Chapter 2, it was concluded that the model was suited to serve as a basis for process design which was the focus of Chapter 3 . When introducing pores to the channel described before, it is important to know how fast the shear-induced diffusion profile recovers after the liquid passes the pore. Here we used the model to look at the effect of design, and process parameters such as bulk particle volume fraction, channel height, particle diameter 
and the ratio between the latter two parameters. For different channel heights and bulk particle volume fractions we charted effects on transmission and recovery lengths when using a single pore, and found promising results with relatively low transmissions (between $59-78 \%)$ and relatively short recovery lengths at a permeate split of $10 \%$.

The next step described in Chapter 4, was to focus on membrane design. We looked at the effect of pore size, distance between the pores, and number of pores on transmission. At an equal permeate split of $10 \%$ and using double sided pores, the number of pores reduced transmission only slightly, and the recovery lengths were very short. This implies that important requirements for the ultimate design of the separation process were met.

The transmission was expected to be affected more when instead of a mono-disperse, a bior polydisperse suspension, that are known to have rather different shear induced diffusion profiles, are considered. In Chapter 5, we did an experimental study using a polydisperse cream suspension and it was shown that shear induced diffusion was quite effective, with the transmission being a function of the applied pressure, as expected from our monodisperse particle simulations. When compared with the CFD model of the monodisperse suspension, it could be concluded that the trends given by the model are indicative for the performance of shear induced diffusion based separation.

\subsection{Shear induced diffusion in perspective}

As mentioned above, this thesis focusses on flow based segregation as a result of shear induced diffusion. This is a complex mechanism that until now has mainly been approached using computer models that can only be implemented by specialists. In our view, and as discussed in Chapter 2, using commercially available CFD to investigate this mechanism is an important step to bring this technology toward people without a modelling background. The model presented in this thesis will make it possible to systematically investigate the influence of different process and membrane parameters as we have done in Chapters 3 and 4, which we consider important steps toward application in various fields.

In this general discussion, we like to share first impressions of the performance of the novel technology, using pores on both sides of the channel. For this we use simulations done with the nonporous channel profile, that we found to be indicative of transmission in Chapter 4 in which we also showed that the pores hardly influence the shear-induced diffusion profile when the pores are placed on both sides of the channel. This enables us to tentatively explore permeate split ratios higher than 10 percent and thus obtain a broader view on the possible performance of shear induced diffusion based segregation. 


\subsubsection{Permeate split ratio}

In Chapter 3 the transmissions for two channel heights and three bulk particle volume fractions were given for permeate split ratios of $2.5,5,7.5$ and $10 \%$. The profiles of the particle volume fractions are shown in Figure 6.1.

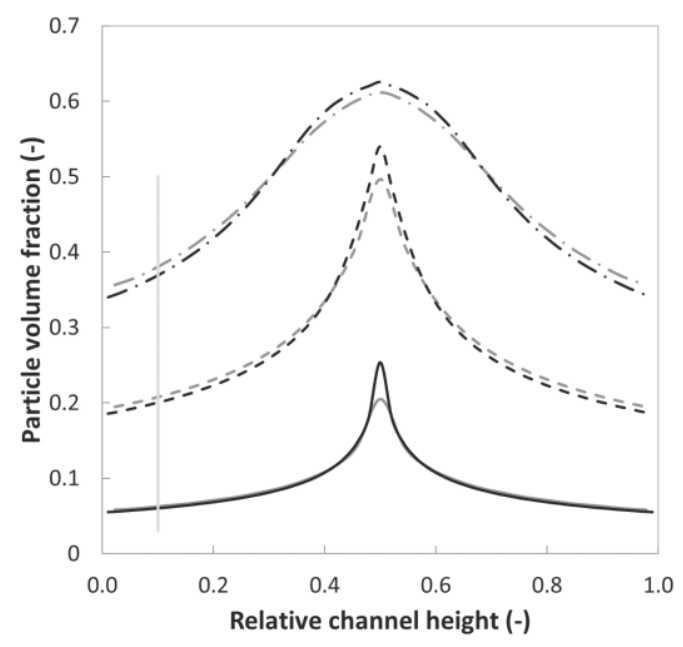

Figure 6.1. Fully developed profile of the particle volume fraction versus the relative channel height for different channel heights: $50 \mu \mathrm{m}$ (grey) and $100 \mu \mathrm{m}$ (black) and for three different bulk particle volume fractions: 10\% (solid line); 30\% (dashed line) and 50\% (dashed dotted line). The grey vertical line represents the split ratio of $10 \%$ (Adapted from Chapter 3 )

Excel was used to fit the particle volume fraction profile shown in Figure 6.1. The area underneath each graph corresponds to the average concentration at different points in the graph, and from this the transmission can be estimated (see Figure 6.2). Please note, the permeate split ratio is directly related to the height in the channel. The calculated transmissions are valid for one double sided or single sided pore (for a double sided pore, on one side, half of the liquid is extracted compared to a single sided pore at the same total permeate split). At permeate split ratios above $10 \%$ in combination with bulk particle volume fractions above $30 \%$, the particle volume fraction profile becomes steeper and nonlinear. This also implies that if multiple pores are used (please remember that after each pore the concentration profile restores fast) at the same total permeate split, a lower transmission is expected. 

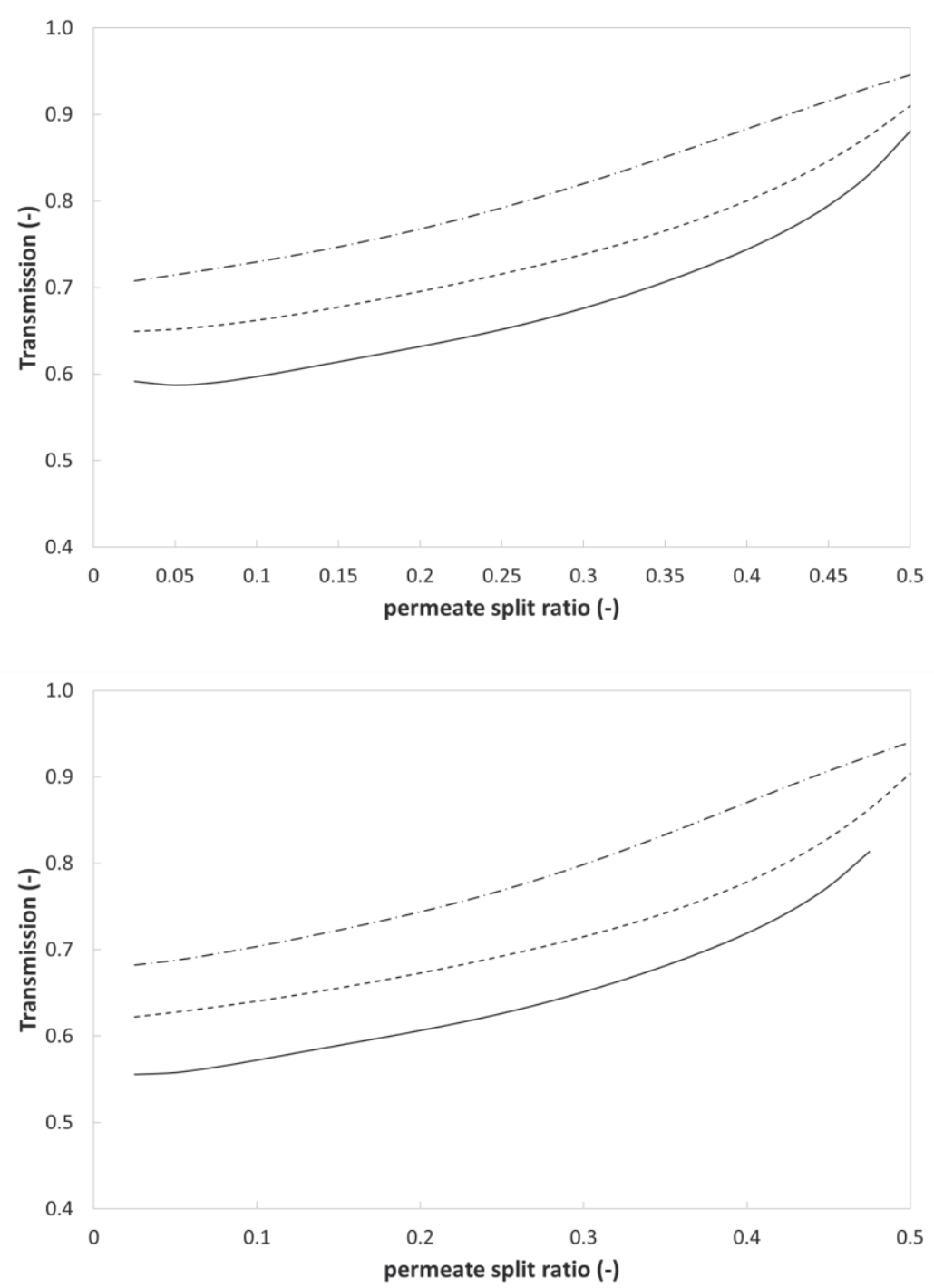

Figure 6.2. The expected transmission versus the permeate split ratio for different channel heights: 50 $\mu \mathrm{m}$ (top graph) and $100 \mu \mathrm{m}$ (bottom graph) and for three different bulk particle volume fractions: 10\% (solid line); 30\% (dashed line) and 50\% (dashed dotted line).

Figure 6.2 shows that at low split ratio intervals the transmission increases linearly as mentioned in Chapter 3, whereas this increase becomes nonlinear when considering higher split ratios as a logical consequence of the shear-induced diffusion profile. When comparing these values to the ones reported in Chapter 3 (see Table 6.1) for a simulation system including pores we see an average deviation of around 7\%, which is most likely due to the more complex flow behaviour in the pores as also touched upon in the next section. Still we 
like to think that the approach that we present here allows us to chart the trends that can be expected when systematically varying permeate split ratios.

When looking in further detail as is done in Table 6.1, it is clear that the calculated transmissions are in all cases lower than the transmissions determined in the simulations. In the extreme case of a permeate split of $50 \%$, the transmission does not reach the value 1 (see Figure 6.2), but please keep in mind that when $50 \%$ is extracted it is not very likely that this can be done without seriously disturbing the shear-induced flow profile, since this implies a considerable reduction in feed volume. When considering less extreme cases, it is clear that looking at the local concentration only, will be a simplification of the actual transmission in a separation process. The different liquid layers will have a different velocity relative to the distance away from the wall and may also contribute differently to the transmission of particles (see also Chapter 4). At the same time, it can be argued that the velocity profile in the pore will be rather different from that in the main channel, and it may even resemble plug-flow. In the latter case, taking the concentration profile as we did here would be an appropriate approach to use.

Table 6.1. Comparison of transmissions reported in Chapter 3 and the values calculated by using the polynomial function reported here for a channel height of $50 \mu \mathrm{m}$ (top) and $100 \mu \mathrm{m}$ (bottom). Bulk pVF is the bulk particle volume fraction.

\begin{tabular}{lllllll}
\hline Permeate & \multicolumn{2}{c}{ bulk pVF = 0.1} & \multicolumn{2}{c}{ bulk pVF = 0.3 } & \multicolumn{2}{c}{ bulk pVF = 0.5 } \\
split (\%) & Polynomial & Chapter 3 & Polynomial & Chapter 3 & Polynomial & Chapter 3 \\
\hline 2.5 & 0.59 & 0.61 & 0.65 & 0.67 & 0.71 & 0.73 \\
5 & 0.59 & 0.63 & 0.65 & 0.69 & 0.71 & 0.75 \\
7.5 & 0.59 & 0.64 & 0.66 & 0.70 & 0.72 & 0.76 \\
10 & 0.60 & 0.66 & 0.66 & 0.71 & 0.73 & 0.78 \\
\hline
\end{tabular}

\begin{tabular}{lllllll}
\hline Permeate & \multicolumn{2}{c}{ bulk pVF $=\mathbf{0 . 1}$} & \multicolumn{2}{c}{ bulk pVF $=\mathbf{0 . 3}$} & \multicolumn{2}{c}{ bulk pVF = 0.5 } \\
split (\%) & Polynomial & Chapter 3 & Polynomial & Chapter 3 & Polynomial & Chapter 3 \\
\hline 2.5 & 0.56 & 0.65 & 0.62 & 0.65 & 0.68 & 0.71 \\
5 & 0.56 & 0.66 & 0.63 & 0.66 & 0.69 & 0.72 \\
7.5 & 0.56 & 0.68 & 0.63 & 0.68 & 0.69 & 0.74 \\
10 & 0.57 & 0.69 & 0.64 & 0.69 & 0.70 & 0.75 \\
\hline
\end{tabular}




\subsubsection{Process design}

In Chapter 4 the pore size, the distance between the pores and the number of pores did not influence the transmission significantly. Looking at Figure 6.2 it can be seen that there is only a slight increase in transmission up to a relative channel height of $10 \%$ (and thus permeate split ratio of $10 \%$ when using single sided pores) and at a bulk particle volume fraction of $30 \%$. This is in complete agreement with our finding presented in Chapter 4 that increasing the number of pores or the distance between the pores has only a slight effect on the transmission. It is expected that larger changes will occur at higher bulk particle volume fractions in combination with higher permeate split ratios for which the concentration profile is steeper. If low transmissions are desired, more pores need to be used through which less liquid is extracted per pore. In this way, high amounts of permeate can be removed at minimal transmission.

Please keep in mind that the volume fraction profile will change after each liquid extraction and that extracting more volume will decrease the velocity through the channel which could be mitigated by using a tapered channel, as also discussed by van Dinther and coworkers [2]. Alternatively, a recycle loop or multiple shorter channels that are placed end to end can be considered. Furthermore, the ratio between pore and particle size needs to be investigated further, since Ferry retention effects cannot be excluded for particles close to the pore size [3]. Also for particles larger than the pore, and that will occur in process liquids, pore shape may influence the transmission as found for microsieves [4].

In conclusion, the conditions used in the innovative process presented here are rather different as standardly used for membrane separation. For the novel process, laminar flow conditions are needed to allow the shear-induced diffusion process to take place. As soon as the concentration profile is established, relatively large amounts of permeate can be removed through a limited number of well-designed pores. As mentioned in Chapter 4, microfiltration membranes of approximately 1 meter long, 50\% porosity, and 0.1 micrometre pores will have over 1 million pores per meter, whereas we consider sieves of at most centimetres with only a few pores. We still find it remarkable that this can lead to the same amount of permeate as standard microfiltration membranes are capable of removing, and even more, which also implies that the total process area needed, and the accompanying costs decrease considerably [5]. All this makes the method described in this thesis an interesting one to explore further for practical application. 


\section{References}

[1] G. Belfort, R.H. Davis, A.L. Zydney, The behavior of suspensions and macromolecular solutions in crossflow microfiltration, J. Memb. Sci. 96 (1994) 1-58.

[2] A.M.C. van Dinther, C.G.P.H. Schroën, R.M. Boom, Particle migration leads to deposition-free fractionation, J. Memb. Sci. 440 (2013) 58-66.

[3] J.D. Ferry, Statitical evaluation of sieve constants in ultrafiltration, J. Gen. Physiol. 20 (1936) 95-104.

[4] G. Brans, R.G.M. van der Sman, C.G.P.H. Schroën, a. van der Padt, R.M. Boom, Optimization of the membrane and pore design for micro-machined membranes, J. Memb. Sci. 278 (2006) 239-250.

[5] K. Schroën, A. van Dinther, R. Stockmann, Particle migration in laminar shear fields: A new basis for large scale separation technology?, Sep. Purif. Technol. 174 (2017) 372-388. 


Summary 
Although microfiltration is used frequently because of the ease of upscaling and the relatively low operational costs, it also has its challenges. Concentration polarization and fouling will (ultimately) decrease the efficiency of the process and at the same time increase operational costs, and costs related to cleaning. This also implies that if these effects can be mitigated, the separation can be carried out in a more sustainable fashion.

To achieve this, we have considered flow-based segregation of particles as a starting point of design, and used shear induced diffusion effects that will make particles that are typically between 0.5 and 10 micrometre migrate towards lower shear regions, which is away from the area where the pores are positioned. The migration rate depends amongst others on the particle size, and particle concentration. This allows for concentration and fractionation inside a channel, that when combined with an area with large pores, can be used to remove a permeate with different composition as the feed. Since the particles move away from the pores, it was expected that the abovementioned complications related to fouling can be mitigated, leading to an innovative separation process. In order to understand this process in detail, the thesis revolved around a computer model that was developed as a tool to elucidate the effect of process and membrane design parameters on separation efficiency.

In Chapter 2 we present a computational fluid dynamics (CFD) model that describes the concentration profile of a monodisperse suspension in laminar flow, based on shear induced diffusion in a nonporous channel. The model is compared to literature and differences with experimental data are most likely due to interactions of particles with the wall. When comparing with a highly idealized experiment carried out within our group we find excellent agreement with the model predictions that were obtained. This made us conclude that the model could serve as a good foundation for further process and membrane design studies.

Chapter 3 focuses on process design, and different parameters (bulk particle volume fraction, channel height, particle diameter and ratio between the height and the diameter) were evaluated on their effect on both the development of the shear induced diffusion profile as well as its steady state profile. We have incorporated one single sided pore in the model, and investigated the effect of channel height and bulk particle volume fraction on transmission and the recovery length of the shear induced diffusion profile. The transmissions found are low considering that a monodisperse suspensions was modelled, and also the recovery lengths are very acceptable; therefore we can take the next step toward more detailed membrane design. 
In Chapter 4 we consider different membrane designs: the number of pores, and pores on one or two sides of the channel are investigated for their effect on transmission. Double sided pores are clearly the preferred option since the shear induced diffusion profile gets less disturbed and therefore the profile also recovers faster after extracting liquid from a pore. When using multiple pores at the same flow split, the transmission decreases with the number of pores because the layer near the pores contains less particles due to the fast recovery of the profile. When looking at $10 \%$ flow split the differences in transmission are small, because the concentration profile is very flat, but as later discussed in chapter 6 , this is very dependent of the flow split and the concentration of particles used.

In Chapter $\mathbf{5}$ we investigate experimentally the transmission of fat from a polydisperse cream and compare that to the monodisperse model of previous chapters. At a permeate split ratio below $5 \%$ there is a clear distinction between the transmission of small and large fat globules in the cream permeate; therefore it can be concluded that the shear induced diffusion effects described earlier for monodisperse dispersions, also hold for this polydisperse suspension. The model shows a similar trend which confirms our previous findings that it can help in setting up process and membrane design

We conclude with Chapter 6 where we put the findings of previous chapters in a broader perspective. The transmissions are extrapolated to higher permeate split ratios and other particle concentrations. These advanced insights are essential to design this innovative process, which is expected to be intrinsically more energy efficient than standard membrane filtration. This is due to the fact that, the novel process revolves around the use of shear-induced diffusion (laminar conditions) and the specific design of a small number of pores, contrary to regular membranes that contain many less defined pores. 



\section{Acknowledgements}

Met het schrijven van dit hoofdstuk, ben ik bijna aan het einde gekomen van mijn periode als PhD. In de ruim zes jaar dat ik hieraan heb gewerkt, zijn er velen geweest die mij direct of indirect hebben bijgestaan. Hen zou ik op deze plaats dan ook graag willen bedanken.

Allereest mijn begeleider Karin. Bedankt voor je steun en je geloof in mij deze afgelopen jaren. Maar ook bedankt voor alle leerzame besprekingen, je luisterend oor, je goede adviezen en de tijd die je elke keer voor me vrijmaakte in je overvolle agenda. Mijn begeleiders bij Veco (Ahmad, Harry en Niels), bedankt voor het vertrouwen in mij en voor de vrijheid die jullie me hebben gegeven. Ook Albert en Christien bedankt voor al het regelwerk dat er gaandeweg mijn PhD voor jullie is bijgekomen. Daarnaast wil ik graag iedereen die bij NanoNextNL betrokken is, bedanken voor deze bijzondere en vooral leerzame periode.

In de jaren die ik bij FPE heb gewerkt, heb ik heel wat mensen zien komen en gaan. Allen bedankt voor de zeer leerzame, maar ook zeer leuke en gezellige tijd! Graag zou ik een aantal mensen in het bijzonder willen bedanken. First I would like to thank my students Ismaël, Xinyi, Ying, Yingqi, Gerrald and Pieter-Jan for helping me exploring the many challenges of this topic and for the lessons I have learned as a supervisor. Ook zou ik Martijntje willen bedanken voor de leerzame discussies. Ties, Ralph en Jos, bedankt voor alle hulp en discussies op experimenteel vlak. Many thanks to my officemates Jimmy, Kashif, Olesya, Marta, Eline, Pina and Isabel for the nice, (not) work related conversations. In particular I would like to thank my officemate Karolina for the nice time and for sharing the ins and outs of everyday life. Jan-Eise, van studiegenoot naar collega. Bedankt voor alle discussies over het modelleren en voor je hulp met menig computerprobleem. Pieter, niet alleen bedankt voor het regelen van de modelleer licenties en alles wat daarbij komt kijken, maar ook voor je positiviteit en je humor. Uiteraard ook Marjan heel erg bedankt voor het regelen van allerlei administratieve zaken en voor onze regelmatige 'bijklets' momentjes!

Ontspanning naast het werk zorgt voor een goede inspanning tijdens het werk. Ik wil dan ook graag familie en vrienden bedanken hiervoor. In het bijzonder Berny. Bedankt voor al je steun en de rust die jij me kon geven in deze soms hectische tijd. Tim en Alexandra, we zijn begonnen als studiegenoten en dat is uitgegroeid tot een goede vriendschap. Bij een PhD komt veel kijken en ik wil jullie dan ook bedanken dat we dit met elkaar konden delen. 
Daarnaast natuurlijk ook heel erg bedankt voor alle gezelligheid daaromheen (uiteraard samen met Nena en Martien)!

Ook mijn ouders en zus hebben een belangrijke bijdrage geleverd. Lieve pap en mam, bedankt voor jullie nuchterheid, jullie adviezen, jullie steun en niet te vergeten jullie gezelligheid. Bedankt dat jullie er altijd voor me zijn en voor me klaarstaan! Lieve Susan, ook jij bedankt voor je nuchterheid, je scherpzinnigheid en bovenal je droge humor! Onze gezellige weekendjes weg houden we erin!

En dan degenen die mij dagelijks bijstaan door lief en leed. Lieve Martyn, je bent mijn man en mijn maatje. We kunnen samen praten, lachen, huilen en vullen elkaar goed aan. Wat hebben wij deze periode veel mogen, maar ook moeten meemaken. Ik ben er dan ook van overtuigd dat wij samen alles aankunnen. Bedankt voor alles, ik hou van jou! Lieve Julian en Jasper, mijn prachtige zoontjes, wat zijn jullie toch heerlijk verhelderend en relativerend. Jullie spontane lachjes, jullie oprechte kusjes en knuffels en jullie eigenwijze karaktertrekjes brengen alles elke keer in perspectief en zorgen bovenal voor een enorme glimlach op mijn gezicht. Met jullie is elke dag bijzonder en is mijn leven een stuk rijker. Ik ben ontzettend dankbaar dat jullie er zijn, ik hou van jullie! 
About the author 


\section{Curriculum Vitae}

Ivon Drijer was born in Roermond, the Netherlands, on June 10 ${ }^{\text {th }} 1988$. In 2006 she completed her secondary education (VWO) at Bisschoppelijk College Schöndeln in Roermond. That same year she started the study Biotechnology at Wageningen University. She obtained her Bachelor degree (with distinction) in 2010 with a thesis on the fermentation of gasified biomass for the production of bio-ethanol. After her BSc, she continued with the master Biotechnology with the specialization Process Technology. During her master she followed an internship at AkzoNobel where she set up an Aspen Plus model. She graduated in 2012 (with distinction) with a thesis on the set up of a process design model for the production of biocontrol fungi.

In March 2012, she started her PhD at Veco B.V. The project was part of the NanoNextNL program and she was positioned at the laboratory of Food Process Engineering of Wageningen University. She studied the fractionation and pre-concentration of suspensions by using shear induced diffusion based flow segregation. She continued her PhD after working as education developer for a period of six months in 2016. The results of her PhD research are described in this thesis. In July 2018 she started working as project leader for MSD Animal Health in Boxmeer. 


\section{List of publications}

I. Drijer, T. van de Laar, H.M. Vollebregt, C.G.P.H. Schroen, From highly specialised to generally available modelling of shear induced particle migration for flow segregation based separation technology, Sep. Purif. Technol. 192 (2018) 99-109

I. Drijer, K. Schroën, Modelling shear induced diffusion based particle segregation: a basis for novel separation technology, Appl. Sci. 8 (2018) 1008

I. Drijer, P. Hazelhoff, C.G.P.H. Schroen, Computational evaluation of membrane pore placement for novel shear-induced diffusion based separation (2018), Submitted for publication

I. Drijer, R. van Zwieten, C.G.P.H. Schroen, The flow induced particle segregation principle applied to the separation of a polydisperse cream suspension (2018), Submitted for publication 


\section{Overview of completed training activities}

\begin{tabular}{|c|c|c|}
\hline \multicolumn{3}{|l|}{ Discipline scpecific activities } \\
\hline \multicolumn{3}{|l|}{ Courses } \\
\hline CFD for chemical engineers & OSPT & 2012 \\
\hline CFD of multiphase flows & OSPT & 2012 \\
\hline STAR-CCM+ distant learning & CD-adapco & 2012 \\
\hline Reaction kinetics in food science & VLAG & 2012 \\
\hline Numerical methods for chemical engineers & OSPT & 2013 \\
\hline Lean Six Sigma Green Belt & MKPC & 2017 \\
\hline \multicolumn{3}{|l|}{ Conferences } \\
\hline ECCE9-ECAB2 (NL) & & 2013 \\
\hline MicroNano Conference (NL)a & & 2013 \\
\hline Membrane symposium Aachen (DE) a & & 2014 \\
\hline NanoCity (NL) $)^{a, b}$ & & 2014 \\
\hline NanoCity (NL) $)^{a, b}$ & & 2015 \\
\hline Filtech $(D E)^{b}$ & & 2016 \\
\hline \multicolumn{3}{|l|}{ General courses } \\
\hline Intellectual property awareness \& valorisation & NanoNextNL & 2012 \\
\hline PhD competence assessment & WGS & 2012 \\
\hline Voice matters & WGS & 2012 \\
\hline VLAG PhD week & VLAG & 2012 \\
\hline Risk analysis and technology assessment & NanoNextNL & 2013 \\
\hline Mobilising your -scientific- network & WGS & 2013 \\
\hline Scientific integrity & WGS & 2013 \\
\hline Gespreksvaardigheden 1 op 1 & ESD & 2013 \\
\hline Scientific writing & WGS & 2015 \\
\hline Career perspectives & WGS & 2017 \\
\hline PhD workshop Carousel & WGS & 2017 \\
\hline \multicolumn{3}{|l|}{ Optional activities } \\
\hline PhD study tour, Finland and the Baltic States & & 2012 \\
\hline VLAG PhD Council & & $2012-2013$ \\
\hline NanoNextNL team meetings $s^{a, b}$ & & $2012-2016$ \\
\hline Food Process Engineering Group day ${ }^{a, b}$ & & 2012-2017 \\
\hline
\end{tabular}


This work is supported by NanoNextNL, a micro and nanotechnology consortium of the Government of The Netherlands and 130 partners

Printed by Proefschriftmaken || Proefschriftmaken.nl

Cover design by Stefanie van den Herik | SVDH Media 


\section{Propositions}

1. Membrane filtration is energy inefficient because of the turbulent conditions that are standardly applied to promote particle mixing. (this thesis)

2. Membrane design should not revolve around creating as many pores as possible, but around precisely designing a few.

(this thesis)

3. The described trends give simulations their value, not the absolute values.

4. Simulating ideal processes helps understand practical non-idealities.

5. To improve productivity, part-time jobs should be stimulated.

6. If PhD students would from the beginning be aware of the typical nonlinear progress in PhD-projects, the so-called 'second year dip' would not exist.

Propositions belonging to the thesis, entitled 'Simulation of shear induced diffusion based separation processes'

Ivon Drijer

Wageningen, 10 October 2018 

